\title{
Intraoperativer Volumenersatz, Transfusion und Behandlung von Gerinnungsstörungen
}

\author{
Oliver Habler
}

\section{Einleitung}

Sowohl der operative Eingriff als auch die Narkose führen zu Veränderungen des intravasalen Volumenstatus des Patienten.

Die Prinzipien der perioperativen Flüssigkeitstherapie zur Aufrechterhaltung einer ausgeglichenen Flüssigkeitsbilanz (u. a. Ausgleich der präoperativen Flüssigkeitskarenz, Ersatz intraoperativer insensitiver Flüssigkeitsverluste) werden in - Kap. 67, „Intraoperatives Flüssigkeitsmanagement“ abgehandelt.

Für den perioperativen Volumenersatz im Rahmen von Blutverlusten stehen kristalloide (z. B. balancierte Vollelektrolytlösungen mit verstoffwechselbaren Anionen) und kolloidale (Hydroxyäthylstärke, Gelatine, Humanalbumin) Infusionslösungen zur Verfügung ( $\triangleright$ Kap. 25, „Volumenersatzlösungen").

\section{Intraoperativer Volumenersatz}

Ziele der perioperativen Flüssigkeits- bzw.

Volumentherapie

- Aufrechterhaltung des zirkulierenden intravasalen Volumen (Normovolämie)

- Aufrechterhaltung einer adäquaten Gewebeperfusion und -oxygenierung

- Aufrechterhaltung des Gleichgewichts im Elektrolythaushalt

- Aufrechterhaltung von Normoglykämie
O. Habler $(\bowtie)$

Klinik für Anästhesiologie, operative Intensivmedizin und Schmerztherapie, Krankenhaus Nordwest, Frankfurt am Main, Deutschland

E-Mail: habler.oliver@khnw.de

\subsection{Bedeutung des intravasalen Volumens für Gewebeperfusion und -oxygenierung}

Bereits der akute Verlust von $40 \%$ des zirkulierenden intravasalen Volumens kann tödlich verlaufen, wenn keine adäquate Therapie mit Volumenersatzlösungen erfolgt. Dies verdeutlicht die besondere Empfindlichkeit des menschlichen Organismus gegenüber akuten Schwankungen des zirkulierenden Blutvolumens und die Bedeutung der Aufrechterhaltung von Normovolämie.

\subsubsection{Normovolämie}

Zur Aufrechterhaltung einer adäquaten Gewebeperfusion und -oxygenierung muss jeder perioperative Blutverlust unmittelbar durch Infusion von Volumenersatzlösungen ausgeglichen werden.

Bei Blutverlusten wird das verlorene Blut nicht sofort durch Eigen- oder Fremdbluttransfusion, sondern initial durch isotone, kristalloide Infusionslösungen im Verhältnis 3:1 bis 4:1 bzw. durch isoonkotische, kolloidale Infusionslösungen im Verhältnis 1:1 ersetzt.

Ziel dieses Vorgehens ist die Aufrechterhaltung des zirkulierenden intravasalen Volumens (Normovolämie) und damit einer adäquaten Organperfusion. Folge ist eine Verdünnung sämtlicher Blutbestandteile (Erythrozyten, Thrombozyten, Gerinnungsfaktoren und der Komponenten des Fibrinolysesystems), eine sog. Hämodilution.

Kompensationsmechanismen der „limitierten“, normovolämischen Hämodilution

Mit zunehmender Verdünnung der zirkulierenden Erythrozytenmasse fallen während einer normovolämischen Hämodilution die Hämoglobinkonzentration $(\mathrm{Hb})$ und der Hämatokrit (Hkt) exponentiell ab. Die Beziehung zwischen $\mathrm{Hb}$ bzw. Hkt und arteriellem $\mathrm{O}_{2}$-Gehalt $\left(\mathrm{C}_{\mathrm{a}} \mathrm{O}_{2}\right)$ ist linear (Abb. 1). 


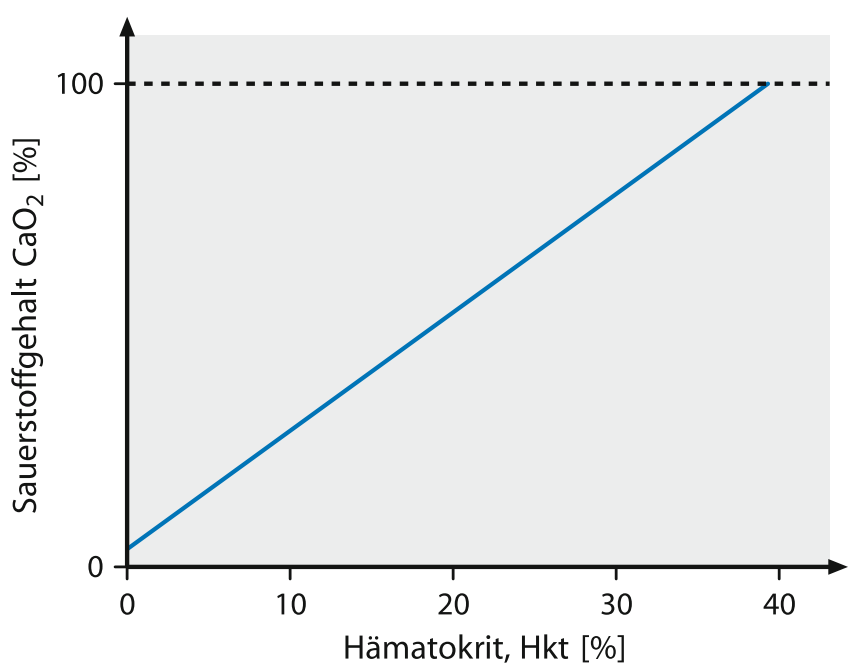

Abb. 1 Veränderung des arteriellen $\mathrm{O}_{2}$-Gehalts $\left(\mathrm{C}_{\mathrm{a}} \mathrm{O}_{2}\right)$ bei normovolämischer Hämodilution

$$
C_{a} O_{2}=\left(H b \times S_{a} O_{2} \times 1,34\right)+\left(p_{a} O_{2} \times 0,0031\right)
$$

\begin{tabular}{l|l}
$\mathrm{C}_{\mathrm{a}} \mathrm{O}_{2}$ & arterieller $\mathrm{O}_{2}$-Gehalt \\
\hline $\mathrm{Hb}$ & Hämoglobinkonzentration \\
\hline $\mathrm{S}_{\mathrm{a}} \mathrm{O}_{2}$ & $\mathrm{O}_{2}$-Sättigung des Hämoglobin im arteriellen Blut \\
\hline 1,34 & $\begin{array}{l}\text { Hüfner-Zahl (ml Sauerstoff, die in 1 } \mathrm{g} \mathrm{Hb} \text { gebunden werden } \\
\text { können) }\end{array}$ \\
\hline $\mathrm{p}_{\mathrm{a}} \mathrm{O}_{2}$ & $\mathrm{O}_{2}$-Partialdruck im arteriellen Blut \\
0,0031 & $\mathrm{O}_{2}$-Löslichkeit im Plasma
\end{tabular}

Diese dilutionsbedingte Anämie wird durch einen Anstieg des Herzzeitvolumens (HZV) kompensiert.

Anfänglich ist dieser HZV-Anstieg proportional stärker ausgeprägt als der gleichzeitige Abfall des $\mathrm{C}_{\mathrm{a}} \mathrm{O}_{2}$. Als Folge steigt das $\mathbf{O}_{2}$-Angebot $\left(\mathrm{DO}_{2}\right)$ an die Gewebe - definiert als das Produkt aus $\mathrm{HZV}$ und $\mathrm{C}_{\mathrm{a}} \mathrm{O}_{2}$ - während normovolämischer Hämodilution bis zu einem Hkt von ca. $30 \%$ zunächst an.

Erst bei Hämodilution auf einen Hkt von ca. $25 \%$ fällt es unter den Ausgangswert ab (Abb. 2).

Der kompensatorische Anstieg des HZV während einer normovolämischen Hämodilution bis zu einem Hkt von $20 \%$ (sog. "limitierte" normovolämische Hämodilution) erfolgt in Narkose ausschließlich über einen Anstieg des ventrikulären Schlagvolumens (SV). Die Herzfrequenz bleibt konstant.

\section{Kompensationsmechanismen der Verdünnungsanämie} bei normovolämischer Hämodilution

- Steigerung des Herzzeitvolumens (HZV) durch

(Fortsetzung)

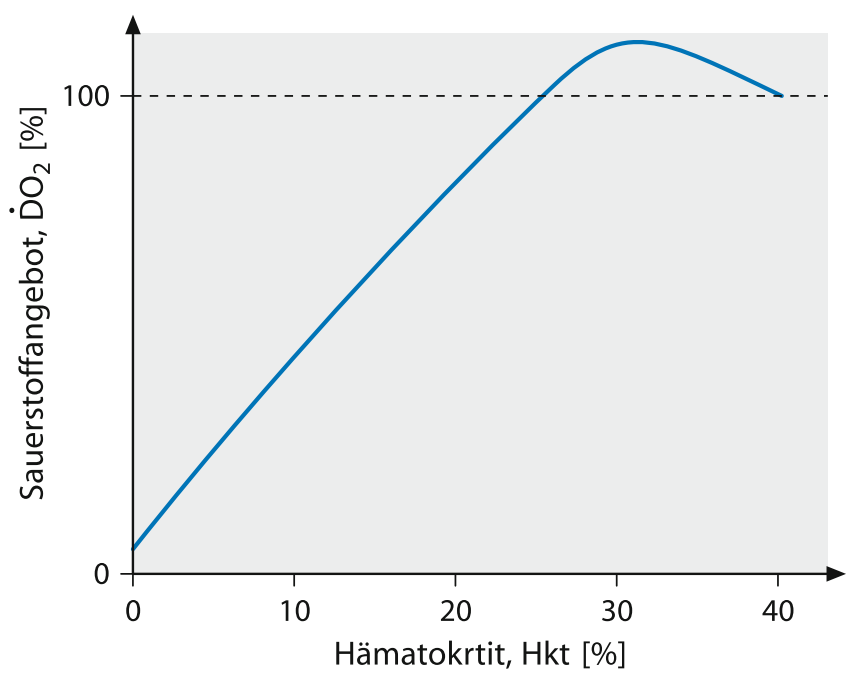

Abb. 2 Veränderung des $\mathrm{O}_{2}$-Angebots an die Gewebe $\left(\mathrm{DO}_{2}\right)$ bei normovolämischer Hämodilution

- Anstieg des ventrikulären Schlagvolumens infolge

- Ventrikuläre Vorlast

- Ventrikuläre Nachlast

- Myokardiale Kontraktilität

- Anstieg der Herzfrequenz (extreme Hämodilution)

- Steigerung der $\mathrm{O}_{2}$-Extraktion der Gewebe

Als Mechanismen der isolierten Erhöhung des ventrikulären Schlagvolumens (SV) während limitierter normovolämischer Hämodilution (bis Hkt 20-25\%) werden die Zunahme der linksventrikulären Vorlast bei gleichzeitiger Abnahme der linksventrikulären Nachlast sowie eine verbesserte myokardiale Kontraktilität diskutiert.

Mit zunehmender Hämodilution nimmt die Blutviskosität ab. Aufgrund der schnelleren Passage des Bluts durch das kapillare Strombett steigt der venöse Rückstrom zum Herzen und damit die ventrikuläre Vorlast. Dies führt über den FrankStarling-Mechanismus zu einer Distension der Myofibrillen mit konsekutiver Steigerung der myokardialen Kontraktilität.

Gleichzeitig führt die Hämodilution über die Zunahme des Blutflusses zu gesteigerten Scherkräften am Endothel der Arteriolen und somit über eine direkte, Stickstoffmonoxid (NO) vermittelte Vasodilatation zu einer zusätzlichen Reduktion der linksventrikulären Nachlast.

\section{Kompensationsmechanismen der „extremen“ normovo- lämischen Hämodilution}

Bei Hkt-Werten unter 20-25 \% (sog. „extreme“ normovolämische Hämodilution) kann das Herz die dilutionsbedingte 


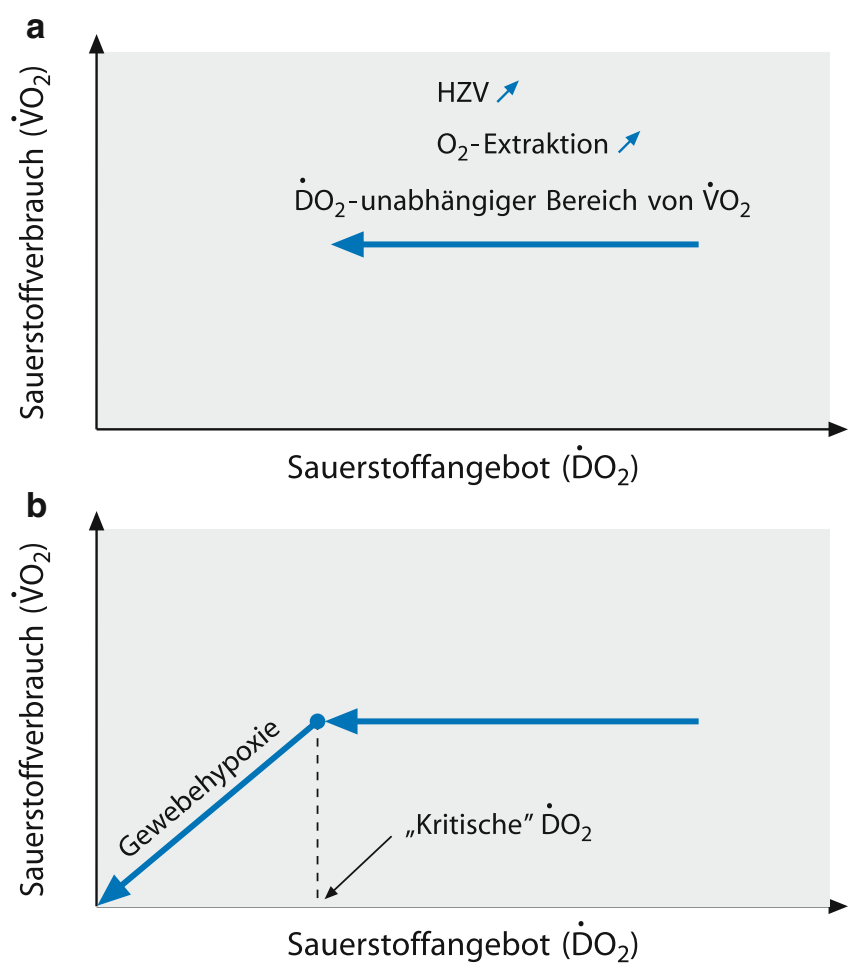

Abb. 3 Veränderung des Gewebe- $\mathrm{O}_{2}$-Verbrauchs $\left(\mathrm{VO}_{2}\right)$ bei normovolämischer Hämodilution bis zum bzw. unter das kritische $\mathrm{O}_{2}$-Angebot

Abnahme des $\mathrm{C}_{\mathrm{a}} \mathrm{O}_{2}$ nicht mehr durch eine isolierte Erhöhung des ventrikulären Schlagvolumens kompensieren.

Die $\mathrm{DO}_{2}$ sinkt an diesem Punkt zwar unter ihren Ausgangswert (Abb. 3) vor Hämodilution ab, der $\mathbf{O}_{2}$-Verbrauch der Gewebe $\left(\mathrm{VO}_{2}\right)$ bleibt jedoch zunächst trotz fallender $\mathrm{DO}_{2}$ konstant. Diese Konstanz des Gewebe- $\mathrm{O}_{2}$-Verbrauchs $\left(\mathrm{VO}_{2}\right)$ reflektiert eine adäquate Versorgung der Organgewebe mit Sauerstoff.

Ursachen für die Konstanz von $\mathrm{VO}_{2}$ und Gewebe- $\mathrm{pO}_{2}$ trotz reduzierter $\mathrm{DO}_{2}$

- Physiologische „Luxus $\mathrm{DO}_{2}{ }^{\text {“"; }}, \mathrm{DO}_{2}$ übersteigt $\mathrm{VO}_{2}$ um Faktor 3-4

- Anstieg des nutritiven Organblutflusses

- Homogenisierung des lokalen $\mathrm{O}_{2}$-Angebots

- Erhöhung der Gewebe- $\mathrm{O}_{2}$-Extraktion

Mit dem Anstieg des HZV während normovolämischer Hämodilution steigt etwa im selben prozentualen Verhältnis auch die nutritive Organdurchblutung.

Ausnahmen bilden die während limitierter, normovolämischer Hämodilution unveränderte Nierenperfusion sowie die im Vergleich zum Gesamt-HZV überproportional gesteigerte Perfusion von Myokard und Splanchnikusorganen.
Zusätzlich verbessert die Hämodilution die zeitliche und räumliche Erythrozytenverteilung in der Mikrozirkulation und homogenisiert das bei normalem Hkt typischerweise heterogene, lokale $\mathrm{O}_{2}$-Angebot.

\section{Myokardiale $\mathrm{O}_{2}$-Bilanz bei Hämodilution}

Das Herz nimmt während normovolämischer Hämodilution eine Sonderstellung ein: Einerseits ist es "Motor" der physiologischen Kompensationsmechanismen bei Verdünnungsanämie (Anstieg des HZV). Gleichzeitig stellt es aber auch das "kritische Organ" dar (Steigerung der Kontraktilität bei gleichzeitiger Reduktion der myokardialen $\mathrm{DO}_{2}$ ).

Da die $\mathrm{O}_{2}$-Extraktion des Myokards bereits unter Normalbedingungen nahezu maximal ist, kann die Verdünnungsanämie nur über eine Steigerung des myokardialen Blutflusses kompensiert werden. Voraussetzung hierfür ist allerdings eine maximale koronare Vasodilatation.

Wird das ,kritische“ myokardiale $\mathrm{O}_{2}$-Angebot unterschritten, kann der myokardiale $\mathrm{O}_{2}$-Bedarf nicht mehr gedeckt werden und der wichtigste Kompensationsmechanismus der Verdünnungsanämie - die Steigerung der Organperfusion über die Steigerung des HZV - bricht zusammen. Folge ist eine generalisierte Organminderperfusion und Gewebehypoxie. Die kardialen Kompensationsmechanismen der Verdünnungsanämie sind bei sklerotisch veränderten Koronargefäßen und damit eingeschränkter Koronardilatation bereits bei höheren Hämatokritwerten erschöpft (Abschn. 2.3).

\subsubsection{Hypovolämie}

\section{Veränderungen der Makrohämodynamik}

Wird ein akuter Blutverlust infolge Operation oder Trauma nicht sofort durch eine adäquate Volumentherapie kompensiert, nimmt das zirkulierende intravasale Volumen ab (Hypovolämie). Die Folge ist eine Reduktion des Herzzeitvolumens (HZV) und des arteriellen Blutdrucks. Durch Erregung von Volu- und Barorezeptoren kommt es in Abhängigkeit von Alter, Konstitution und Geschwindigkeit des intravasalen Volumenverlusts zu einer gesteigerten Katecholaminfreisetzung aus dem Nebennierenmark. Als Folge dieser sympathoadrenergen Gegenregulation nehmen der periphere Gefäßwiderstand, die Herzfrequenz und die myokardiale Kontraktilität zu.

Während Hypovolämie bewirkt die unterschiedliche Verteilung der Adrenorezeptoren innerhalb der Gefäßstrombahn der einzelnen Organe eine inhomogene Verteilung der Vasokonstriktion. Die Folge ist eine "Zentralisation“ des Blutvolumens zugunsten von Herz und Gehirn. Im Gegensatz dazu nimmt die Perfusion der Splanchnikusorgane sowie von Niere, Haut und Muskulatur ab. 
Im Kapillarstromgebiet kommt es zunächst zum Flüssigkeitseinstrom aus dem Interstitium in den Intravasalraum. Darüber hinaus aktiviert Hypovolämie das Renin-Angiotensin-Aldosteron-System und die Freisetzung von Vasopressin (antidiuretisches Hormon, ADH), was $\mathrm{zu}$ einer Natrium- und Flüssigkeitsretention führt. Durch diese Kompensationsmechanismen kann trotz eines Blutverlusts von bis zu $30 \%$ des Blutvolumens Normotension aufrechterhalten werden (Abb. 4).

\section{Störungen der Mikrozirkulation}

Neben Veränderungen der Makrohämodynamik führt Hypovolämie zu Beeinträchtigungen im Bereich der mikrovaskulären Strombahn (Arteriolen, Kapillaren, Venolen). Die arterioläre und venuläre Konstriktion reduziert sowohl die Anzahl der mit Erythrozyten perfundierten Kapillaren (sog. „funktionelle Kapillardichte") als auch die Strömungsgeschwindigkeit in den noch perfundierten Kapillaren. Dort kommt es zur Aggregation von Erythrozyten sowie zur Adhärenz von Leukozyten am Gefäßendothel gefolgt von einer weiteren Verringerung des Blutflusses bis hin zu kompletter Stase.

Neben der Reduktion des lokalen $\mathrm{O}_{2}$-Angebots $\left(\mathrm{DO}_{2}\right)$ imponiert eine Abnahme der für die Diffusion des Sauerstoffs zur Verfügung stehenden Kapillaroberfläche.

Fallen der regionale Blutfluss und damit das regionale $\mathrm{O}_{2}$-Angebot $\left(\mathrm{DO}_{2}\right)$ ab, kann der $\mathrm{O}_{2}$-Bedarf des Gewebes zwar vorübergehend durch eine Steigerung der Gewebe$\mathrm{O}_{2}$-Extraktion aufrecht erhalten werden. Ist jedoch dieser
Kompensationsmechanismus erschöpft, resultiert jede weitere Abnahme der $\mathrm{DO}_{2}$ in einer Abnahme des Gewebe- $\mathrm{O}_{2}-$ Verbrauchs $\left(\mathrm{VO}_{2}\right)$. Die Folge ist Gewebehypoxie.

Bei längerdauernder Hypovolämie und zunehmender Gewebeazidose (Laktazidose infolge anaerober Glykolyse) nimmt die Empfindlichkeit der arteriolären Sphinktern für Katecholamine ab. Folge ist eine arterioläre Dilatation bei fortbestehender venulärer Konstriktion. Es resultiert ein erhöhter transkapillärer Filtrationsdruck. Zusammen mit der hypoxiebedingten Zunahme der Kapillarpermeabilität für Proteine führt dieser zu einem gesteigerten transkapillären Verlust von Flüssigkeit, Proteinen und Elektrolyten aus dem Intravasalraum in das Zellinterstitium. Die konsekutive Endothelzellschwellung verschlechtert die Kapillarperfusion weiter.

\section{Hypovolämischer Schock}

Diese Veränderungen kennzeichnen den beginnenden hypovolämischen Schock. Im Rahmen der fortbestehenden Mikrozirkulationsstörung werden Mediatorsysteme (Komplement- und Kallikrein-Kinin-System) sowie der Arachidonsäuremetabolismus aktiviert. Die Aktivierung neutrophiler Granulozyten und Makrophagen sowie die konsekutive Freisetzung von Zytokinen (TNF- $\alpha$, Interleukin 1) tragen zur Entstehung von Organdysfunktionen bei.

Der Darm ist durch Hypovolämie in besonderem Maße gefährdet. Gründe sind der bereits normalerweise hohe $\mathrm{O}_{2}$-Verbrauch der Darmmukosa sowie die ausgeprägte Blutflussreduktion im Rahmen der sympathoadrenerg induzierten
Abb. 4 Effekte von

Hypovolämie auf

Makrohämodynamik und

Mikrozirkulation

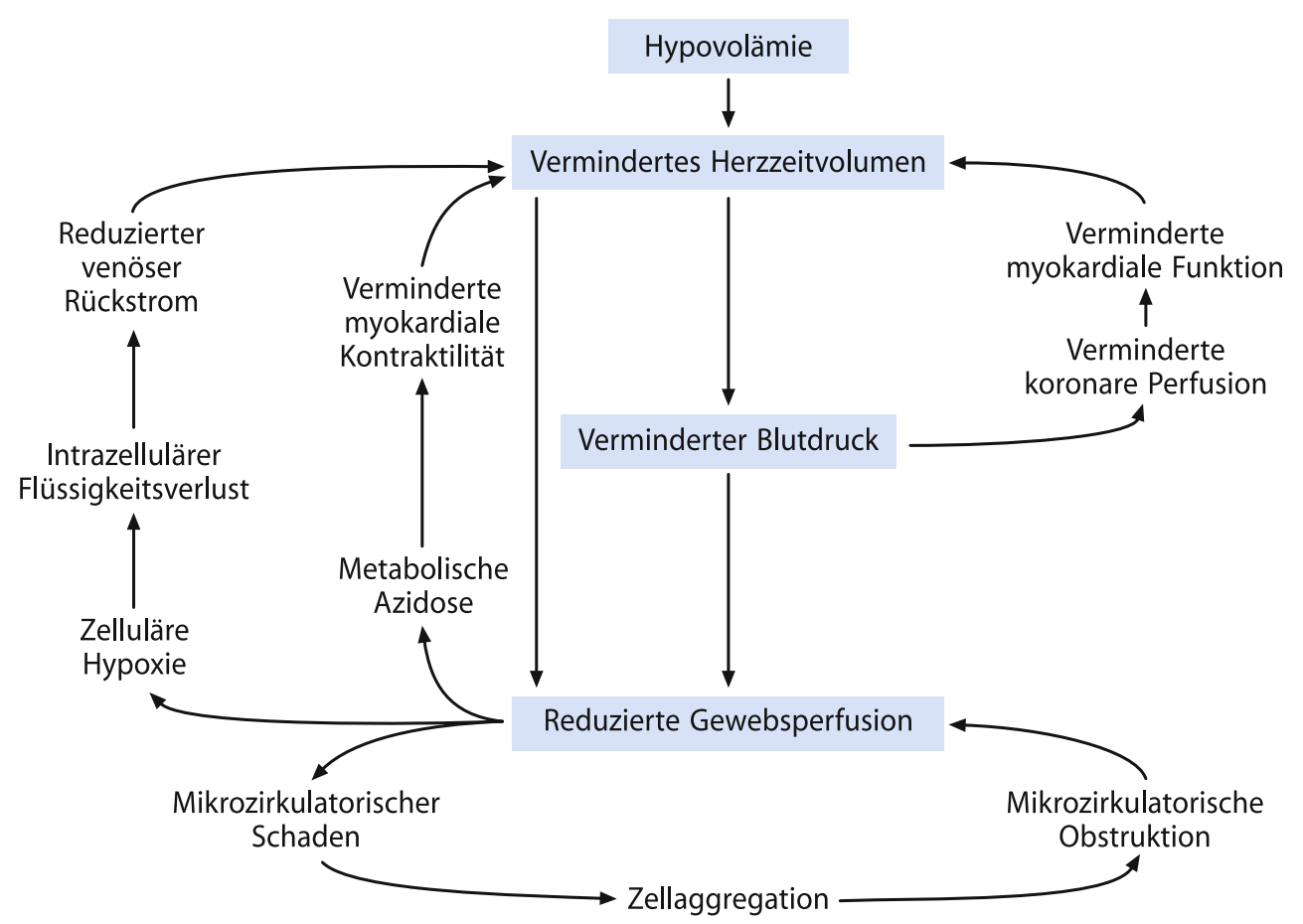


Kreislaufzentralisation. Hohe Konzentrationen an Xanthindehydrogenase machen die Darmmukosa zusätzlich besonders anfällig für einen Reperfusionsschaden (Abschn. 1.4). Wird die Barrierefunktion der Darmmukosa zerstört, kommt es zur Translokation von Enterobakterien in das Blut mit Entwicklung einer systemischen inflammmatorischen Reaktion (SIRS) und dem Risiko der Entwicklung von Sepsis, schwerer Sepsis, septischem Schock und Multiorganversagen (MOV).

\subsection{Intraoperatives Monitoring zur Beurteilung des intravasalen Volumenstatus}

Das intraoperative Monitoring des intravasalen Volumenstatus richtet sich nach den erwarteten intravasalen Volumenschwankungen (Art des chirurgischen Eingriffs) sowie nach präexistenten kardiopulmonalen Erkrankungen des Patienten ( $\triangleright$ Kap. 27, „Kardiozirkulatorisches und respiratorisches Monitoring“").

\section{Herzfrequenz}

Bei nichtkompensierter Hypovolämie tritt Tachykardie ab dem Verlust von etwa $15 \%$ des Gesamtblutvolumens auf und reflektiert dann häufig bereits eine manifeste Gewebehypoxie.

Bei normovolämischer Hämodilution erfolgt ein Anstieg der Herzfrequenz erst nach einem Ersatz von mehr als $50 \%$ des Blutvolumens durch Infusionslösungen (Hkt 20-25\%). Die Tachykardie ist in dieser Situation ein Kompensationsmechanismus der Verdünnungsanämie und kein Symptom einer Gewebehypoxie.

Das Ausmaß der Tachykardie wird sowohl bei Hypo- als auch bei Normovolämie durch verschiedene Faktoren (Narkosetiefe, Pharmaka, z. B. $\beta$-Blocker, Clonidin) beeinflusst und gilt daher alleine als unzuverlässiger Parameter zur Beurteilung des Volumenstatus.

\section{Arterieller Blutdruck}

Während bei Aufrechterhaltung von Normovolämie ein Austausch eines gesamten Blutvolumens durch kristalloide und kolloidale Infusionslösungen (Abfall des Hkt auf $9 \%$ ) ohne Hypotension und ohne Zeichen einer Gewebehypoxie möglich ist, tritt bei inadäquater Infusionstherapie (Hypovolämie) ein Blutdruckabfall bereits bei einem Verlust von $30 \%$ des Blutvolumens auf. Bei kontinuierlicher Ableitung einer intraarteriellen Druckkurve weisen deren atemabhängige Schwankungen auf intravasalen Volumenmangel hin.

Das gemeinsame Auftreten von Tachykardie und Hypotonie sollte intraoperativ immer als Zeichen eines absoluten oder relativen Volumenmangels gewertet werden.

\section{Ventrikuläre Füllungsdrücke}

Der Abfall des linksventrikulären enddiastolischen Volumen (LVEDV) ist ein Zeichen von Hypovolämie.

- Cave Der häufig zur Steuerung einer Volumentherapie herangezogene zentrale Venendruck (ZVD) variiert außer mit dem intravasalen Volumen auch mit dem Gefäßtonus, dem intrathorakalen Druck und der Volumendehnbarkeit (Compliance) der Ventrikel. Ein direkter Rückschluss insbesondere von hohen Absolutwerten auf den intravasalen Volumenstatus ist daher problematisch [1]. Bestenfalls können relative Veränderungen bei sonst unveränderten Rahmenbedingungen zur Beurteilung des Volumenstatus herangezogen werden. Gleiches gilt für den pulmonalkapillären Verschlussdruck (PCWP).

Wenn durchführbar, sollte zur Diagnose eines Volumenmangels bzw. zur Sicherung einer entsprechenden Volumenreagibilität ein Lagerungsmanöver zur Autotransfusion (Trendelenburg-Position, Anheben der Beine) durchgeführt werden. Zur Steuerung der Volumentherapie bei erwachsenen, insbesondere beatmeten Intensivpatienten sollten Überwachungsverfahren, die eine Einschätzung der Volumenreagibilität anhand flussbasierter (Schlagvolumen) und/oder dynamischer Vorlastparameter (,stroke volume variation“, SVV) erlauben (Abschn. 1.3), statischen Parametern wie ZVD und PCWP vorgezogen werden [2].

\section{PiCCO-Monitoring}

Mit dem sog. PiCCO-Monitoring (,pulscontour continuous cardiac output") lassen sich Parameter ermitteln, die mit hoher Sensitivität Schwankungen des intravasalen Volumens aufzeigen ( $\mathrm{Kap}$. 27, „Kardiozirkulatorisches und respiratorisches Monitoring"). Es handelt sich hierbei um die ,stroke volume variation“ (SVV), das ,intrathoracic blood volume" (ITBV) und das ,global enddiastolic volume“ (GEDV).

\section{Zentral- und gemischtvenöse Blutgasanalyse}

Nach Ausschluss von extremer Anämie und ventrikulärem Pumpversagen muss ein intraoperativer Abfall des $\mathrm{O}_{2}$-Partialdrucks $\left(\mathrm{p}_{\mathrm{v}} \mathrm{O}_{2}\right)$ bzw. der $\mathrm{O}_{2}$-Sättigung $\left(\mathrm{S}_{\mathrm{v}} \mathrm{O}_{2}\right)$ im zentralbzw. gemischtvenösen Blut als Zeichen einer manifesten Hypovolämie gewertet werden. Gleichzeitig sinkt der Gesamtkörper- $\mathrm{O}_{2}$-Verbrauch $\left(\mathrm{DO}_{2}\right)$ (Tab. 1).

$$
V O_{2}=H Z V \times\left(C_{a} O_{2}-C_{v} O_{2}\right)
$$

\begin{tabular}{l|l}
$\mathrm{VO}_{2}$ & Gesamtkörper- $\mathrm{O}_{2}$-Verbrauch \\
\hline $\mathrm{HZV}$ & Herzzeitvolumen \\
\hline $\mathrm{C}_{\mathrm{a}} \mathrm{O}_{2}$ & arterieller $\mathrm{O}_{2}$-Gehalt \\
\hline $\mathrm{C}_{\bar{\vee}} \mathrm{O}_{2}$ & gemischtvenöser $\mathrm{O}_{2}$-Gehalt
\end{tabular}


Tab. 1 Veränderungen von arterieller $\mathrm{O}_{2}$-Sättigung $\left(\mathrm{S}_{\mathrm{a}} \mathrm{O}_{2}\right)$, gemischtvenöser $\mathrm{O}_{2}$-Sättigung $\left(\mathrm{S}_{\nabla} \mathrm{O}_{2}\right)$ und $\mathrm{O}_{2}$-Extraktion $\left(\mathrm{O}_{2}\right.$ ER) mit zunehmender Hypovolämie

\begin{tabular}{|l|c|c|c|} 
& $\mathrm{S}_{\mathrm{a}} \mathrm{O}_{2}$ & $\mathrm{~S}_{\bar{v}} \mathrm{O}_{2}$ & $\mathrm{O}_{2} \mathrm{ER}$ \\
\hline Normal & $>95 \%$ & $>65 \%$ & $20-30 \%$ \\
\hline Hypovolämie & $>95 \%$ & $50-65 \%$ & $30-50 \%$ \\
\hline Hypovolämer Schock & $>95 \%$ & $<50 \%$ & $>50 \%$
\end{tabular}

\section{Monitoring von regionaler $\mathrm{DO}_{2}$ und Gewebeoxygenie- rung}

Die noninvasive Beurteilung von Gewebeperfusion bzw. oxygenierung ist schwierig. Durch direkte Analyse der inund exspiratorischen $\mathrm{O}_{2}$-Gehalts mit einem metabolischen Monitor kann ein Abfall des Gesamtkörper- $\mathrm{O}_{2}$-Verbrauchs $\mathrm{VO}_{2}$ als Zeichen einer globalen Gewebehypoxie detektiert werden (Abb. 3). Auf regionaler Ebene ist dies mit Hilfe von $\mathrm{O}_{2}$-sensitiven Oberflächen-, bzw. Stichelektroden möglich.

Ebenfalls in klinischer Anwendung ist die gastrointestinale Tonometrie (z. B. TONOCAP von Datex Ohmeda). Die Methode basiert auf der Annahme, dass es bei Hypoperfusion bzw. Hypoxie der gastrointestinalen Mukosa zu einem Anstieg des intramukosalen $\mathrm{CO}_{2}$-Partialdrucks $\left(\mathrm{p}_{\mathrm{i}} \mathrm{CO}_{2}\right)$ und $\mathrm{zu}$ einem Abfall des intramukosalen $\mathrm{pH}-$ Werts $\left(\mathrm{pH}_{\mathrm{i}}\right)$ kommt. Das in der Mukosa produzierte $\mathrm{CO}_{2}$ diffundiert in einen speziellen, mit Kochsalzlösung gefüllten Ballonkatheter, welcher mit der Mukosa in Kontakt steht. Der $\mathrm{pCO}_{2}$ des Balloninhalts wird in einem Blutgasanalysegerät bestimmt. Anschließend wird aus dem $\mathrm{pCO}_{2}$ der Tonometrieflüssigkeit, der arteriellen Bikarbonatkonzentration, der Löslichkeit von $\mathrm{CO}_{2}$ in Kochsalz und einem Korrekturfaktor für die Äquilibrierungszeit zwischen Mukosa und Balloninhalt, der $\mathrm{p}_{\mathrm{i}} \mathrm{CO}_{2}$ und der $\mathrm{pH}_{\mathrm{i}}$ errechnet.

$$
p h=6,1+\log \frac{a \mathrm{HCO}_{3}^{-}}{p_{i} \mathrm{CO}_{2}}
$$

\begin{tabular}{l|l}
$\mathrm{pH}_{\mathrm{i}}$ & intestinaler mukosaler $\mathrm{pH}$-Wert \\
$\mathrm{aHCO}_{3}{ }^{-}$ & arterielle Bikarbonatkonzentration \\
$\mathrm{p}_{\mathrm{i}} \mathrm{CO}_{2}$ & intestinaler mukosaler $\mathrm{CO}_{2}$-Partialdruck
\end{tabular}

Der Anstieg des $\mathrm{p}_{\mathrm{i}} \mathrm{CO}_{2}$ scheint dabei eine Hypoperfusion bzw. Hypoxie der gastrointestinalen Mukosa besser widerzuspiegeln als der Abfall des $\mathrm{pH}_{\mathrm{i}}$. Mit Hilfe von fiberoptischen Sonden ist eine kontinuierliche Messung des $\mathrm{p}_{\mathrm{i}} \mathrm{CO}_{2}$ möglich.

\section{Serumlaktatkonzentration}

Laktat ist das Endprodukt der anaeroben Glykolyse. Unterschreitet das $\mathrm{O}_{2}$-Angebot den $\mathrm{O}_{2}$-Bedarf der Gewebe (Abb. 3), steigt als Zeichen einer Gewebehypoxie die Laktatproduktion. Die Serumlaktatkonzentration ist die Summe aus dem Zusammenfluss der Gefäßstromgebiete verschiedener Organe. Es ist daher denkbar, dass die Laktatproduktion eines hypoxischen Organgewebes unentdeckt bleibt, da es alleine nicht in der Lage ist, die Gesamtlaktatkonzentration im Serum zu erhöhen.

Zudem ist die Kinetik von Laktatproduktion und -metabolismus nur schwer abschätzbar. Bei eingeschränkter Leberfunktion oder Laktatproduktion durch enterale Mikroorganismen kann die Serumlaktatkonzentration ansteigen, ohne dass eine Gewebehypoxie vorliegt.

\section{Basendefizit}

Eine Zunahme des Basendefizits im arteriellen Blut trotz adäquatem Hkt gilt als Zeichen einer regionalen Gewebehypoperfusion. Bei Traumapatienten korrelierte die Höhe des Basendefizits mit dem Schweregrad der Hypovolämie. Ein Basendefizit $>6 \mathrm{mmol} / \mathrm{l}$ ging mit einer erhöhten Inzidenz von ARDS und Multiorganversagen einher [3].

\subsection{Zielgrößen der intraoperativen Volumentherapie}

Eine adäquate Gewebeoxygenierung ist nicht an eine „normale" $\mathrm{Hb}-$ Konzentration gebunden. Bei konstantem zirkulierenden Blutvolumen (Normovolämie) toleriert der gesunde

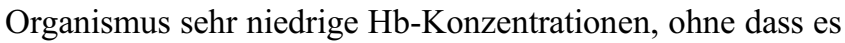
zu Gewebehypoxie kommt (Abschn. 2.3). Die perioperative Flüssigkeitstherapie hat daher initial ausschließlich mit kristalloiden und kolloidalen Infusionslösungen zu erfolgen. Die Transfusion von Erythrozyten ist erst erforderlich, wenn die Kompensationsmechanismen der normovolämischen Verdünnungsanämie erschöpft sind (Abschn. 2.3). Als ZielgröBen der perioperativen Volumentherapie können folgende klinische Parameter herangezogen werden.

Zielgrößen der intraoperativen Flüssigkeitstherapie

- Stabile Herzfrequenz, stabiler arterieller Blutdruck

- Stabile arterielle Druckkurve (Fehlen atemabhängiger Schwankungen)

- $\mathrm{ZVD}=10-15 \quad \mathrm{mmHg} \quad$ (mit Einschränkungen; Abschn. 1.2)

- $\mathrm{PCWP}=10-12 \mathrm{mmHg}$ (mit Einschränkungen; Abschn. 1.2)

- $\mathrm{p}_{\nabla} \mathrm{O}_{2}>38 \mathrm{mmHg}$

- $\mathrm{s}_{\nabla} \mathrm{O}_{2}>65 \%$

- $\mathrm{HI}>3 \mathrm{l} / \mathrm{min} / \mathrm{m}^{2}$

- $\mathrm{SVV}<10 \%$

- ITBVI 850-1000 ml/m²

- $\mathrm{O}_{2}$-Aufnahme $\left(\mathrm{VO}_{2}\right)>100 \mathrm{ml} / \mathrm{min} / \mathrm{m}^{2}$

- $\mathrm{O}_{2}$-Extraktion $\left(\mathrm{O}_{2}\right.$ ER $)=0,2-0,3$

- Laktatkonzentration $<4 \mathrm{mmol} / \mathrm{l}$ 
- $\mathrm{BD}-3$ bis $+3 \mathrm{mmol} / \mathrm{l}$

- Intramukosaler $\mathrm{pH}>7,35$

- Capillary refill $\leq 3 \mathrm{~s}$

- Urinausscheidung $>1 \mathrm{ml} / \mathrm{kgKG} / \mathrm{h}$

\subsection{Unerwünschte Begleiteffekte der intraoperativen Volumentherapie}

\section{Reperfusionsschaden}

Die Reduktion bzw. Unterbrechung der Gewebeperfusion (Ischämie) führt zum sog. ischämischen bzw. hypoxischen Gewebeschaden. Wird durch eine adäquate Infusionstherapie der Blutfluss in ischämischen Gewebebezirken wiederhergestellt, kommt zum ischämischen Gewebeschaden der durch Sauerstoffradikale mediierte Reperfusionsschaden hinzu. Sauerstoffradikale führen über Lipidperoxidation zu einer Schädigung der Zellmembranen. Endothelzellschwellung und gesteigerte Adhäsion von neutrophilen Granulozyten am Gefäßendothel reduzieren die mikrovaskuläre Perfusion (,Noreflow"-Phänomen). Da das Ausmaß des Reperfusionsschadens von der Dauer der Gewebeischämie abhängt, gilt es die Ischämiezeit z. B. bei gefäßchirurgischen Eingriffen so kurz wie möglich zu halten.

\section{Hypothermie}

Die Infusion größerer Mengen kalter Flüssigkeit reduziert die Blut- und Körperkerntemperatur des Patienten.

Cave Bereits eine milde Hypothermie $\left(33-35^{\circ} \mathrm{C}\right)$ beeinträchtigt die Blutgerinnung [4] und erhöht das Risiko postoperativer Wundinfektionen [5].

Um einer perioperativen Hypothermie vorzubeugen, können vorgewärmte Infusionen oder Infusionswärmesysteme eingesetzt werden.

\section{Beeinträchtigung der Blutgerinnung}

- Cave Außer durch die Verdünnung zirkulierender Thrombozyten und Gerinnungsfaktoren (Abschn. 2.3) können Infusionslösungen die Blutgerinnung spezifisch beeinträchtigen ( $\triangleright$ Kap. 25, „Volumenersatzlösungen“).

Dextranlösungen verringern in hoher Dosierung $(>1,5 \mathrm{~g} /$ kgKG) die Aktivität der Gerinnungfaktoren II, V und VIII. Außerdem wird bereits nach Infusion kleiner Volumina (100-150 ml) die Thrombozytenaggregation durch Umhüllung der Thrombozyten mit Dextranmolekülen (sog. „Thrombozyten-Coating“") gehemmt.
Hydroxyäthylstärke (HES) reduziert die Aktivität des v.-Willebrand-Jürgens-Faktors (vWF) alleine sowie des Faktor-VIII/vWF-Komplexes. Eine Störung der Thrombozytenfunktion tritt erst nach Infusion größerer Volumina ( $>1,5$ 1/Tag) auf. Weiterhin wird eine verminderte Stabilität des Fibringerinnsels infolge gestörter Fibrinpolymerisation diskutiert [6]. Bei niedermolekularen, niedrigsubstituierten HES-Lösungen (z. B. HES 130.000/0,4, HES 130.000/ $0,42)$ scheinen diese Effekte jedoch geringer ausgeprägt zu sein. Die Tageshöchstdosis beträgt für HES 200.000/ $0,533 \mathrm{ml} / \mathrm{kgKG}$ und für HES 130.000/0,4 $50 \mathrm{ml} / \mathrm{kgKG}$. Bei Infusion von HES-Präparaten während hoher, intraoperativer Blutverluste kann die Tageshöchstdosis erweitert werden, da durch die anhaltende Blutung auch Teile des infundierten Volumenersatzmittels wieder verloren gehen.

Wenn die Tageshöchstdosis für künstliche Kolloide erreicht ist, kann auf die Infusion von Humanalbuminlösungen zurückgegriffen werden.

\section{Metabolische Azidose}

Isotone Kochsalzlösung ( $\mathrm{NaCl}$ 0,9 \%) und Ringer-Lösung weisen mit etwa $154 \mathrm{mmol} / \mathrm{l}$ unphysiologisch hohe Chloridionenkonzentrationen auf. Die rasche Infusion größerer Mengen (>30 ml/kgKG/h) dieser Lösungen führt daher $\mathrm{zu}$ einer hyperchlorämischen, metabolischen Azidose. Bei Anwendung sog. balancierter kristalloider Lösungen mit verstoffwechselbaren Anionen (z. B. Azetat, Malat oder Laktat) fehlt dieser Effekt weitestgehend [7]. Durch Verwendung von Ringer-Laktat (Chloridionenkonzentration $112 \mathrm{mmol} / \mathrm{l}$ ) kann die Azidose vermieden werden ( $>$ Kap. 25, ,Volumenersatzlösungen").

Auch die Infusion von $6 \%$ HES 200.000/0,5 (pH-Wert der Lösung 3,5-6,0), 6 \% HES 130.000/0,4 (pH-Wert der Lösung 4,0-5,0) oder $5 \%$ Humanalbumin kann direkt oder durch Verdünnung von Bikarbonat eine metabolischen Azidose bedingen.

\section{Immunmodulation}

Tierexperimentelle Studien deuten auf immunmodulatorische Wirkungen von Infusionslösungen hin. So kam es bei der Volumentherapie des hämorrhagischen Schocks nach Infusion von hypertoner Kochsalzlösung $\mathrm{zu}$ einer geringeren Aktivierung von neutrophilen Granulozyten und $\mathrm{zu}$ einer geringeren Rate an akutem Lungenversagen als nach Infusion von Ringer-Laktat-Lösung. Zudem erholte sich die im Schock supprimierte T-Lymphozyten Funktion deutlich schneller. Kolloidale Infusionslösungen (v. a. HES und Gelatine) scheinen die Produktion von Sauerstoffradikalen zu hemmen und so den Reperfusionsschaden zu reduzieren. Die klinische Relevanz dieser Effekte ist bislang unklar. 
2

\section{Fremdblutsparende Maßnahmen}

\subsection{Risiken der Fremdbluttransfusion}

In der Bundesrepublik Deutschland werden jährlich etwa 4-6 Mio. Fremdblutkonserven (Synonym: ,allogene“ oder „homologe“ Blutkonserven) transfundiert. Trotz ständiger Weiterentwicklung der Qualitätssicherungsverfahren ist die Fremdbluttransfusion nach wie vor mit einem Restrisiko für den Empfänger verbunden.

Potenzielle Risiken bei der Fremdbluttransfusion

1. Transfusionsassoziierte Infektion

- Viren: Hepatitis-B, -C, Zytomegalie, EpsteinBarr, „human immunodeficiency virus“ (HIV), West-Nile Virus

- Bakterien: Yersinia enterocolitica, Serratia marcescens, Pseudomonas aeruginosa, Enterobacter

- Plasmodien (Malaria), Treponema pallidum (Syphilis), Trypanosoma cruzi (Chagas-Krankheit)

- weitere, bis heute noch unbekannte Erreger

2. Hämolysereaktion

- Blutgruppeninkompatibilität (,,clerical error“)

- Transfusion alter Konserven, thermische Schädigung (Blutwärmesysteme), bakterielle Kontamination

3. Allergische Transfusionsreaktion

4. Transfusionsbedingtes Lungenversagen

5. Immunmodulation

\subsubsection{Transfusionsassoziierte Infektion}

Tab. 2 gibt einen Überblick über das mit der Transfusion von Erythrozytenkonzentraten assoziierte Infektrisiko.

Anders als die Infektion mit dem ,human immunodeficiency virus" (HIV), die zwar bei Patienten besonders gefürchtet ist, aber sehr selten auftritt, stellen virale Hepatitiden die häufigste Form der transfusionsassoziierten Virusinfektionen in der BRD dar [9]. In mehr als $90 \%$ der Fälle handelt es sich dabei um Infektionen durch das Hepatitis-B- und -C-Virus. Die Verabreichung einer HCV-infizierten Konserve führt beim Empfänger in jedem Falle zu einer Infektion mit Bildung spezifischer Antikörper. Etwa $50 \%$ der infizierten Empfänger entwickeln eine chronische Hepatitis, die wiederum in ca. $20 \%$ der Fälle in einer Leberzirrhose endet.

Aufgrund der hohen Durchseuchung der Bevölkerung (50-90 \%) mit dem Zytomegalievirus (CMV) muss bei Personen ohne Risikofaktoren nicht auf die Transfusion von CMV-freiem Blut geachtet werden. Bei Feten, Frühgeborenen, Patienten mit angeborenem oder erworbenem Immundefekt sowie bei Organ- und Stammzelltransplantierten kann eine CMV-Infektion zu einer lebensbedrohlichen Erkrankung führen.

Zwei Maßnahmen sind in der Prävention der transfusionsassoziierten CMV-Infektion wirksam $(90 \%$ Reduktion der Inzidenz): der Einsatz zellulärer Blutkomponenten von CMV-seronegativen Spendern und/oder die Leukozytendepletion zellulärer Blutkomponenten (seit 01.10.2001 in der BRD obligat). Die Effektivität der genannten Maßnahmen wird derzeit als gleichwertig eingeschätzt [8]. Nach Infusion von gefrorenem Frischplasma wurden CMV-Infektionen bislang nicht beobachtet.

Bakterielle Infektionen des Empfängers nach allogener Transfusion sind auf die Kontamination der Konserven infolge asymptomatischer Bakteriämie des Spenders zurückzuführen. Hauptsächlich betroffen sind die bei Raumtemperatur gelagerten Thrombozytenkonzentrate. Die wichtigsten Keime sind Yersinia enterocolitica, Serratia marcescens, Pseudomonas aeruginosa und Enterobacter.

\subsubsection{Nichtinfektionsbedingte Risiken bei der Übertragung von Fremdblut}

Nichtinfektionsbedingte, hauptsächlich immunologisch vermittelte Reaktionen können entweder unmittelbar während oder in den ersten Tagen bis Wochen nach Transfusion auftreten (Tab. 2).

\section{Hämolytische Transfusionsreaktionen}

- Immunologisch vermittelte Hämolysereaktionen: Die akute Reaktion vom Soforttyp wird in etwa $80 \%$ der Fälle durch Transfusion blutgruppeninkompatiblen Bluts ausgelöst. Ursächlich sind häufig Ettikettierungsfehler von Blutgruppen-, bzw. Kreuzprobenröhrchen bzw. Verwechslung von Blutkonserven am Ort der Transfusion (sog. „,clerical error"). Bei verzögerter Reaktion führt die erneute Transfusion eines durch frühere Transfusionen immunisierten Patienten zu einem verzögerten Auftreten von Alloantikörpern. Die konsekutive Hämolyse tritt erst deutlich nach der Transfusion (14 Tage oder später) auf.

- Nichtimmunologisch vermittelte Hämolysereaktionen können nach Transfusion alter Erythrozyten, thermisch bedingt bei unkontrollierter Anwendung von Blutwärmern oder durch bakterielle Kontamination der Konserve auftreten. In der Regel verlaufen diese Reaktionen klinisch unbemerkt.

\section{Transfusionsassoziierte Graft-versus-Host-Krankheit (GvHD)}

Ursache ist die Transfusion proliferationsfähiger T-Lymphozyten des Spenders auf einen immundefizienten Empfänger. In speziellen Situationen (u. a. Transfusion unter Blutsverwandten, intrauterine Transfusion, Austauschtransfusion des Neugeborenen, Transfusion vor und während autologer Stammzellentnahme bzw. Stammzell- und Knochenmarks- 
Tab. 2 Risiken einer Transfusion von Erythrozytenkonzentraten (Nach: [8-12])

\begin{tabular}{|c|c|c|c|}
\hline \multicolumn{3}{|c|}{ Risiken } & Häufigkeit \\
\hline 1 & \multicolumn{2}{|c|}{$\begin{array}{l}\text { Allergische Transfusionsreaktion } \\
\text { - Schwerer Verlauf }\end{array}$} & $\begin{array}{l}1: 200 \text { bis } 1: 2000 \\
1: 100.000\end{array}$ \\
\hline 2 & \multicolumn{2}{|c|}{$\begin{array}{l}\text { Transfusionsbedingtes Lungenversagen (TRALI) } \\
\text { - Bei Ausschluss von Spenderinnen mit Schwangerschaftsanamnese }\end{array}$} & $\begin{array}{l}1: 10.000 \text { bis } 1: 100.000 \\
-\end{array}$ \\
\hline \multirow[t]{3}{*}{3} & \multicolumn{3}{|c|}{ Kreuzblut-, Konservenverwechslung („,clerical error“) } \\
\hline & & $\begin{array}{l}\text { Akute hämolytische Raktion } \\
\text { - Letaler Verlauf }\end{array}$ & $\begin{array}{l}1: 10.000 \text { bis } 1: 100.000 \\
1: 500.000 \text { bis } 1: 1 \text { Mio }\end{array}$ \\
\hline & & $\begin{array}{l}\text { Verzögerte hämolytische Reaktion } \\
\text { - Letaler Verlauf }\end{array}$ & $\begin{array}{l}1: 10.000 \text { bis } 1: 100.000 \\
1: 1 \text { Mio bis } 1: 2,5 \text { Mio }\end{array}$ \\
\hline \multirow[t]{10}{*}{4} & \multicolumn{3}{|c|}{ Transfusionsassoziierte Infektion } \\
\hline & \multirow[t]{7}{*}{ Viral } & Hepatitis-A-Virus & 1:1 Mio \\
\hline & & Hepatitis-B-Virus & $1: 360.000$ bis $1: 1$ Mio \\
\hline & & Hepatitis-C-Virus & $<1: 1$ Mio \\
\hline & & Zytomegalievirus & Einzelfälle \\
\hline & & Epstein-Barr-Virus & $1: 200$ \\
\hline & & HI-Virus & $<1: 1$ Mio \\
\hline & & West-Nile-Virus & $1: 3000$ bis $1: 5000$ \\
\hline & Bakteriell & Yersinia enterodolitica, Serratia marcescens, Pseudomonas aeruginosa, Enterobacter & $1: 100.000$ bis $1: 1$ Mio \\
\hline & Prionen & Creutzfeldt-Jakob-Krankheit & Verdachtsfälle in Großbritannien \\
\hline 5 & \multicolumn{2}{|c|}{ Immunmodulation/-suppression (TRIM) } & unklar \\
\hline 6 & \multicolumn{2}{|c|}{ Transfusionsbedingte Hypervolämie (TACO) } & $1: 15$ \\
\hline
\end{tabular}

transplantation) ist zur Vermeidung einer GvHD die Transfusion von bestrahltem Blut (30 Gy) indiziert.

\section{Allergische Transfusionsreaktionen \\ Zugrunde liegt eine IgE-vermittelte Histaminausschüttung aus Mastzellen des Empfängers. Die Präsenz von IgE-Anti- körpern beim Empfänger gegen Plasmaproteine des Spenders oder gegen evtl. in der Konserve befindliche Allergene (z. B. Nahrungs-, Medikamentenspuren) scheint die Ursache zu sein. Die klinische Manifestation reicht von milden urtikari- ellen Reaktionen bis hin zum tödlich verlaufenden anaphy- laktischen Schock.}

\section{Transfusionsbedingtes akutes Lungenversagen (TRALI)} Bei der Ausbildung eines TRALI (,transfusion associated lung injury") imponiert typischerweise innerhalb der ersten Minuten nach Transfusion eine Verschlechterung des pulmonalen Gasaustauschs. Radiologisch werden bilaterale alveoläre Infiltrate beobachtet, die sich in der Regel innerhalb von 3-4 Tagen vollständig zurückbilden. Die Pathophysiologie des TRALI ist nicht vollständig geklärt, scheint aber amehesten immunologisch vermittelt (transfundierte Antikörper gegen Empfänger-Antigene des HLA- bzw. HNA-Komplexes). Hauptauslöser stellt gefrorenes Frischplasma weiblicher Spender nach vorangegangener Schwangerschaft dar (Inzidenz $1: 5000 ;[13])$.

\section{Transfusionsbedingte Hypervolämie (TACO)}

Insbesondere bei kardial vorerkrankten Patienten (KHK, Herzinsuffizienz) führt die schnelle Transfusion bzw. Infu- sion größerer Volumina an Blut und Blutprodukten nicht selten zu kardialer Dekompensation mit der Entwicklung eines akuten Lungenödems (,transfusion associated circulatory overload“", TACO; [14]).

\section{Transfusionsassoziierte Immunmodulation (TRIM)}

Die Transfusion von allogenem Blut kann zu einer unspezifischen Immunmodulation des Empfängers führen (transfusionrelated immunomodulation, TRIM). So ist das Risiko für das postoperative Auftreten von Infektionen (v. a. Pneumonien und Wundinfektionen) nach allogener Transfusion signifikant höher als nach autologer Transfusion [15]. Dabei korrelierten Häufigkeit und Ausprägung der infektiösen Komplikationen mit der Menge an transfundiertem Fremdblut. Darüber gibt es Hinweise, dass die Rezidivrate maligner Tumoren mit der Menge an verabreichtem allogenem Blut zunehmen könnte $[16,17]$. Der hierbei zugrunde liegende Pathomechanismus ist derzeit nicht vollständig geklärt. Aus medikolegaler Sicht ist die „vollständigen“ Aufklärung des Patienten über die Risiken und Konsequenzen einer TRIM (bis hin zu einer gesteigerten Letalität, s. unten) zu empfehlen.

\subsubsection{Transfusionsassoziierte Letalität}

In großen randomisierten Studien sowie in einer Reihe großer Observationsstudien bei Intensivpatienten, Patienten nach nichtherzchirurgischen operativen Eingriffen und Patienten mit gastrointestinaler Blutung, zeigte sich ein statistisch signifikanter Zusammenhang zwischen einer großzügigen (,liberalen“) Indikationsstellung zur Fremdbluttransfusion und der Lettalität der transfundierten Patienten. Die unnötige 
Fremdbluttransfusion muss mittlerweile als ,unabhängiger Risikofaktor“ für das Überleben angesehen werden. Der zugrunde liegende Pathomechanismus ist derzeit noch nicht vollständig geklärt. Ein Zusammenhang mit der transfusionsassoziierten Immunmodulation (TRIM) wird diskutiert.

\subsection{Kostenentwicklung im Transfusionswesen}

Der Anteil von alten Menschen ( $>65$ Jahre) an der Gesamtbevölkerung und damit auch die Zahl chirurgischer Eingriffe mit hohen Blutverlusten in dieser Altersgruppe nimmt stetig zu. Bei gleichzeitig rückläufiger Spendebereitschaft ist in Zukunft mit einem zunehmenden Defizit an allogenen Blutkonserven zu rechnen. Hinzu kommt, dass bis zu $5 \%$ der Konserven aufgrund positiver Testung für virale Infektionen verworfen werden müssen. Was dies für die Kostenentwicklung im Transfusionswesen bedeuten wird, ist derzeit nicht abzusehen. Noch ist im europäischen Vergleich der Preis eines allogenen Erythrozytenkonzentrates in der BRD mit 75-80€ niedrig. Man geht jedoch davon aus, dass dieser in den kommenden Jahren national und international deutlich steigen wird [18].

\subsection{Fremdblutsparende Konzepte zur Reduktion perioperativer allogener Bluttransfusionen („,Patient Blood Management" - PBM)}

Der diskutierte Zusammenhang zwischen Fremdbluttransfusion und Morbidität bzw. Letalität sowie die zu erwartende Kostensteigerung im Transfusionswesen - zum einen bedingt durch Spendermangel, zum anderen durch die Behandlungspflicht transfusionsassoziierter Folgeerkrankungen (u. a. chronische Hepatitis, Leberzirrhose, Wundinfektion, Tumorrezidiv) - erhöhen den Stellenwert Fremdblut vermeidender bzw. reduzierender Maßnahmen in der operativen Medizin. Am erfolgversprechendsten erscheint dabei die sinnvolle, Kosten-Nutzen-orientierte Kombination präoperativer und intraoperativer Verfahren im Sinne eines konzeptionellen, interdisziplinär akzeptierten und praktizierten „Patient Blood Managements“ - PBM (Abb. 5).

Übersicht über prä- und intraoperative Maßnahmen zur Reduktion von Fremdbluttransfusionen

- Präoperativ

- Identifikation und Korrektur von präoperativer Anämie

- Identifikation und Korrektur einer präoperativen Gerinnungsstörung

- Eigenblutspende
- Hämodilution

- akute normovolämische Hämodilution (ANH)

- akute hypervolämische Hämodilution (AHH)

- Intraoperativ

- Operatives Vorgehen

- Anämietoleranz

- Lagerung des Patienten

- Wahl des Anästhesieverfahrens

- Kontrollierte Hypotension

- Maschinelle Autotransfusion

- Temperaturmanagement

- pH-Management

- ZVD-Management

- Volumentherapie

- Antifibrinolytika

- Desmopressin

- Gerinnungsmanagement

\subsubsection{Präoperative Maßnahmen}

Identifikation und Korrektur von präoperativer Anämie Bei Anwendung der derzeit geltenden WHO-Kriterien für die Diagnose von Anämie (prämenopausale Frauen: $\mathrm{Hb}$ $<12$ g/dl; Schwangere <11 g/dl; Männer: $\mathrm{Hb}<13$ g/dl) variiert die Inzidenz einer präoperativen Anämie abhängig von Lebensalter und vorhandenen Begleiterkrankungen wie Diabetes, Niereninsuffizienz, chronisch inflammatorischen

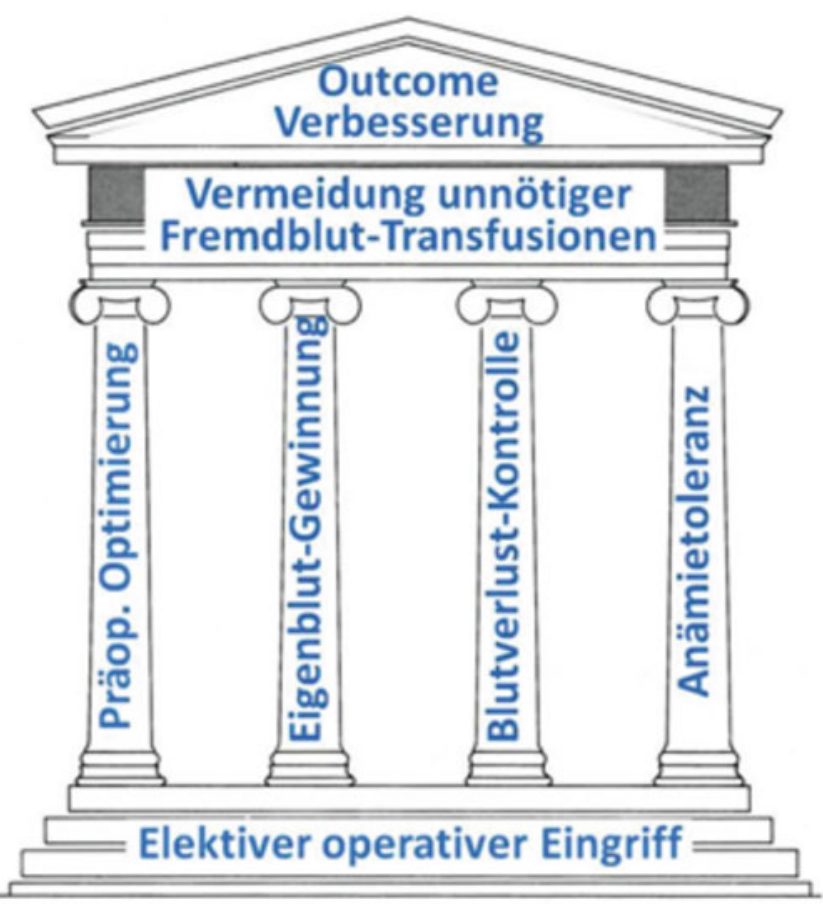

Säulenmodell des „Patient Blood Managements“ (PBM)

Abb. 5 Säulenmodell des „Patient Blood Managements“ (PBM) 
Syndromen und onkologischen Erkrankungen. Häufig wird eine Anämie erstmals während der präoperativen Routinediagnostik entdeckt und bleibt bis zum Operationstermin unbehandelt.

Zwischen 15 und $40 \%$ der operativen Patienten weisen präoperativ eine Anämie auf.

Präoperative Anämie geht mit erhöhter postoperativer Morbidität und Letalität einher. In einer retrospektiven Analyse an 1958 Zeugen Jehovas [19], die sich nichtkardiochirurgischen Eingriffen unterziehen mussten, war eine präoperative $\mathrm{Hb}$ Konzentration von $<10 \mathrm{~g} / \mathrm{dl}$ mit einer signifikant erhöhten postoperativen Letalität verbunden, besonders ausgeprägt bei den 221 eingeschlossenen Patienten mit kardiovaskulären Vorerkrankungen. Die niedrigste Letalität fand sich bei herzgesunden Patienten mit einem perioperativen Hb-Abfall von $\leq 2 \mathrm{~g} /$ $\mathrm{dl}$, die höchste Letalität bei kardialen Risikopatienten mit einem perioperativen $\mathrm{Hb}-\mathrm{Abfall}$ von $\geq 4 \mathrm{~g} / \mathrm{dl}$.
Für eine optimale Vorbereitung ist die Vorstellung des Patienten 3-4 Wochen vor seinem geplanten Eingriff in der Prämedikationsambulanz erforderlich. Ziel ist es, eine zu diesem Zeitpunkt diagnostizierte Anämie weiter zu differenzieren (Eisenmangel, renale Anämie, ,anemia of chronic disease"). Hierzu ist neben der Hb-Konzentration die Bestimmung von $\mathrm{MCV}, \mathrm{MCH}$, Transferrinsättigung, Serumferritinkonzentration und der Serumkreatininkonzentration erforderlich. In schwierigen Fällen kann der Anteil hypochromer Erythrozyten (\%HYPO) und der Hb-Gehalt der Retikulozyten $(\mathrm{CHr})$ differenzialdiagnostisch herangezogen werden (Abb. 6; [20]).

Eisenmangelanämie Etwa ein Drittel der vor operativen Eingriffen als anämisch identifizierten Patienten weist einen signifikanten Eisenmangel auf. Laborchemisch hinweisgebend sind verringertes $\mathrm{Hb}, \mathrm{MCV}$ und $\mathrm{MCH}$ (mikrozytäre, hypochrome Anämie), verringertes Ferritin $(<30 \mu \mathrm{g} / \mathrm{l})$ und Transferrinsättigung $(<20 \%)$ und verringertes retikulozytä-

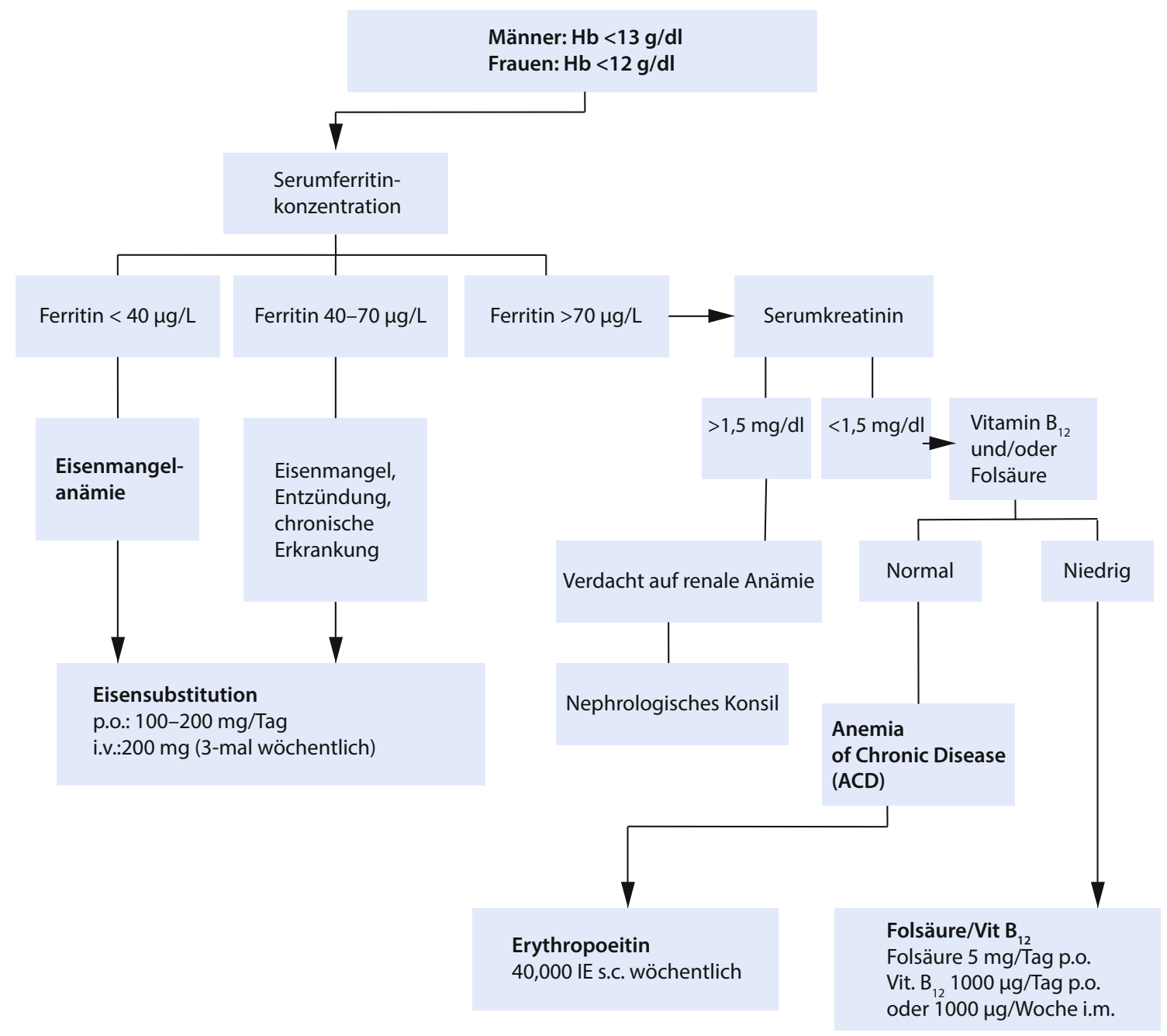

Abb. 6 Algorithmus zur Abklärung einer präoperativen Anämie. (Nach: [20]) 
res $\mathrm{Hb}(<28$ pg). Unter effektiver Eisentherapie - aufgrund des Zeitdrucks häufig bevorzugt intravenös (z. B. niedermolekulares Eisen-III-hydroxid-Dextran oder -Saccharose, Eisencarboxymaltose) - sollte die Hb-Konzentration innerhalb weniger Tage signifikant ansteigen.

Anemia of chronic disease (ACD) Die ACD tritt im Verlauf einer chronischen entzündlichen Erkrankung, Infektionskrankheit und bei malignen Tumoren auf. Ursächlich ist eine inadäquate Eisenfreisetzung aus häufig normal gefüllten Eisenspeichern. Laborchemisch hinweisend sind erniedrigtes $\mathrm{Hb}$, normales $\mathrm{MCV}$ und $\mathrm{MCH}$ (normozytäre, normochrome Anämie). Die Transferrinsättigung ist verringert, das Serumferritin als Akut-Phase-Protein häufig erhöht. Die ACD kann nur durch die Verabreichung von rekombinantem humanen Erythropoeitin (rHuEPO) korrigiert werden.

Renale Anämie Ursache einer renalen Anämie ist eine verminderte Synthese von Erythropoeitin in Kombination mit der toxischen Wirkung harnpflichtiger Substanzen. Hinweisgebend ist neben einer normochromen, normozytären Anämie eine Serumkreatininkonzentration von $>1,5 \mathrm{mg} / \mathrm{dl}$ und eine Kreatininclearance von $<40 \mathrm{ml} / \mathrm{min} / 1,73 \mathrm{~m}^{2}$. Häufig liegt gleichzeitig ein Eisenmangel vor. Die Therapie der renalen Anämie erfolgt durch die Verabreichung von rekombinant hergestelltem, humanem Erythropoeitin (rHuEPO) ggf. in Kombination mit der oralen oder i.v.-Applikation von Eisen.

\section{Identifikation und Korrektur einer präoperativen Gerin- nungsstörung}

Jeder operative Eingriff ist mit einem potenziellen Blutungsrisiko verbunden, welches durch eine unerkannte, präoperativ bereits existente Gerinnungsstörung erheblich erhöht werden kann. Plasmatische Globaltests (aktivierte partielle Thromboplastinzeit aPTT, Thromboplastinzeit TPZ bzw. Quick-Wert) und die Thrombozytenzahl besitzen für sich alleine betrachtet eine nur geringe Aussagekraft bezüglich der Prädiktion intraoperativer Blutungsprobleme.

\section{- Erforderlich ist die zusätzliche Erhebung einer individuel- len Gerinnungs-, bzw. Blutungsanamnese anhand standar- disierter und validierter Fragebögen [21].}

Die Angaben des Patienten ermöglichen in der Mehrzahl der Fälle die Erkennung bzw. den Ausschluss einer hämorrhagischen Diathese sowie bereits eine grobe Abschätzung des Schweregrads. Bei entsprechendem Verdacht auf reduzierte Einzelfaktorenaktivitäten bzw. Thrombozytenfunktionsstörungen sollte die weitere präoperative Abklärung durch einen Hämostaseologen erfolgen.
Besonderes Augenmerk sollte auf die Medikamentenanamnese gelegt werden.

Viele Patienten nehmen im Rahmen einer internistischen oder analgetischen Dauertherapie, aber auch zur Stabilisierung ihrer Gedächtnisleistung (Ginkgo) gerinnungswirksame Präparate ein. Wenn möglich sollten die entsprechenden Pharmaka präoperativ mit ausreichendem zeitlichem Abstand zur Operation abgesetzt bzw. umgestellt werden. Eine Orientierungshilfe geben hierbei Empfehlungen zum Umgang mit Antikoagulanzien bei der Planung rückenmarknaher Anästhesien [22]. Insbesondere bei Patienten unter ASS $100 \mathrm{mg}$ muss eine kritische Risiko-Nutzen-Abwägung bezüglich einer präoperativen Unterbrechung der Therapie erfolgen, da hieraus negative Auswirkungen auf die behandelte Grunderkrankung erwachsen können.

\section{Präoperative Eigenblutspende}

Bei der präoperativen Eigenblutspende wird dem Patienten in wöchentlichen Abständen Vollblut entnommen. Die maximale Lagerungszeit beträgt für CPDA-1-konserviertes Vollblut 35 Tage, kann aber durch Separierung von Erythrozyten und Plasma sowie durch Zusatz von Konservierungslösungen (SAG-Mannitol, PAGGS-Mannitol) auf 42-49 Tage ausgedehnt werden. Autologes Plasma kann tiefgefroren bis zu einem Jahr gelagert werden. Vor dem ersten Abnahmetermin wird der Eigenblutspender auf HIV, Hepatitis B und C getestet. Die entnommenen Konserven werden nach dem AB0- und Rhesus-Blutgruppensystem klassifiziert und durch Identifizierungscodes dem Spender verwechslungsfrei zugeordnet. Eine virologische Testung der Eigenblutkonserven erfolgt in der BRD nicht.

Wird dem Patienten wöchentlich eine Konserve entnommen, die letzte eine Woche vor dem Operationstermin, ergibt sich theoretisch ein frühest möglicher Spendebeginn 5-6 Wochen vor der Operation mit der Abnahme von maximal 5-6 Konserven. Die Entnahmemenge pro Eigenblutspende beträgt $450-900 \mathrm{ml}$ Vollblut, bei maschineller Separierung sollten nicht mehr als $600 \mathrm{ml}$ Eigenplasma pro Sitzung entnommen werden.

Patienten in Eigenblutspendeprogrammen weisen häufig präoperativ niedrigere $\mathrm{Hb}$-Konzentrationen auf als andere Patienten. Dieser Effekt kann durch die subkutane Verabreichung von Erythropoeitin (rhuEPO) und/oder die orale oder i.v.-Verabreichung von Eisenpräparaten abgeschwächt werden. Allerdings sinkt dadurch die Kosteneffektivität der Eigenblutspende.

Die Eigenblutspende ist für elektive chirurgische Eingriffe bei Patienten mit einem präoperativen Hämatokrit $>40 \%$ und einer Transfusionswahrscheinlichkeit von mindestens $50 \%$ geeignet [23]. Sie wurde auch bereits bei alten Menschen, Kleinkindern und schwangeren Frauen erfolgreich angewandt. 
- Malignome oder eine Hepatitis stellen keine Kontraindikation für eine Eigenblutspende dar.

Angehörige der Glaubensgemeinschaft der Zeugen Jehovahs akzeptieren in der Regel die Eigenblutspende nicht (Abschn. 5).

Bei Eigenblutspendern ohne kardiopulmonale Vorerkrankungen gilt das Verfahren als sicher. In einer retrospektiven Analyse von 5600 Eigenblutspenden fanden sich keine tödlichen Zwischenfälle [24]. Milde vasovagale Reaktionen (Blässe, Schwindel, Übelkeit, Hyperventilation) traten bei 7,5 \% von insgesamt 2091 Eigenblutspendern auf, kurz dauernde Bewusstlosigkeit in 0,1\% und lang dauernde Bewusstlosigkeit in 0,02\%. Bei kardialen Risikopatienten (Herzinsuffizienz, KHK) wird die Eigenblutspende dagegen kontrovers diskutiert. Zwischenfälle im Sinne von Hypotonie, Angina pectoris, Myokardinfarkt und Arrhythmien innerhalb der ersten $24 \mathrm{~h}$ nach Spende traten - je nach Untersuchung - bei 0-20\% der Eigenblutspender auf.

- Cave Bei Patienten mit instabiler Angina pectoris, signifikanter Hauptstammstenose der linken Koronararterie oder einem innerhalb der letzten 6 Monate vor dem ersten Spendetermin abgelaufenen Myokardinfarkt sollte keine Eigenblutspende durchgeführt werden.

Generell kann durch simultanen Ersatz des entnommenen Eigenbluts durch kristalloide oder kolloidale Lösungen eine Stabilisierung der Hämodynamik während der Spende erzielt werden.

In Abhängigkeit von der Art des operativen Eingriffs, der Transfusionswahrscheinlichkeit und der präoperativ noch verfügbaren Zeit, muss die Anzahl der Eigenblutspenden für jeden Patienten individuell festgelegt werden. Hilfestellung geben institutionseigene Transfusionsstatistiken sowie institutionsübergreifende, statistische Analysen des Transfusionsbedarfs bei verschiedenen chirurgischen Eingriffen (MSBOS: „maximum surgical blood ordering schedule“ [25]; SANGUIS: „safe and good use of blood in surgery“ [26]).

Ziel derartiger Analysen ist es, bei Eigenblutspendern allogene Transfusionen zu vermeiden, gleichzeitig aber auch unnötige Entnahmen von Eigenblut zu minimieren und damit die Kosteneffektivität zu wahren.

Die Übernahme ungenutzter Eigenblutkonserven zur allogenen Transfusion (sog. „crossover") ist in der BRD verboten.

Durch die Kombination mit präoperativer Gabe von Erythropoetin, präoperativer Hämodilution und maschineller
Autotransfusion (MAT) kann der Fremdblutbedarf bei Eigenblutspendern mit zu erwartenden großen Blutverlusten noch stärker reduziert werden. Die präoperative Eigenblutspende selbst ist dann jedoch nicht mehr kosteneffektiv.

Nach Entnahme und Aufbereitung wird das Eigenblut in einer dafür vorgesehenen Einrichtung für maximal 5-6 Wochen aufbewahrt. Wie bei allogener Transfusion besteht auch bei der Eigenbluttransfusion ein durch Verwechslung bzw. bakterielle Verunreinigung der Konserven bedingtes Transfusionsrisiko für den Empfänger.

Bei der Indikation zur Transfusion von Eigenblut gelten dieselben Grundsätze wie bei der Transfusion von Fremdblut (Abschn. 3.2). Zudem ist die direkt vor Transfusion durchgeführte Blutgruppenbestimmung (Beside-Test) von Empfänger- und Konservenblut vorgeschrieben.

\section{Akute normovolämische Hämodilution}

Während einer akuten normovolämischen Hämodilution (ANH) wird dem Patienten unmittelbar vor einem elektiven chirurgischen Eingriff - in der Regel zwischen Narkoseeinleitung und Hautschnitt - Vollblut entnommen und simultan durch kolloidale und/oder kristalloide Infusionslösungen ersetzt.

Bei Verdünnung des zirkulierenden Blutes auf Hämatokritwerte (Hkt) von bis zu $20 \%$ spricht man von "limitierter"$\mathrm{ANH}$, bei Hkt unter $20 \%$ von "extremer" $\mathrm{ANH}$ (Abschn. 1.1).

Da das intravasale Blutvolumen während ANH konstant bleiben muss (Normovolämie!), richtet sich das Verhältnis von entnommenem Blut zu infundierter Lösung nach der Art des verwendeten Diluens.

Bei der zu favorisierenden Dilution mit einem isotonen Kristalloid wird im Verhältnis 1:3 ausgetauscht, bei Verwendung eines isoonkotischen Kolloids (z. B. 6 \% Hydroxyäthylstärke oder 5 \% Humanalbumin), im Verhältnis 1:3.

Bei der Wahl des Diluens sind die derzeit geltenden Kontraindikationen für hydroxyäthylstärkehaltige Infusionslösungen zu berücksichtigen ( $\triangleright$ Kap. 25, „Volumenersatzlösungen").

Das entnommene autologe Vollblut wird bei Raumtemperatur in nummerierten und beschrifteten Blutbeuteln (Patientenetikett, Abnahmeuhrzeit, Unterschrift des behandelnden Anästhesisten) mit CPDA-1-Stabilisatorlösung in direkter Nähe des Patienten gelagert.

Eine ANH kann bei elektiven chirurgischen Eingriffen erwogen werden, die im Regelfall die Transfusion von 2 oder 
mehr Erythrozytenkonzentraten erfordern. Die Menge des entnommenen ANH-Bluts wird an Größe und Blutungsrisiko des geplanten Eingriffs angepasst [27]. Bei zu erwartendem hohen Blutverlust muss ebenso wie bei geringem Ausgangshämatokrit ein niedrigerer Zielhämatokrit während $\mathrm{ANH}$ angestrebt werden, um genügend autologes ANH-Blut für perioperative Transfusionen zur Verfügung $\mathrm{zu}$ haben (Abb. 7; [28]).

\section{Drei Faktoren für die Effektivität der ANH bei der Einsparung von Fremdblut \\ - Ausgansgshämatokrit vor ANH \\ - Zielhämatokrit der ANH \\ - Perioperativer Blutverlust}

Theoretisch könnte jede ANH primär bis zum individuellen kritischen $\mathrm{Hkt}\left(\mathrm{Hkt}_{\mathrm{krit}}\right)$ (Abschn. 2.3) des Patienten durchgeführt und somit die maximal mögliche Menge autologen Bluts gesammelt werden. Im Falle eines akuten intraoperativen Blutverlusts bestünde dann jedoch keinerlei Sicherheitsbereich mehr für die Gewebeoxygenierung. Jeder weitere Abfall der $\mathrm{DO}_{2}$ würde $\mathrm{zu}$ einer sofortigen Abnahme der $\mathrm{VO}_{2}$ führen. Die Folge wäre eine Gewebehypoxie.

In der klinischen Praxis wird daher die ANH nicht bis zum Hktkrit durchgeführt, sondern bei herzgesunden Patienten auf einen Hkt von $21 \%(\mathrm{Hb} 7 \mathrm{~g} / \mathrm{dl})$ und bei alten Patienten mit eingeschränkter Herzfunktion (KHK, Herzinsuffizienz, chronische $\beta$-Rezeptorblockade) auf einen Hämatokrit von $30 \%(\mathrm{Hb} 10 \mathrm{~g} / \mathrm{dl})$ limitiert.

Die Überwachung des intravasalen Volumenstatus bei extremer Hämodilution ( $\mathrm{Hkt}<20 \%$ ) ist schwierig und erfordert zumindest die kontinuierliche Messung des zentralen Venendrucks, ZVD, besser die kontinuierliche Bestimmung der Variation des ventrikulären Schlagvolumens, SVV, die intermittierende Messung des intrathorakalen Blutvolumens, ITBV, oder die Beurteilung der ventrikulären Füllung mittels transthorakaler oder transösophagealer Echokardiographie.

Bei Aufrechterhaltung von Normovolämie wird die iatrogene, dilutionsbedingte Anämie durch die in Abschn. 1.1 aufgeführten Mechanismen ohne die Gefahr von Gewebehypoxie und Organdysfunktion kompensiert. Eine durch die

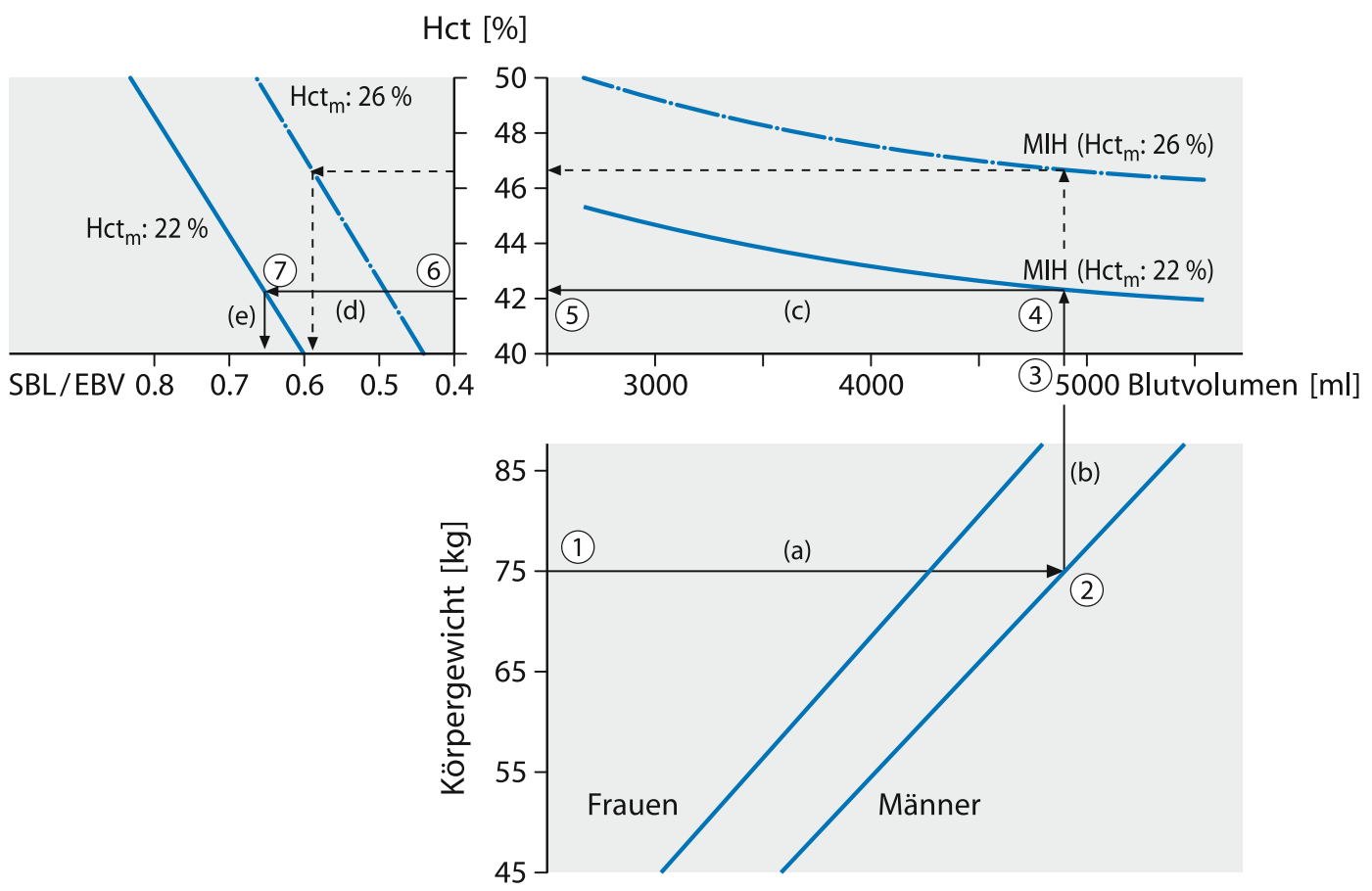

Abb. 7 Nomogramm für ein ANH mit dem Ziel der Einsparung einer Fremdblutkonserve. Startpunkt ist die Körpergewichtsskala (1). Die horizontale Linie führt zum geschätzten Blutvolumen (EBV) (2), ablesbar bei (3). Der Schnittpunkt mit der Linie für ANH-Zielhämatokrit $22 \%$ bei (4) gibt bei (5) den mindestens geforderten Ausgangshämatokrit an. (8) gibt das Verhältnis von Blutverlust und geschätztem Blutvolumen an. Beispiel: Ein $75 \mathrm{~kg}$ schwerer Mann (1) mit einem geschätzten Blutvolumen von ca. 49001 (3) benötigt bei einem
ANH-Zielhämatokrit von $22 \%$ (4) einen Ausgangshämatokrit von mindestens $42 \%$ (5), damit die ANH effektiv wird. Zudem muss der Blutverlust ca. $65 \%$ des geschätzten Blutvolumens betragen (8). Die unterbrochenen Pfeile zeigen dieselbe Situation für einen Patienten, der lediglich auf einen Zielhämatokrit von $26 \%$ hämodilutiert werden soll. Der errechnete Ausganghämatokrit liegt mit etwa $46 \%$ entsprechend höher. (Nach: [28]) 
ANH bedingte, klinisch relevante Verschlechterung der Blutgerinnung ist bei einem angestrebten Ziel-Hkt zwischen 21 und $30 \%$ unwahrscheinlich [27].

Die Wahl des Diluens bei der ANH scheint bezüglich der Blutgerinnung keine klinisch relevante Rolle zu spielen [29]. Insbesondere niedermolekularen HES-Lösungen mit niedrigem Substitutionsgrad interferieren nur in geringem Maße mit der Blutgerinnung. Die Anwärmung der Infusionslösungen ist jedoch in jedem Falle anzuraten sowohl im Tierexperiment als auch bei Patienten beeinträchtigte Hypothermie die Blutgerinnung [4].

Eine ANH kann auch bei Kindern, alten Patienten, Patienten mit eingeschränkter kardialer Pumpfunktion sowie Patienten mit chronischer $\beta$-Rezeptorblockade durchgeführt werden. Auch Malignome stellen keine Kontraindikation für eine ANH dar. Zeugen Jehovas akzeptieren ANH unter der Voraussetzung, dass Patient, Schlauchsystem und Blutbeutel zu jedem Zeitpunkt ein geschlossenes System bilden (Abschn. 5).

\section{Kontraindikationen für eine ANH}

- Schwere KHK (instabile Angina pectoris, signifikante Hauptstammstenose der linken Koronararterie, innerhalb der letzten 6 Monate abgelaufener Myokardinfarkt)

- Hochgradige Aortenklappenstenose

- Stenosen der A. carotis

- Niereninsuffizienz

- Manifeste Bakteriämie

Im Falle eines Blutverlusts profitiert der Patient in zweierlei Hinsicht von einer ANH:

- zum einen verliert er verdünntes Blut und damit bei gleichem Blutverlust weniger Erythrozytenmasse als ein Patient mit normalem Hkt (Tab. 3).

- Zum anderen steht bei Indikation zur Transfusion frisches, autologes Vollblut einschließlich sämtlicher Gerinnungsfaktoren und funktionsfähiger Thrombozyten zur Verfügung.

Tab. 3 Ausmaß des Hämoglobinverlusts bei identischem Blutverlust: Einfluss des Ausgangshämatokrits

\begin{tabular}{|l|l|l|l|} 
& $\begin{array}{l}\text { Ohne } \\
\text { Hämodilution }\end{array}$ & $\begin{array}{l}\text { Limitierte } \\
\text { ANH }\end{array}$ & $\begin{array}{l}\text { Extreme } \\
\text { ANH }\end{array}$ \\
\hline $\mathrm{Hkt}(\%)$ & 45 & 21 & 9 \\
\hline $\mathrm{Hb}(\mathrm{g} / \mathrm{dl})$ & 15 & 7 & 3 \\
\hline Blutverlust $(\mathrm{ml})$ & 500 & 500 & 500 \\
\hline Hb-Verlust $(\mathrm{g})$ & 75 & 35 & 15
\end{tabular}

Die Retransfusion des ANH-Bluts sollte möglichst bis nach Abschluss der chirurgischen Blutstillung hinausgezögert werden, um einen hohen Prozentsatz des transfundierten Bluts im Patienten zu halten.

Muss dennoch während eines anhaltenden Blutverlusts mit der Retransfusion begonnen werden, so sollte dies in der umgekehrten Reihenfolge der Abnahme geschehen, um so die Transfusion des „besten Beutels", d. h. des Beutels mit dem höchsten Hkt, wiederum bis nach Beendigung der Blutstillung hinauszuzögern.

Die Durchführung eines Bedside-Tests (Abschn. 3.3) ist nicht erforderlich. Die Transfusion des ANH-Blutes erfolgt über 170- bis 200- $\mu \mathrm{m}$-Filter (Gerinnselbildung bei schlechter Durchmischung von Blut und Stabilisatorlösung).

ANH-Blut sollte wegen des potenziellen Bakterienwachstums bei Raumtemperatur nicht länger als 6-8 h gelagert werden. Für die Transfusion des ANH-Bluts gelten prinzipiell dieselben Kriterien wie für die Transfusion von Fremdblut (Abschn. 3.3).

Je nach Zustand des Patienten und Schweregrad einer intraoperativen Blutung wird ein intraoperativer Blutverlust wie folgt therapiert:

- Sofortige Retransfusion von autologem ANH-Blut,

- Infusion kristalloidaler und kolloidaler Lösungen, bis Transfusionstrigger (Abschn. 3.3) eine beginnende Gewebehypoxie anzeigen oder bis beim Herzgesunden ein Hkt von $18-21 \%(\mathrm{Hb} 6-7 \mathrm{~g} / \mathrm{dl})$ und beim alten bzw. kardial vorgeschädigten Patienten ein $\mathrm{Hkt}$ von $24-30 \%(\mathrm{Hb}$ $8-10 \mathrm{~g} / \mathrm{dl})$ erreicht ist $[8,30,31]$.

Eine bei normovolämischer Anämie auftretende Gewebehypoxie ist meist bereits nach Transfusion von wenigen Millilitern des autologen ANH-Blutes reversibel.

In besonderen Fällen (mikrochirurgische Eingriffe, große Wundflächen, Knochenmarkeröffnung etc.) kann das ANHBlut zur Verbesserung der Blutgerinnung transfundiert werden.

Während in einzelnen klinischen Studien bei abdominal-, herzchirurgischen, orthopädischen, gynäkologischen, urologischen und Mund-Kiefer-gesichtschirurgischen Eingriffen die Effektivität der ANH bei der Einsparung von Fremdblut wiederholt eindrücklich nachgewiesen werden konnte, war dieser Effekt nach Metaanalyse der in der Literatur vorhandenen Daten nicht eindeutig reproduzierbar [32, 33]. Eine der Hauptursachen hierfür dürfte das heterogene Transfusionsmanagement (Transfusionstrigger, Transfusionsvolumen etc.) in den einzelnen Studien sein, welches die Vergleichbarkeit der untersuchten Patientenkollektive 
erschwert. In vergleichenden Studien erwiesen sich ANH und präoperative Eigenblutspende bei urologischen (radikale Prostatektomie) und orthopädischen Eingriffen (Hüft- bzw. Knie-TEP) als gleichwertig.

Eine $\mathrm{ANH}$ ist jedoch deutlich kostengünstiger als eine präoperative Eigenblutspende.

Bei Patienten mit niedrigem Ausgangshämatokrit (z. B. Tumoranämie, renale Anämie) konnte die Menge an präoperativ gewonnenem ANH-Blut durch präoperative Verabreichung von rhEPO gesteigert werden. Die Kombination von ANH mit anderen fremdblutsparenden Maßnahmen (kontrollierte Hypotension, maschinelle Autotransfusion) reduzierte bei herzchirurgischen und orthopädischen Eingriffen den Fremdblutbedarf um 60-90\%. Neuere Studien zeigten, dass eine ANH bei Beatmung mit reinem Sauerstoff (sog. „hyperoxische ANH“) ohne die Gefahr einer Gewebehypoxie auf niedrigere Hkt-Werte durchgeführt werden konnte als bei Beatmung mit Raumluft. Noch ausgeprägter war dieser Effekt, wenn zur Hämodilution künstliche $\mathrm{O}_{2}$-Träger verwendet wurden (Abschn. 4).

\section{Argumente für die Bevorzugung der ANH vor der}

\section{präoperativen Eigenblutspende}

- Beide Verfahren können bezüglich ihrer Effektivität als gleichwertig betrachtet werden.

- Bei der ANH entfallen die kostenintensiven Faktoren der Anfahrt sowie Personal-, Material- und Gerätekosten für Aufbereitung und Testung des Eigenbluts. In einer amerikanischen Studie wurde für eine Eigenblutkonserve ein Preis von 226 US-\$, für eine ANH-Konserve ein Preis von 28 US-\$ errechnet [34]. Eine deutsche Studie ergab vergleichbare Zahlen (Eigenblutkonserve $€$ 200.-, ANH-Konserve $€ 12 .-;[27])$

- Die ANH ermöglicht eine flexiblere Planung des Operationstermins, da die aufwändige Logistik der präoperativen Eigenblutspende entfällt.

Insgesamt erlebt die lange Zeit in Vergessenheit geratene ANH derzeit eine Renaissance als kostengünstiges und effektives Verfahren zur Einsparung von Fremdbluttransfusionen bei elektiven operativen Eingriffen.

\footnotetext{
Akute hypervolämische Hämodilution (AHH)

Auch bei der präoperativen AHH wird eine Verdünnung des zirkulierenden Bluts angestrebt, um während eines intraoperativen Blutverlusts die pro $\mathrm{ml}$ Blutverlust verlorene Erythrozytenmenge $\mathrm{zu}$ reduzieren. Dies geschieht durch die
}

Infusion von kolloidalen und kristalloiden Lösungen ohne gleichzeitige Entnahme von Vollblut. Dadurch nimmt das intravasale Blutvolumen zu.

In Analogie zur ANH wird die verdünnungsbedingte Abnahme des $\mathrm{O}_{2}$-Gehalts des Bluts hauptsächlich durch eine Erhöhung des Schlagvolumens kompensiert, während die Herzfrequenz konstant bleibt. Aufgrund der Zunahme des Blutvolumens steigen allerdings die enddiastolischen, ventrikulären Füllungsdrücke. Dies kann bei eingeschränkter ventrikulärer Pumpfunktion zum Lungenödem führen.

Die AHH wird daher nur für herzgesunde Patienten empfohlen, gilt dann aber auch bei Infusion von zusätzlich bis zu $3000 \mathrm{ml}$ als sicher [35].

Eine Erhöhung der klinischen Blutungsneigung ist nicht beschrieben. Sowohl im mathematischen Modell als auch am Patienten wurde der Nachweis erbracht, dass durch präoperative AHH trotz großer intraoperativer Blutverluste Fremdbluttransfusionen vermieden werden können. Die AHH stellt somit bei herzgesunden Patienten eine zeitsparende und kostengünstige Alternative zu ANH dar [36].

\subsubsection{Intraoperative Maßnahmen Operatives Vorgehen}

Die effektivste Maßnahme zur Vermeidung einer Fremdbluttransfusion ist schonendes, blutverlustarmes Operieren.

Bestandteile chirurgischer Strategien sind hierbei u. a. die Wahl des operativen Zugangswegs, atraumatische Gewebepräparation (z. B. Wasserstrahl-, Ultraschallresektoren), Drosselung der Perfusion des Operationsgebiets (z. B. Blutsperre, Pringle-Manöver) sowie der Einsatz technischer und pharmakologischer Hilfsmittel (z. B. Argon-Beamer, Fibrinkleber, lokale Hämostyptika) zur effektiven Stillung selbst kleinster Blutungen.

\section{Anämietoleranz}

Es besteht heute kein Zweifel mehr, dass der menschliche Organismus nicht auf seine ,normale“ Hb-Konzentration angewiesen ist, sondern - Normovolämie vorausgesetzt deutlich niedrigere $\mathrm{Hb}$-Konzentrationen ohne Schädigung der Organfunktionen toleriert (Übersicht und ausführliches Literaturverzeichnis in [37]).

Der operative Patient profitiert in verschiedener Hinsicht von einer Nutzung seiner natürlicherweise vorhandenen Anämietoleranz:

1. e ausgeprägter der Grad der normovolämischen Verdünnungsanämie, desto geringer die Reduktion der zirkulierenden Erythrozytenmasse mit jedem Milliliter Blutverlust. 
2. e vollständiger die Anämietoleranz des Patienten intraoperativ ausgeschöpft wird, desto länger kann der Transfusionsbeginn hinausgezögert werden - im Optimalfall bis nach erfolgreichem Abschluss der chirugischen Blutstillung. Zudem kann im Rahmen einer maschinellen Autotransfusion (MAT) das aus dem Operationsfeld abgesaugte Blut gesammelt werden und die darin enthaltenen Erythrozyten können nach Reinigung und evtl. hochenergetischer Bestrahlung (Tumorchirurgie) retransfundiert werden. Je ausgedehnter die Ausschöpfung der Anämietoleranz des Patienten, desto mehr autologe Erythrozyten können gesammelt und aufbereitet werden; je später mit der Retransfusion des MAT-Bluts begonnen wird, desto geringer der Nettoverlust an retransfundierter Erythrozytenmasse.

3. Die „Anämisierung“ des Patienten kann bereits präoperativ, iatrogen im Rahmen einer sog. akuten normovolämischen Hämodilution (ANH) erfolgen. Je niedriger der Ziel-Hkt der ANH gewählt wird, desto mehr profitiert der Patient von den in 1. und 2. beschriebenen Mechanismen.

Ein anämischer Patient toleriert bei gleichem absolutem $\mathrm{Hb}$-Abfall größere Blutverluste, als ein Patient mit normaler Hb-Konzentration, da er zunehmend "verdünntes Blut" verliert.

Mechanismen der natürlichen Anämietoleranz In Allgemeinanästhesie wird eine Verdünnungsanämie im Rahmen der Infusionstherapie eines akuten Blutverlusts bis auf sehr niedrige Hb-Konzentrationen bzw. Hkt-Werte ohne Gefährdung von Organperfusion, -oxygenierung und -funktion toleriert („natürliche Anämietoleranz" des menschlichen Organismus). Die Kompensationsmechanismen einer normovlämischen Hämodilution sind in Abschn. 1.1 beschrieben. Sie können auch bei Säuglingen, Kindern, alten Patienten, kardial vorerkrankten Patienten und Patienten unter chronischer $\beta$-Rezeptorblockade nachgewiesen werden.

Grenzen der natürlichen Anämietoleranz - Konzept der kritischen $\mathrm{DO}_{2}$ Erst bei extremer Hämodilution wird ein Punkt erreicht, an dem sich $\mathrm{O}_{2}$-Angebot $\left(\mathrm{DO}_{2}\right)$ und $\mathrm{O}_{2}$-Bedarf des Gesamtorganismus die Waage halten (Abb. 3). Man spricht von der sog. kritischen $\mathrm{DO}_{2}\left(\mathrm{DO}_{2}\right.$ krit $)$. Das Unterschreiten von $\mathrm{DO}_{2}$ krit ist mit einem konsekutiven Abfall der $\mathrm{VO}_{2}$ als Zeichen einer beginnenden Mangelversorgung der Gewebe mit $\mathrm{O}_{2}$ und damit einer beginnenden Gewebehypoxie vergesellschaftet (sog. Angebotsabhängigkeit der $\mathrm{VO}_{2}$; Abb. 3). Der Organismus deckt jetzt seinen Energiebedarf zunehmend über anaerobe Glykolyse und als Folge dessen steigt die Serumlaktatkonzentration. Diejenige $\mathrm{Hb}-$ Konzentration bzw. derjenige Hkt-Wert, an dem diese physiologische Grenze der Anämietoleranz erreicht ist, wird als kritische $\mathrm{Hb}$-Konzentration $\left(\mathrm{Hb}_{\text {krit }}\right)$ bzw. als kritischer Hkt-Wert ( $\mathrm{Hkt}_{\mathrm{krit}}$ ) bezeichnet. Ohne Intervention (hyperoxische Beatmung oder Transfusion) tritt bei Unterschreiten von $\mathrm{Hk}_{\mathrm{tkrit}}$ innerhalb kurzer Zeit der Tod des Organismus ein.

D Die kritische $\mathrm{Hb}$-Konzentration, $\mathrm{Hb}_{\text {krit }}$ bzw. der kritische Hämatokrit, $\mathrm{Hkt}_{\text {krit }}$ definieren den „point of no return“ einer normovolämischen Hämodilution. Bei Unterschreiten von $\mathrm{Hb}_{\text {krit }}$ bzw. $\mathrm{Hkt}_{\text {krit }}$ imponiert eine Gewebehypoxie.

Die Anämietoleranz des Gesamtorganismus kann beeindruckende Dimensionen annehmen: bei gesunden, wachen Probanden war die kritische $\mathrm{DO}_{2}$ selbst nach Hämodilution auf $\mathrm{Hb}$ 4,8 g/dl nicht erreicht. Bei herzgesunden Versuchstieren und Patienten in Allgemeinanästhesie wurde die Grenze der Verdünnungsanämie bei einem Hkt zwischen $12 \%$ und $3 \%$, entsprechend Hb-Konzentrationen zwischen 3,3 und $1,1 \mathrm{~g} / \mathrm{dl}$ gefunden (Tab. 4; detaillierte Literaturangaben in [37]). Säuglinge (1-7 Monate) und ältere Kinder (12,5 Jahre) tolerierten $\mathrm{Hb}-$ Konzentrationen von $3 \mathrm{~g} / \mathrm{dl}$ und niedriger, ohne dabei ihr kritisches $\mathrm{O}_{2}$-Angebot zu unterschreiten. Bei trächtigen Schafen blieb die fetale Gewebeoxygenierung bis zu einem mütterlichen Hkt von $15 \%$ ( $\mathrm{Hb} 5 \mathrm{~g} / \mathrm{dl}$ ) erhalten.

Cave Eine Angabe allgemein gültiger Zahlenwerte für die minimal tolerable $\mathrm{Hb}$-Konzentration eines Menschen ist unmöglich, da $\mathrm{DO}_{2}$ krit, $\mathrm{Hb}_{\text {krit }}$ und $\mathrm{Hkt}_{\text {krit }}$ sowohl inter-, als auch intraindividuell unterschiedlich sind und von einer Reihe von Faktoren beeinflusst werden. Adäquate Narkosetiefe, Hyperoxämie, komplette Muskelrelaxierung und milde Hypothermie steigern die Anämietoleranz, Hypovolämie, eingeschränkte Koronarreserve, Herzinsuffizienz, zu tiefe Narkose, Polytrauma und Sepsis reduzieren sie.

Des Weiteren ist nicht auszuschließen, dass sich die Anämietoleranz des Gesamtorganismus von der Anämietoleranz einzelner Organe unterscheidet. Es wäre denkbar, dass einzelne Organe ihre organspezifische $\mathrm{DO}_{2}$ krit $\mathrm{zu}$ einem früheren Zeitpunkt, d. h. bei einer höheren Hb-Konzentration bzw. einem höheren Hkt-Wert erreichen, als der Gesamtorganismus. Dies birgt die Gefahr einer bereits manifesten spezifischen Organgewebehypoxie noch vor Auftreten entsprechender Veränderungen auf Ebene des Gesamtorganismus. In Narkose scheint sich die Anämietoleranz des Gesamtorganismus nicht von derjenigen des Gehirns, des Herzens mit intakter Koronarperfusion und des Splanchnikussystems zu unterscheiden.

\section{Die Anämietoleranz des Herzens mit eingeschränkter Ko- ronarreserve ist geringer ausgeprägt.}

Im Tierexperiment traten bei narkotisierten Hunden mit einer experimentellen, hochgradigen (50-80\%) Koronar- 
Tab. 4 Übersicht über kritische Hb-Konzentrationen $\left(\mathrm{Hb}_{\mathrm{krit}}\right)$ bzw. kritische Hämatokritwerte $\left(\mathrm{Hk}_{\mathrm{tkrit}}\right)$ im Tierexperiment und bei Patienten

\begin{tabular}{|c|c|c|c|c|c|c|c|}
\hline Author & Spezies & Anästhesie & $\mathrm{F}_{\mathrm{i}} \mathrm{O}_{2}$ & Diluens & $\begin{array}{l}\text { Identifikation } \\
\text { von } \mathrm{DO}_{2} \text { krit }\end{array}$ & $\begin{array}{l}\mathrm{Hkt}_{\text {krit }} \\
(\%)\end{array}$ & $\begin{array}{l}\mathrm{Hb}_{\text {krit }} \\
(\mathrm{g} / \mathrm{dl})\end{array}$ \\
\hline $\begin{array}{l}\text { Fontana et al. } \\
1995\end{array}$ & $\begin{array}{l}\text { Mensch } \\
\text { (Kind) }\end{array}$ & $\begin{array}{l}\text { Isoflurane, Sufentanil, } \\
\text { Vecuronium }\end{array}$ & 1,0 & Albumin & $\begin{array}{l}\text { ST-Segment- } \\
\text { Senkung }\end{array}$ & & 2,1 \\
\hline $\begin{array}{l}\text { van Woerkens } \\
\text { et al. } 1992\end{array}$ & $\begin{array}{l}\text { Mensch } \\
\text { (84 Jahre) }\end{array}$ & $\begin{array}{l}\text { Enflurane, Fentanyl, } \\
\text { Pancuronium }\end{array}$ & 0,4 & Gelatine & Abfall der $\mathrm{VO}_{2}$ & 12 & 4 \\
\hline $\begin{array}{l}\text { Zollinger et al. } \\
1997\end{array}$ & $\begin{array}{l}\text { Mensch } \\
\text { (58 Jahre) }\end{array}$ & $\begin{array}{l}\text { Propofol, Fentanyl, } \\
\text { Pancuronium }\end{array}$ & 1,0 & Gelatine & $\begin{array}{l}\text { ST-Segment- } \\
\text { Senkung }\end{array}$ & & Ca. 1,1 \\
\hline Cain et al. 1977 & Hund & Pentobarbital & 0,21 & Dextran & Abfall der $\mathrm{VO}_{2}$ & 9,8 & 3,3 \\
\hline $\begin{array}{l}\text { Perez-de-Sá et al. } \\
2002\end{array}$ & Schwein & $\begin{array}{l}\text { Isofluran, Fentanyl, } \\
\text { Midazolam, Vecuronium }\end{array}$ & 0,5 & Dextran & Abfall der $\mathrm{VO}_{2}$ & & $2,3 \pm 0,2$ \\
\hline Meier et al. 2004 & Schwein & Propofol, Fentanyl & 0,21 & HES & Abfall der $\mathrm{VO}_{2}$ & & $3,1 \pm 0,4$ \\
\hline Pape et al. 2006 & Schwein & $\begin{array}{l}\text { Propofol, Fentanyl, } \\
\text { Pancuronium }\end{array}$ & 0,21 & HES & Abfall der $\mathrm{VO}_{2}$ & & $2,4 \pm 0,4$ \\
\hline $\begin{array}{l}\text { Kemming et al. } \\
2003\end{array}$ & Schwein & $\begin{array}{l}\text { Midazolam, Morphin, } \\
\text { Pancuronium }\end{array}$ & 0,21 & HES & $\begin{array}{l}\text { ST-Segment- } \\
\text { Senkung }\end{array}$ & $7,2 \pm 1,2$ & $2,6 \pm 0,3$ \\
\hline $\begin{array}{l}\text { Meisner et al. } \\
2001\end{array}$ & Schwein & $\begin{array}{l}\text { Diazepam, Morphin, } \\
\text { Pancuronium }\end{array}$ & 0,21 & Albumin & $\begin{array}{l}\text { ST-Segment- } \\
\text { Senkung }\end{array}$ & $6,1 \pm 1,8$ & $2,0 \pm 0,8$ \\
\hline Meier et al. 2007 & Schwein & $\begin{array}{l}\text { Propofol, Fentanyl, } \\
\text { Pancuronium }\end{array}$ & 0,21 & HES & Abfall der $\mathrm{VO}_{2}$ & & $2,4 \pm 0,5$ \\
\hline
\end{tabular}

stenose myokardiale Ischämiezeichen und/oder eine Verschlechterung der Herzfunktion bei Hb-Konzentrationen zwischen 7 und $10 \mathrm{~g} / \mathrm{dl}$ auf. In einer retrospektiven Kohortenanalyse an 1958 Zeugen Jehovas mit erhöhtem kardialen Risikoprofil (KHK, Herzinsuffizienz), die sich nichtkardiochirurgischen operativen Eingriffen unterziehen mussten, fand sich eine signifikant erhöhte postoperative Letalität, wenn eine postoperative $\mathrm{Hb}$-Konzentration von $8 \mathrm{~g} / \mathrm{dl}$ unterschritten wurde. Die Grenze der renalen Anämietoleranz lag im Tierexperiment bei gesunden narkotisierten Ratten zwischen 4 und $7 \mathrm{~g} / \mathrm{dl}$, in klinischen Studien bei herzchirurgischen Patienten bereits bei Hb-Konzentrationen zwischen 7 und $8 \mathrm{~g} / \mathrm{dl}$.

Cave In der klinischen Praxis ist es schwierig, die Grenze der individuellen Anämietoleranz des Patienten zu identifizieren. Die Messung von $\mathrm{VO}_{2}$ ist apparativ aufwendig. Indirekte Hinweise für das das Erreichen von $\mathrm{DO}_{2}$ krit wie neu aufgetretene EKG-Veränderungen, regionale Wandbewegungsstörungen in der Echokardiographie, Laktazidose und Abfälle von gemischt- bzw. zentralvenöser $\mathrm{O}_{2}$-Sättigung sind unsicher.

Hilfestellung bei der Einschätzung einer perioperativ auftretenden Verdünnungsanämie quoad vitam leisten die Ergebnisse umfangreicher Patientenstudien, in denen der Zusammenhang zwischen postoperativer Anämie und Letalität der Patienten analysiert wurde. In der Regel stammen diese Daten von Zeugen Jehovas. Bis zu einer postoperativen $\mathrm{Hb}$-Konzentration von $8 \mathrm{~g} / \mathrm{dl}$ konnte auch bei alten Patienten mit kardiopulmonalen Vorerkrankungen sowie bei multimorbiden Intensivpatienten kein statistischer Zusammenhang mit einer erhöhten postoperativen Letalität hergestellt werden.
Bei anämischen Patienten $(\mathrm{Hb}<8 \mathrm{~g} / \mathrm{dl})$, deren Tod kausal mit Anämie in Verbindung zu bringen war, lag die $\mathrm{Hb}-$ Konzentration immer unter $5 \mathrm{~g} / \mathrm{dl}$. In Einzelfällen wurden jedoch auch deutlich niedrigere $\mathrm{Hb}-$ Konzentrationen bis $\mathrm{zu}$ $1,5 \mathrm{~g} / \mathrm{dl}$ ohne Transfusion überlebt (Übersicht in [38]).

Therapeutische Beeinflussung der Anämietoleranz Im Falle unvorhergesehener Blutverluste und der Entwicklung einer potenziell lebensbedrohlichen Anämie kann die Anämietoleranz des Patienten durch verschiedene Maßnahmen effektiv gesteigert werden. Hierdurch kann Zeit bis zur chirurgische Kontrolle der Blutung gewonnen werden.

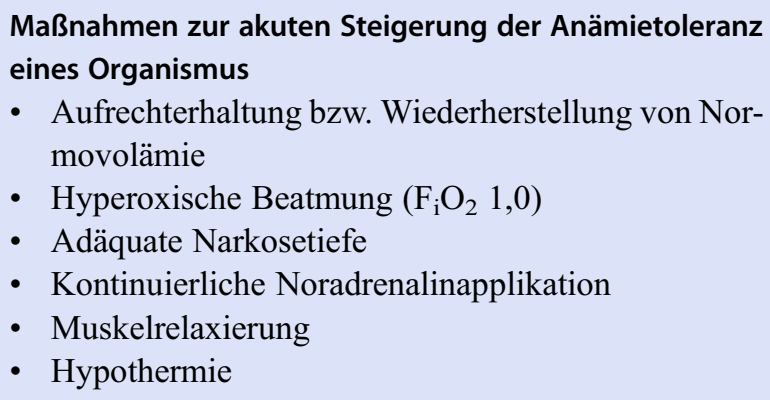

- Aufrechterhaltung bzw. Wiederherstellung von Normovolämie

- Hyperoxische Beatmung $\left(\mathrm{F}_{\mathrm{i}} \mathrm{O}_{2} 1,0\right)$

- Adäquate Narkosetiefe

- Kontinuierliche Noradrenalinapplikation

- Muskelrelaxierung

- Hypothermie

\section{Lagerung des Patienten}

Durch Lagerung des Operationsgebiets auf oder über Herzhöhe kann der hydrostatische Druck in den Venen und damit der venöse Blutverlust effektiv reduziert werden (z. B. $20^{\circ}$-Trendelenburg-Lagerung, Seitenlagerung). Bei gleichzeitiger iatrogener Absenkung des ZVD muss die Gefahr einer Luftembolie beachtet werden. 


\section{Wahl des Anästhesieverfahrens}

Das Anästhesieverfahren beeinflusst den intraoperativen Blutverlust.

Wenn möglich sollte ein Regionalverfahren in Spontanatmung einer Allgemeinanästhesie vorgezogen werden (geringere pharmakologische Vasodilatation, physiologische intrathorakale Druckverhältnisse; [39]). Kann eine Allgemeinanästhesie nicht vermieden werden, erscheint eine totale intravenöse Anästhesie (TIVA) der balancierten Anästhesie mit Inhalationsanästhetika überlegen.

\section{Kontrollierte Hypotension}

- Unter kontrollierter Hypotension $(\mathrm{KH})$ versteht man die pharmakologische Senkung des systolischen arteriellen Blutdrucks auf $80 \mathrm{mmHg}$ bzw. des mittleren arteriellen Drucks auf $50 \mathrm{mmHg}$.

Eine KH kann durch Vasodilatation mit Inhalationsanästhetika, mit intravenös verabreichten vasoaktiven Substanzen (Nitroprussid-Na, Nitroglycerin, Hydralazine, Urapidil, Esmolol, Nicardipin, Prostaglandin E1, Magnesiumsulfat, Adenosin) oder mit einer Periduralanästhesie induziert werden. Durch Anwendung des Verfahrens lässt sich der arterielle Blutverlust aus dem Operationsgebiet signifikant reduzieren [40].

\footnotetext{
Voraussetzung für die gefahrlose Anwendung der $\mathrm{KH}$ ist die Aufrechterhaltung von Normovolämie. Folge von $\mathrm{KH}$ und gleichzeitiger Hypovolämie sind Umverteilungsstörungen im Bereich der Mikrozirkulation mit konsekutiver Organischämie und -hypoxie.
}

Sowohl KH als auch normovolämische Anämie lösen identische vaskuläre Kompensationsmechanismen aus (periphere Vasodilatation, Ausschöpfung der vaskulären Reserve). Daher tritt bei Kombination von KH und normovolämischer Hämodilution eine Verschlechterung der Gewebeoxygenierung (insbesondere Myokardischämie, -hypoxie) bereits bei einem höheren Hkt auf als bei Normotonie. Dieser Effekt ist besonders ausgeprägt, wenn zur Induktion der $\mathrm{KH}$ Substanzen verwendet werden, die das Herzzeitvolumen reduzieren (z. B. $\beta$-Blocker). Während KH sollte bei Patienten mit bereits manifester, generalisierter Gefäßsklerose die $\mathrm{Hb}-$ Konzentration nicht unter $8 \mathrm{~g} / \mathrm{dl}$ abfallen. Zur frühzeitigen Erkennung einer Myokardischämie empfiehlt sich die kontinuierliche Analyse der ST-Strecke in den EKG-Ableitungen II und V5.
Cave Während $\mathrm{KH}$ und gleichzeitiger normovolämischer Anämie $(\mathrm{Hb}<8 \mathrm{~g} / \mathrm{dl})$ stellt die ischämische Neuropathie des N. opticus bei Patienten mit manifester Gefäßsklerose bzw. entsprechenden Risikofaktoren (arterieller Hypertonus, Diabetes mellitus, Hyperlipidämie, exzessiver Nikotinabusus) eine gefürchtete Komplikation dar.

Bei Normovolämie und Vermeidung extremer normovolämischer Anämie bleiben während $\mathrm{KH}$ myokardialer und zerebraler Blutfluss sowie das $\mathrm{O}_{2}$-Angebot trotz Abfall der entsprechenden Organperfusionsdrücke konstant (Autoregulation des Organblutflusses). Zeichen einer Myokardischämie sowie zerebrale Funktionseinschränkungen wurden auch bei mehr als 2-stündiger KH postoperativ nicht beobachtet.

- Cave Im Gegensatz zu Herz und Gehirn wird die Grenze der Autoregulation der renalen Perfusion während $\mathrm{KH}$ unterschritten.

Die resultierende Abnahme von renalem Blutfluss, glomerulärer Filtrationsrate und fraktionierter Natriumexkretion ist jedoch nach Restitution eines normalen renalen Perfusionsdrucks reversibel.

Substanzen mit negativ inotroper Wirkung ( $\beta$-Blocker) oder Vasodilatatoren mit steigernder Wirkung auf den myokardialen $\mathrm{O}_{2}$-Verbrauch (Reflextachykardie, z. B. durch Hydralazine) sollten nicht zur Induktion der $\mathrm{KH}$ eingesetzt werden. $\mathrm{KH}$ mit Nitroprussid-Na verschlechterte im Tierexperiment die Durchblutung und Oxygenierung des Skelettmuskels sowie des parietalen Hirnkortex. KH mit Inhalationsanästhetika beeinträchtigte ebenfalls im Tierexperiment die Durchblutung im Splanchnikusgebiet und die Koronarreserve.

Dagegen scheinen Urapidil und Nitroglyzerin die Organperfusion und Gewebeoxygenierung weniger zu beeinflussen [41]. Da zudem bei Verabreichung von Urapidil keine bzw. nur eine geringe Reflextachykardie auftritt, sollte dieser Substanz für die KH der Vorzug gegeben werden.

Bei Patienten mit eingeschränkter Autoregulation der Organperfusion (pAVK, KHK, arterieller Hypertonus, zerebralvaskulärer Insuffizienz, Hypovolämie, Anämie) sowie Patienten mit Nieren- bzw. Leberinsuffizienz sollte auf eine „klassische“ $\mathrm{KH}$ verzichtet und bestenfalls eine modifizierte $\mathrm{KH}$ mit deutlich moderateren Zielblutdruckwerten durchgeführt werden.

\section{Maschinelle Autotransfusion}

Unter maschineller Autotransfusion (MAT) versteht man die Reinigung und Retransfusion von direkt aus dem Operationsfeld aspiriertem Wundblut. Über einen Doppellumensauger wird Blut aus dem Operationsfeld abgesaugt, mit Heparin 
versetzt (15.000 E Heparin in $500 \mathrm{ml} \mathrm{NaCl}$, langsam tropfend, Verhältnis zu Blut 1:5 bis 1:10) und in einem Reservoir gesammelt.

Der an das Reservoir angelegte Unterdruck sollte $150 \mathrm{mmHg}$ nicht überschreiten, um die Hämolyserate der aspirierten Erythrozyten gering zu halten.

Nach Ansammlung von 800-1000 ml Blut wird der Inhalt des Reservoirs über ein geschlossenes Schlauchsystem mittels einer Rollerpumpe in eine Waschglocke gepumpt. Diese wird in Rotation (5000 U/min) versetzt. In der rotierenden Waschglocke ordnen sich die im Wundblut enthaltenen Erythrozyten an anderer Stelle an als noch vorhandene Gewebereste. Letztere können mit einer die Waschglocke durchströmenden Kochsalzlösung ausgewaschen werden. Nach dem Waschvorgang werden die gereinigten Erythrozyten in einen Beutel gepumpt und stehen für die Transfusion zur Verfügung. Die Transfusion erfolgt über einen 170-200 $\mu \mathrm{m}$ Filter.

Das nach Zentrifugation und Spülung entstandene ,gereinigte“, autologe Erythrozytenkonzentrat besitzt - abhängig von der Dauer des Waschvorgangs und von der Art des verwendeten MAT-Systems - einen Hämatokrit von 60-70 \%. Es enthält nur noch klinisch unbedeutende Spuren von Heparin, Leukozyten, Thrombozyten und Gerinnungsfaktoren. Der Anteil von freiem Hämoglobin (im aspirierten Wundblut 200-500 mg/dl) wird durch den Waschvorgang um 50-70\%, der Anteil des zugesetzten Heparins um $99 \%$ reduziert. $\mathrm{O}_{2}$-Transport in sowie $\mathrm{O}_{2}$-Abgabe aus ,gewaschenen“ Erythrozyten bleiben aufgrund einer stabilen 2,3Diphosphoglycerat-Konzentration unbeeinträchtigt. Der $\mathrm{pH}$ Wert von gewaschenem MAT-Blut liegt im alkalischen, die Elektrolytkonzentrationen im physiologischen Bereich.

Für den Einsatz der MAT geeignet sind elektive operative Eingriffe sowie Notfalleingriffe mit einem Blutverlust von mehr als 800-1000 ml.

Die Infusion von potenziell kontaminiertem gewaschenem Wundblut führte bei Patienten mit penetrierendem Abdominaltrauma nachweislich nicht zu einer Zunahme der Wundinfektionsrate. Umgekehrt können auch in aufbereitetem Blut aus nichtkontaminierten Wunden in 12,7 \% aller Fälle Keime (z. B. Staphylococcus epidermidis) nachgewiesen werden.

Die ursprüngliche, absolute Kontraindikation der Autotransfusion von potenziell kontaminiertem Blut wurde auf Operationen mit Implantation von Fremdmaterial (künstliche Herzklappen, Gefäßersatz und Gelenkprothesen) beschränkt.

Bei tumorchirurgischen Eingriffen anfallendes Wundblut kann gereinigt und problemlos transfundiert werden, sofern die Möglichkeit zur hochenergetischen Gammabestrahlung (50 Gy) des gewaschenen Erythrozytenkonzentrats besteht [42]. Hierdurch ist die Reduktion von Tumorzellen um mehr als 10 Logstufen möglich. Allerdings muss auf die Einhaltung spezifischer medikolagaler Voraussetzungen (Verfügung über eine Arzneimittelherstellungserlaubnis) geachtet werden.

Die Aufbereitung von Blut aus sicher infizierten und mit Urin, Galle oder Darminhalt kontaminierten Wundgebieten sollte vermieden werden.

Während Applikation von Methylacrylat (Palakos), gerinnungsfördernden Substanzen (z. B. Fibrinkleber) sowie antibakteriellen Spüllösungen (z. B. Chloramin) sollte die Aspiration in das MAT-Reservoir unterbrochen werden. Bei Blutungen im Rahmen geburtshilflicher Maßnahmen und insbesondere bei der Sectio caesarea wird die bisher absolute Kontraindikation für MAT (Gefahr der Transfusion von Amnionzellen und fetalen Erythrozyten) zunehmend relativer gesehen [43].

Cave Das dem aspirierten Wundblut zugesetzte Heparin wird durch den Schleuderwaschvorgang um $99 \%$ reduziert. Trotzdem sollte bei Patienten mit bekannter Veranlagung zu heparininduzierter Thrombopenie (HIT) entweder ganz auf MAT verzichtet werden oder das aspirierte Wundblut mit Heparinersatzstoffen z. B. DanaparoidNatrium (Orgaran) antikoaguliert werden.

Die MAT ist eine äußerst effektive, intraoperativ durchführbare Methode zur Einsparung von Fremdbluttransfusionen [44]. Durch Anwendung des Verfahrens kann die Fremdbluttransfusionsrate um $38 \%$ gesenkt werden. Besonders eindrücklich sind die Ergebnisse bei orthopädischen und herzchirurgischen Eingriffen. Bei Kombination des Verfahrens mit der ebenfalls sehr kostengünstigen akuten normovolämischen Hämodilution (ANH) kann eine Fremdbluttransfusion auch bei chirurgischen Eingriffen mit hohem, intraoperativem Blutverlust häufig vermieden werden.

\section{Temperaturmanagement}

Die einzelnen Reaktionsschritte der Gerinnungskaskade und die Thrombozytenfunktion sind temperaturabhängig. Bereits milde Hypothermie $\left(35,0 \pm 0,5^{\circ} \mathrm{C}\right)$ führt zu einer Zunahme des intraoperativen Blutverlusts. Entscheidend ist daher die Aufrechterhaltung von Normothermie durch die konsequente Wärmung von Infusionen und Patient.

\section{pH-Management}

Die Aktivität der Gerinnungsfaktoren ist $\mathrm{pH}$-abhängig mit einem Aktivitätsoptimum im basischen Bereich. Ein Abfall des $\mathrm{pH}$ von 7,4 auf 7,2 führt zu einem $50 \%$-Abfall der Thrombingeneration. Azidose verstärkt darüber hinaus die 
gerinnungshemmenden Effekte von Hypothermie [45]. Eine Verbesserung der Blutgerinnung durch pharmakologische Korrektur der Azidose (z. B. Natriumbikarbonat oder TRISPuffer) konnte allerdings bisher weder im Tierexperiment noch bei Patienten nachgewiesen werden.

\section{ZVD-Management}

Da Lebervenen keine Venenklappen besitzen, pflanzt sich der Druck in der V. cava inferior unmittelbar in die Lebervenen fort. Während Leberteilresektionen führt die Absenkung des zentralen Venendrucks (Oberkörperhochlagerung, PEEP-Reduktion) zu einer signifikanten Reduktion des Blutverlusts [46].

\section{Volumentherapie}

Neben der Induktion einer Verdünnungskoagulopathie besitzen nahezu alle Infusionslösungen direkte Effekte auf die Blutgerinnung. Kristalloide Lösungen mit hohem ChloridAnteil (z. B. NaCl, Ringer-Lösung) führen bei hochvolumiger Applikation zu einer hyperchlorämischen Azidose und damit zu einer potenziellen Beeinträchtigung der Blutgerinnung (pH-Management). Bei Anwendung sog. balancierter kristalloider Lösungen mit verstoffwechselbaren Anionen (z. B. Azetat, Malat oder Laktat) fehlt dieser Effekt weitestgehend [7]. Hochmolekulare und -substituierte HES-Lösungen (z. B. HES 450.000/0,7, HES 200.000/0,62) reduzieren die Aktivität des von-Willebrand-Faktor, des Faktor VIII und der Thrombozyten. Weiterhin wird eine verminderte Stabilität des Fibringerinnsels infolge gestörter Fibrinpolymerisation diskutiert [6]. Bei niedermolekularem, niedrigsubstituierten HES-Lösungen (z. B. HES 130.000/0,4, HES $130.000 / 0,42)$ scheinen diese Effekte jedoch geringer ausgeprägt zu sein. Der direkte Effekt von Gelatine- und Humanalbuminlösungen auf die Blutgerinnung wird als vernachlässigbar eingestuft.

\section{Antifibrinolytika}

Antifibrinolytika hemmen die Plasminbildung. Klinische Unter-suchungen liegen v. a. für die Substanzen Aprotinin, \&-Aminokapronsäure und Tranexamsäure vor (Tab. 5).

Durch Anwendung jeder dieser Substanzen ließ sich die Transfusion von Fremdblut reduzieren. Dabei war Aprotinin der Tranexamsäure und diese wiederum der $\varepsilon$-Aminokapronsäure überlegen. Aufgrund einer signifikant erhöhten Rate an Nierenversagen nach herzchirurgischen Eingriffen [47] setzte der Hersteller die Vermarktung von Aprotinin im Jahre 2008 aus. Eine kritische Neubewertung der Risikodaten führte jedoch dazu, dass die Substanz mittlerweile in einigen Ländern (u. a. Kanada) wieder zum Vertrieb freigegeben wurde.

\section{Desmopressin}

Desmopressin (Minirin) ist ein synthetisch hergestelltes Vasopressinanalogon. Nach i.v.-Infusion $(0,3-0,4 \mu \mathrm{g} / \mathrm{kgKG}$
Tab. 5 Dosierung von Antifibrinolytika

\begin{tabular}{ll} 
Präparat & \multicolumn{1}{|l}{ Dosierung } \\
\hline Tranexamsäure & Initial: $10-15 \mathrm{mg} / \mathrm{kgKG}$ \\
& Danach: $1-5 \mathrm{mg} / \mathrm{kgKG} / \mathrm{h}$ \\
\hline E-Aminokapronsäure & Initial: $100-150 \mathrm{mg} / \mathrm{kgKG}$ \\
& Danach: $10-15 \mathrm{mg} / \mathrm{kgKG} / \mathrm{h}$ \\
(Aprotinin) - derzeit nicht verfügbar & Initial: $1-2 \mathrm{Mio} . \mathrm{E}$ i.v. \\
& Danach: $500.000 \mathrm{E} / \mathrm{h}$
\end{tabular}

innerhalb von $30 \mathrm{~min}$ ) führt Desmopressin zu einer sofortigen Knochenmarkfreisetzung von Thrombozyten sowie nach 4-12 h zu einer Steigerung der Plasmaaktivität von Faktor VIII und v.-Willebrand-Faktor (vWF). Bei urämischer Thrombozythopathie verbessert Desmopressin die Thrombozytenfunktion.

Mögliche Indikationen für Desmopressin zur Reduktion perioperativer Blutverluste sind:

- dringliche bzw. Notfalleingriffe bei Patienten unter pharmakologischer Thrombozytenaggregationshemmung (ASS, Diclofenac, Glykoprotein-IIb/IIIa-Antagonisten),

- dringliche Eingriffe bei dialysepflichtigen Patienten,

- Eingriffe an der Herz-Lungen-Maschine ( Kap. 77, „Anästhesie in der Chirurgie des Herzens und der herznahen Gefäße").

Eindeutige Hinweise für die Reduktion perioperativer Fremdbluttransfusionen durch die Verabreichung von Desmopressin fehlen bislang.

\section{Gerinnungsmanagement}

Cave Der Ersatz eines Blutverlusts durch kristalloide und kolloidale Infusionslösungen führt zu einer Verdünnung sämtlicher Komponenten des Gerinnnungs- und Fibrinolysesystems und letztlich zur Ausbildung einer Verdünnungskoagulopathie.

In Tierexperimenten und Untersuchungen an blutenden Patienten zeigte sich, dass während einer Hämodilution die Plasmafibrinogenkonzentration als erster prokoagulatorischer Faktor in einen substitutionsbedürftigen Bereich ( $<150 \mathrm{mg} / \mathrm{dl})$ abfällt, gefolgt von der Aktivität von Gerinnungsfaktoren des Prothrombinkomplexes und zuletzt der Thrombozytenzahl [48]. Fibrinogen und Fibrin sind elementar für die Stabilität eines sich an der Blutungsquelle formierenden Thrombus. Das Fehlen von Fibrinogen führt $\mathrm{zu}$ labilen Thromben, die dem erhöhten Blutfluss in den geschädigten Gefäßstrombezirken nicht standhalten und eine Blutung nicht stoppen können. Hinzu kommt, dass die Fibrinogenkonzentration des Plasmas durch kolloidale Infusions- 
lösungen auf der Basis von Hydroxyäthylstärke zusätzlich reduziert wird.

Die genaue Bestimmung von „kritischen“ Grenzwerten für einzelne Komponenten des Gerinnungssystems ist schwierig und in der klinischen Situation des stark blutenden Patienten ohne entsprechende Zeitverluste häufig unmöglich.

Bei moderater Dynamik des Blutverlusts kann ein differenziertes Gerinnungsmanagement auf der Basis sog. „Point-of-care“ (POC)-Monitoringverfahren (Rotationsthrombelastographie/-metrie, Thrombozytenaggregometrie) erwogen werden [49]. In Ermangelung dieser differenzierten Analysemethode und in Gegenwart stärkerer Blutverluste muss jedoch häufig frühzeitig und kalkuliert mit gerinnungsstabilisierenden Maßnahmen begonnen werden [21]. Nach Etablierung prokoagulatorischer Rahmenbedingungen (Normothermie, normaler $\mathrm{pH}$-Wert) erfolgen in Abhängigkeit von Intensität und Dynamik des Blutverlusts sowie Qualität der Blutung (diffuse Blutungsneigung, Reaktivierung von Blutungen aus bereits „trockenen“ Blutungsquellen) auf der Basis eines Stufenplans (Abb. 8): die Substitution von Fibrinogenkonzentrat, PPSB, gefrorenem Frischplasma (GFP) bzw. lyophilisiertem Plasma und die Applikation eines Antifibrinolytikums (z. B. Tranexamsäure).

Die Applikation von Desmopressin führt zu einer Mobilisierung endogener Faktor-VIII-Reserven, einer Zunahme der Aktivität des von-Willebrand-Faktors sowie einer Stimulation der Thrombozytenfunktion. Zusätzlich kann die Stabilität des Thrombus durch die Applikation von Faktor-XIIIKonzentrat erhöht werden. Bei starken Blutungen sollte frühzeitig die Applikation von rekombinantem humanen Faktor VIIa (,off-label-use“) in Erwägung gezogen werden, da die maximale Wirksamkeit der Substanz nur bei stabilen Rahmenbedingungen für die Blutgerinnung (Temperatur,

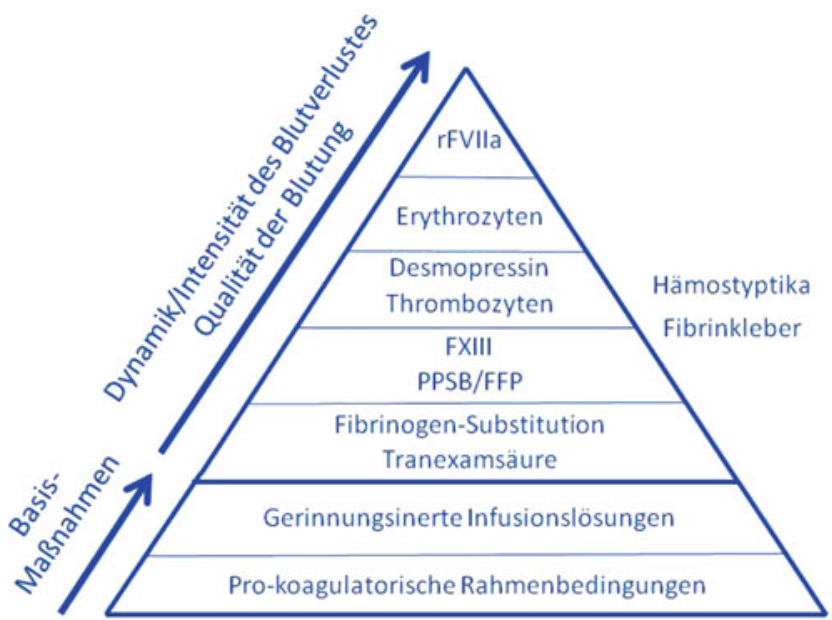

Abb. 8 Gerinnungstherapie bei massivem Blutverlust - Vorgehen ohne „Point-of-care“ (POC)-Monitoring der Gerinnung (Aus: [50], mit freundl. Genehmigung von O. Habler)
$\mathrm{pH}$, Thrombozytenzahl) erwartet werden kann (Tab. 6). Bei weiterhin eingeschränkter Gerinnung kann die Transfusion von Erythrozyten (Ziel-Hämatokrit $30 \%$, Ziel Hb-Konzentration $10 \mathrm{~g} / \mathrm{dl}$ ) in Erwägung gezogen werden.

\section{Transfusion von Blutprodukten}

\subsection{Geschichte der Bluttransfusion}

Blut wurde bereits sehr früh mit dem Wohlbefinden des Menschen in Verbindung gebracht. So wird im 7. Buch von Ovids Metamorphosen oder den Büchern Leviticus und Genesis des Alten Testaments häufig - allerdings auf einer eher mystischen Basis - über die verjüngende Wirkung von enteral verabreichtem Blut berichtet.

Die Grundlage für die Erforschung des therapeutischen Nutzens von transfundiertem Blut bei akuten und chronischen Blutverlusten stellt zweifellos die detaillierte Beschreibung des Blutkreislaufs durch William Harvey im Jahre 1613 dar. Dennoch dauerte es mehr als 300 Jahre, bis die Bluttransfusion als sichere und effektive Therapie bei akuter und chronischer Anämie anerkannt wurde. Im Folgenden sind die Meilensteine dieser Entwicklung dargestellt (Tab. 7).

Im Jahre 1666 - also 53 Jahre nach Harveys Erstbeschreibung des Blutkreislaufs - zeigte der englische Arzt Richard Lower, dass ein Hund den Verlust nahezu seines gesamten Blutvolumens überlebte, wenn ihm simultan das Blut eines anderen Hundes infundiert wurde. Am 23.11.1667 transfundierte Lower bei einem Mann namens Arthur Coga Schafsblut in der Absicht, die labile psychische Situation des manisch-depressiven Patienten zu verbessern. Die Transfusion verlief ohne Zwischenfälle, der therapeutische Effekt wurde hingegen als zweifelhaft beurteilt.

Etwa zeitgleich mit Lower veröffentlichte Jean Denis Leibarzt am Hofe des französischen Königs Ludwig XIV. seine Beobachtungen während einer Bluttransfusion, die

Tab. 6 Dosierung gerinnungswirksamer Pharmaka bei massivem Blutverlust

\begin{tabular}{|c|c|}
\hline Gefrorenes Frischplasma & $\begin{array}{l}>30 \mathrm{ml} / \mathrm{kgKG} \\
\text { Ziel: Quick-Wert }>30-40 \%\end{array}$ \\
\hline Fibrinogenkonzentrat & $\begin{array}{l}2-4 \mathrm{~g} \\
\text { Ziel: Serumfibrinogenkonzentration } \\
>150 \mathrm{mg} / \mathrm{dl}\end{array}$ \\
\hline $\begin{array}{l}\text { Prothrombinkomplex- } \\
\text { Präparate }\end{array}$ & $\begin{array}{l}20-25 \mathrm{IE} / \mathrm{kgKG} \\
\text { Ziel: Quick-Wert }>30-40 \%\end{array}$ \\
\hline Tranexamsäure & $\begin{array}{l}\text { Initialer Bolus: } 10-15 \mathrm{mg} / \mathrm{kgKG} \\
\text { Danach: } 1-5 \mathrm{mg} / \mathrm{kgKG} / \mathrm{h}\end{array}$ \\
\hline Desmopressin & $0,3 \mu \mathrm{g} / \mathrm{kgKG}$ über $30 \mathrm{~min}$ \\
\hline Faktor-XIII-Konzentrat & 10-20 IE/kgKG \\
\hline $\begin{array}{l}\text { Rekombinanter humaner } \\
\text { Faktor VIIa }\end{array}$ & $90 \mu \mathrm{g} / \mathrm{kgKG}$ \\
\hline
\end{tabular}


Tab. 7 Historische Entwicklung der Bluttransfusion

\begin{tabular}{|l|l|}
\hline 1613 & $\begin{array}{l}\text { Beschreibung des Blutkreislaufs durch William Harvey } \\
\text { Allogene Bluttransfusion beim Hund durch Richard } \\
\text { Lower }\end{array}$ \\
\hline 15.06 .1667 & $\begin{array}{l}\text { Erste xenogene Bluttransfusion (Kalbsblut) bei einem } \\
\text { Menschen, durchgeführt von Jean Denis }\end{array}$ \\
\hline 22.12 .1818 & $\begin{array}{l}\text { Erste allogene Bluttransfusion beim Menschen, } \\
\text { durchgeführt von James Blundell }\end{array}$ \\
\hline 1900 & $\begin{array}{l}\text { Beschreibung der Isoagglutinine A, B und 0 durch Karl } \\
\text { Landsteiner } \\
\text { Beschreibung der Blutgruppe AB durch DeCastello } \\
\text { und Sturli }\end{array}$ \\
\hline 1902 & $\begin{array}{l}\text { Antikoagulation von Blutkonserven mit Natriumzitrat } \\
\text { durch Albert Hustin }\end{array}$ \\
\hline 1914 & $\begin{array}{l}\text { Einführung von Transfusionsfiltern } \\
\text { Beschreibung des Rhesus-Faktors durch Landsteiner } \\
\text { und Weiner }\end{array}$ \\
\hline 1940 & $\begin{array}{l}\text { Einführung von Zitrat, Phosphat, Dextrose und Adenin } \\
\text { als Additiva zu Blutkonserven }\end{array}$ \\
\hline 1957
\end{tabular}

vermutlich noch vor der Lower's durchgeführt worden war. Am 15.06.1667 transfundierte Denis einen aufgrund multipler Aderlässe anämischen 15-jährigen Jungen mit Kalbsblut. Die Transfusion verbesserte den Allgemeinzustand des Jungen deutlich. Im selben Jahr transfundierte Denis mindestens 4 weitere Patienten. Bei der letzten, durchgeführt bei dem 34-jährigen psychisch kranken Antoine Mauroy kam es wohl zur ersten dokumentierten hämolytischen Transfusionsreaktion. Noch während der Kalbsbluttransfusion entwickelte der Patient eine Tachykardie, Schweißausbrüche und starke Nierenschmerzen, gefolgt von einer kurzdauernden Bewusstlosigkeit. Einige Stunden später fiel der Abgang von schwarzem Urin auf. Mauroy überlebte diesen Transfusionszwischenfall, verstarb aber wenige Monate später während einer zweiten Bluttransfusion.

Der Tod von Antoine Mauroy löste heftige Diskussionen über Sinn und Unsinn der Transfusion von Blut aus, die darin gipfelten, dass das Verfahren im Jahr 1678 zunächst vom englischen und französischen Parlament und im Jahre 1679 letztendlich vom Papst per Dekret offiziell verboten wurde. Für mehr als ein Jahrhundert ebbte das Interesse an Bluttransfusionen ab.

Die nächste wissenschaftliche Dokumentation einer Transfusion datiert erst wieder aus dem Jahr 1818, ist aber von herausragender Bedeutung. Am 22.12.1818 transfundierte der englische Arzt und Geburtshelfer James Blundell erstmals einen 35 Jahre alten Patienten mit ausgeprägter Kachexie infolge eines Magenkarzinoms mit menschlichem Blut. Nach kurzdauernder Verbesserung des Allgemeinzustands verstarb der Patient $56 \mathrm{~h}$ später. Weitere von Blundell durchgeführte Transfusionen bei Frauen mit schwerer postpartaler Blutung verliefen dagegen erfolgreich. 1840 beschrieb Blundell, dass nach einer operativen Strabismuskorrektur die Transfusion von frischem Vollblut die Blu- tungsneigung bei einem 11-jährigen Patienten mit Bluterkrankheit verringerte.

In der Folge bestimmten in erster Linie technische Verbesserungen die Weiterentwicklung im Transfusionswesen. 1835 empfahl Bischoff die Transfusion von defibriniertem Blut, 1860 tranfundierte Neudorfer zum ersten Mal Blut, das zuvor mit Natriumbikarbonat antikoaguliert worden war. Erst 1914 führte der Belgier Albert Hustin die Antikoagulation von Blut mit Natriumzitrat ein.

Die moderne Ära im Bluttransfusionswesen begann mit der Entdeckung der Isoagglutinine A, B und 0 im Jahr 1900 durch Landsteiner. 1902 wurde das AB0-Blutgruppensystem um die von DeCastello u. Sturli beschriebene vierte Blutgruppe AB erweitert. 1940 entdeckten Landsteiner u. Weiner den Rhesus-Faktor.

Bereits 1907 empfahlen Richard Weil u. Reuben Ottenberg vor jeder Transfusion die Testung des Transfusionsbluts auf seine Kompatibilität mit dem Blut des Empfängers. Ottenberg war auch der erste, der bei Kühlung die Möglichkeit der Lagerung von zitratantikoaguliertem Blut für mehrere Tage beschrieb.

Während des ersten Weltkrieges berichtete Oswald Robertson anlässlich der Schlacht von Cambrai im November 1917 über 20 erfolgreiche Transfusionen bei verwundeten Soldaten mit schwerem hämorrhagischem Schock. Robertson verwendete dabei ausschließlich Blut der Blutgruppe 0 .

1943 wurde von Loutit u. Mollison ein Zitrat-DextroseGemisch als Additiv zu konserviertem Blut eingeführt, welches 1957 durch Phosphat und Adenin ergänzt wurde.

1938 wurden Filter zur Transfusion empfohlen, zunächst aus Seide, später aus Baumwolle mit einer Porengröße von etwa $200 \mu \mathrm{m}$. 1960 wurden Mikroaggregatfilter mit einer Porengröße zwischen 20 und $40 \mu \mathrm{m}$ und etwa zur selben Zeit die ersten Plastiktransfusionsbestecke eingeführt.

\subsection{Konzept der Therapie mit Blutkomponenten}

Um einen Patienten nicht unnötig den Risiken einer Fremdbluttransfusion (Abschn. 2.1) auszusetzen, wird intraoperativ verlorenes Blut zunächst durch erythrozytenfreie Infusionslösungen (Kristalloide, Kolloide) ersetzt. Ziel dieses Vorgehens ist die Aufrechterhaltung des zirkulierenden Blutvolumens (Normovolämie) und damit einer adäquaten Organperfusion. Folge ist eine Verdünnung sämtlicher Blutbestandteile (Hämodilution).

Der wesentliche Unterschied zwischen dieser Vorgehensweise und der ANH (Abschn. 2.3) ist lediglich, dass eine ANH als geplante, fremdblutsparende Maßnahme vor Beginn des intraoperativen Blutverlusts durchgeführt wird. Das während einer ANH entnommene Blut steht somit in 
seiner Gesamtheit als Vollblut einschließlich funktionsfähiger Thrombozyten und sämtlicher Plasmaproteine (Gerinnungsfaktoren, Fibrinolysesystem) für die Retransfusion zur Verfügung.

Wird hingegen auf eine präoperative ANH verzichtet und der Patient während des intraoperativen Blutverlustes hämodiluiert, kann das verlorene Blut zwar ebenfalls gesammelt und für die Retransfusion wiederaufbereitet werden (Abschn. 2.3). Es enthält dann aber keine Thrombozyten und Gerinnungsfaktoren in klinisch relevanter Menge.

Eine Hämodilution löst - unabhängig davon, ob sie präoperativ als ANH oder intraoperativ als Kompensation eines Blutverlusts durchgeführt wird - identische Kompensationsmechanismen aus (Abschn. 1.1).

Die Grenze der intraoperativen Hämodilution ist erreicht, wenn die Verdünnungsanämie den $\mathrm{O}_{2}$-Transport und die Gewebeoxygenierung beeinträchtigt (Abschn. 2.3) bzw. wenn Thrombozytopenie und reduzierte Aktivität der verschiedenen Komponenten des Gerinnungssystems zu einer klinisch manifesten Blutungsneigung führen. Erst dann ist die differenzierte Anwendung von Blutkomponenten indiziert.

\subsection{Spezifische Eigenschaften der verschiedenen Blutkomponenten}

\subsubsection{Erythrozytenkonzentrate}

\section{Herstellung}

Erythrozytenkonzentrate (EK) werden durch Zentrifugation aus frischem Vollblut eines Einzelspenders hergestellt. Zugelassene EK unterscheiden sich geringfügig im Gehalt an noch verbliebenen Thrombozyten, Plasma und additiver Lösung.

\section{Zur Verfügung stehende Präparate}

- Leukozytendepletiertes EK in Additivlösung: Spezielle Leukozytenfiltration. Restleukozytenzahl $<5 \times 10^{6}$ Zellen/EK. Durch den Einsatz von Additivlösung wird der Plasmagehalt stark reduziert. Seit 01.10.2001 „Standard-EK“ zur perioperativen Transfusion.

- Gewaschenes EK: Entfernung von restlichen Plasmaproteinen und Thrombozyten aus leukozytendepletierten EK durch mehrmaliges Aufschwemmen und Zentrifugieren der Erythrozyten. Indikation bei Patienten mit seltener Antikörperkonstellation.

- Kryokonserviertes EK: Nach Zusatz eines Gefrierschutzmittels (meist Glyzerin) bei $-80{ }^{\circ} \mathrm{C}$ tiefgefrorenes EK. Enthält sehr geringe Mengen an Plasma, funktionsfähigen Leukozyten und Thrombozyten.

(Fortsetzung)
Kann unter geeigneten Bedingungen für bis $\mathrm{zu}$ 10 Jahre gelagert werden. Wegen des hohen Aufwands werden kryokonservierte EK seltener Blutgruppen in wenigen nationalen und internationalen Blutbanken in begrenzter Menge vorrätig gehalten.

- Bestrahlte leukozytendepletierte EK: Abschn. 2.1.

Der Hämatokrit eines Erythrozytenkonzentrats sollte zwischen 50 und $70 \%$, die Hämolyserate unter 0,8 \% der Erythrozytenmasse liegen.

\section{Konservierung und Lagerung}

EK werden üblicherweise mit einer Stabilisatorlösung (CPDA-1): (Zitrat, Phosphat, Dextrose, Adenin) versetzt und können so bei $+4 \pm 2{ }^{\circ} \mathrm{C}$ für 35 Tage gelagert werden. Die Natriumzitratlösung dient hierbei als Antikoagulans, der Phosphatpuffer verhindert den $\mathrm{zu}$ schnellen Abfall des pH. Dextrose ist der Energielieferant für die Glykolyse der Erythrozyten, Adenin wird zur Produktion von Adenosintriphosphat (ATP) genutzt.

Durch Zusatz spezieller Additive (z. B. SAG-Mannitol, PAGGS-Mannitol) ist eine Verlängerung der Lagerungszeit auf bis zu 49 Tage möglich, bei Zusatz von Glyzerol und anschließender Kryokonservierung $\left(-80{ }^{\circ} \mathrm{C}\right)$ auf bis $\mathrm{zu}$ 10 Jahre.

Einfluss von Konservierung und Lagerung Die Lagerung eines EK führt zu spezifischen, strukturellen und funktionellen Veränderungen der enthaltenen Erythrozyten. Die anaerobe Glykolyse bedingt die Akkumulation von Wasserstoffionen $\left(\mathrm{H}^{+}\right)$und den Abfall des pH-Werts innerhalb der Konserve. Die Aktivitätsabnahme der Natrium-KaliumPumpe in der Erythrozytenmembran führt zu einem Kaliumverlust der Erythrozyten bei gleichzeitiger intrazellulärer Anreicherung von Natriumionen. Azidose und Hypokaliämie steigern die osmotische Fragilität der Erythrozytenmembran, ersichtlich an einer gesteigerten Hämolyserate bei zunehmenden Lagerungszeiten. Darüber hinaus nimmt die Verformbarkeit der Erythrozytenmembran ab. Das spiegelt sich nach Transfusion in einem ungünstig veränderten Fließverhalten innerhalb der mikrovaskulären Strombahn wider.

Die zunehmend rundlichen und steifen Erythrozyten embolisieren in Arteriolen und Kapillaren und reduzieren so die sog. funktionelle Kapillardichte (Anzahl mit Erythrozyten perfundierter Kapillaren) sowie das regionale $\mathbf{O}_{\mathbf{2}}$-Angebot. Zudem nimmt mit zunehmender Lagerungsdauer der Konserven der intraerythrozytäre Gehalt an 2,3-Diphosphoglycerat (2,3-DPG) $\mathrm{ab}$ (Abb. 9). Folge ist eine gesteigerte $\mathbf{O}_{\mathbf{2}}$-Affinität des Hämoglobinmoleküls. 


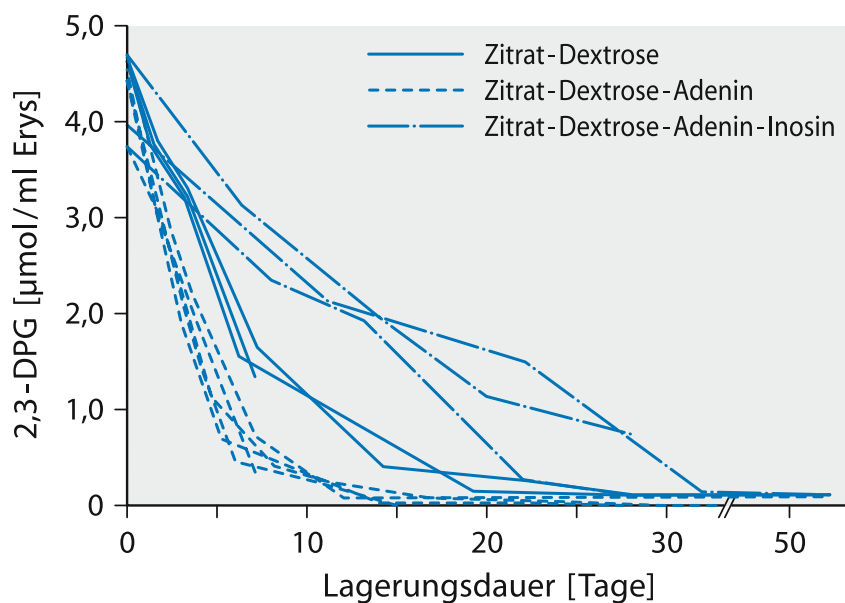

Abb. 9 Einfluss von Lagerungsdauer und Art der zugesetzten Stabilisatorlösung auf den erythrozytären Gehalt an 2,3-Diphosphoglycerat von Erythrozytenkonzentraten. (Nach: [51])

Mindestanforderung an die Qualität eines gelagerten EK ist, dass nach der Transfusion $70 \%$ der transfundierten Erythrozyten für mindestens $24 \mathrm{~h}$ im Blutkreislauf nachweisbar sind.

\section{Infektionsrisiko}

Abschn. 2.1

\section{Indikation zur Transfusion von Erythrozytenkonzen- traten}

Die Indikation zur intraoperativen Transfusion von Erythrozytenkonzentraten wird anhand sog. „Transfusionstrigger“ gestellt. Hierzu zählen Parameter des $\mathrm{O}_{2}$-Transports und der Gewebeoxygenierung (sog. physiologische Transfusionstrigger) sowie die Hb-Konzentration des Patienten (Übersicht in: [37]).

Physiologische Transfusionstrigger Aus den Erläuterungen der (patho)physiologischen Grenzen einer Verdünnungsanämie (Abschn. 2.3) ergibt sich, dass die Transfusion von Erythrozyten zwingend erst bei extremer Hämodilution und kritischer Reduktion der $\mathrm{O}_{2}$-Transportkapazität des Bluts bzw. beginnender Gewebehypoxie notwendig ist (Abb. 3). Der kritische Abfall des O2-Angebots $\left(\mathrm{DO}_{2}\right)$ an die Gewebe äußert sich dabei in einem Abfall des Gesamtkörper- $\mathrm{O}_{2}$-Verbrauchs $\left(\mathrm{VO}_{2} ; \mathrm{Abb} .3\right)$. Der Abfall der $\mathrm{VO}_{2}$ kann entweder durch direkte Messung (kontinuierliche Atemgasanalyse und indirekte Kalorimetrie z. B. mit Hilfe eines Deltatrac-Messgeräts) oder durch Berechnung aus arteriellem und gemischtvenösem $\mathrm{O}_{2}$-Gehalt und Herzzeitvolumen (Fick-Prinzip) identifiziert werden (Abb. 10).

Darüber hinaus wird eine Reduktion des Gesamtkörper- bzw. des myokardialen $\mathrm{O}_{2}$-Verbrauchs indirekt durch die in nachfolgender Übersicht aufgelisteten Veränderungen reflektiert [37].

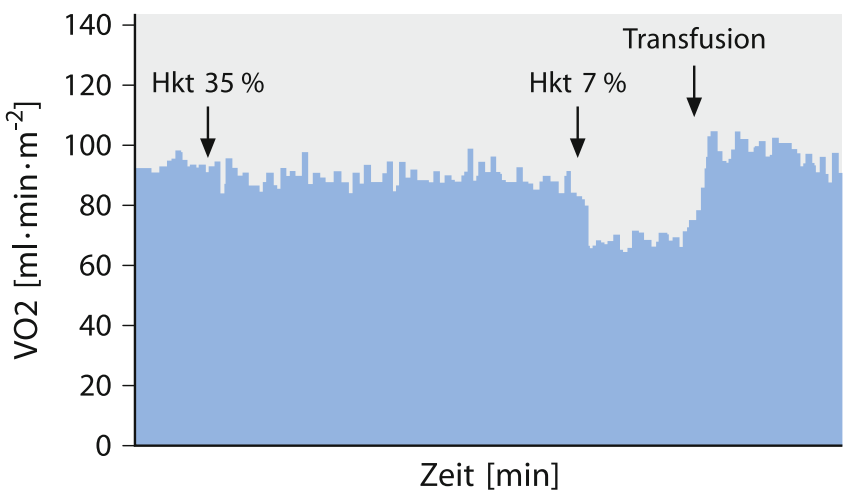

Abb. 10 Effekte einer extremen Hämodilution (unter Hkt $7 \%$ ) und der Transfusion „frischer“ Erythrozyten auf den Gesamtkörper- $\mathrm{O}_{2}$-Verbrauch $\left(\mathrm{VO}_{2}\right)$. Bei Hkt $7 \%$ ist das ,kritische“ $\mathrm{O}_{2}$-Angebot $\left(\mathrm{DO}_{2}\right)$ im Gewebe erreicht. Die Folge ist ein Abfall der $\mathrm{VO}_{2}$ als Zeichen einer manifesten Gewebehypoxie. Die Transfusion frischer Erythrozyten (Lagerungsdauer $<5 \mathrm{~h}$ ) führt zu einem sofortigen Wiederanstieg der $\mathrm{VO}_{2}$ als Zeichen einer Normalisierung der Gewebeoxygenierung. Der Anstieg der $\mathrm{VO}_{2}$ über Ausgangsniveau reflektiert den Abbau der während der Phase der Gewebehypoxie angefallenen $\mathrm{O}_{2}$-Schuld

\section{Physiologische Transfusionstrigger}

- Ausgeprägte Tachykardie und Hypotension

- Anstieg der Gesamtkörper $\mathrm{O}_{2}$-Extraktion (>50 \%)

- Abfall der zentral- bzw. gemischtvenösen Sättigung $(<50-60 \%)$

- Abfall des zentral- bzw. gemischtvenösen $\mathrm{O}_{2}$-Partialdrucks $(<32 \mathrm{mmHg})$

- ST-Streckensenkung $>0,1 \mathrm{mV}$ in den EKG-Ableitungen II und/oder V5

- Regionale Wandbewegungsstörungen in der transösophagealen Echokardiographie (TEE)

- Laktazidose (Laktat $>2 \mathrm{mmol} / \mathrm{l})$

Grundsätzlich müssen Änderungen von Narkosetiefe sowie eine Hypovolämie als Ursachen der genannten Veränderungen ausgeschlossen bzw. vor endgültiger Indikationsstellung zur Transfusion korrigiert werden.

Eine niedrige $\mathrm{Hb}$-Konzentration stellt per se bei Anwendung des Konzepts der physiologischen Transfusionstrigger keine Indikation zur Transfusion dar.

Wegen der reduzierten kardialen Kompensationsfähigkeit treten die genannten Veränderungen bei kardial vorgeschädigten Patienten (Herzinsuffizienz, KHK) früher, d. h. bei geringerem Hämodilutionsgrad auf als bei Herzgesunden. Der Beginn der Transfusion erfolgt daher in der Regel bei dieser Patientengruppe bereits nach geringeren Blutverlusten. Grundsätzlich gelten jedoch die identischen Transfusionskriterien. 
Hämoglobinkonzentration Folgende Argumente können gegen die Wahl physiologischer Transfusionstrigger als Entscheidungskriterium für die intraoperative Transfusion von Erythrozyten angeführt werden:

- Das wohl zuverlässigste Verfahren, die kontinuierliche Messung der $\mathrm{VO}_{2}$ mittels indirekter Kalorimetrie, ist technisch und finanziell aufwändig und wird intraoperativ hauptsächlich zur Beantwortung wissenschaftlicher Fragestellungen eingesetzt; zudem kann das Verfahren bei Beatmung mit inspiratorischen $\mathrm{O}_{2}$-Konzentrationen $>60 \%$ aus technischen Gründen nicht mehr angewandt werden. Veränderungen der $\mathrm{VO}_{2}$ können daher bei Beatmung des Patienten mit reinem Sauerstoff nicht analysiert werden.

- Das Platzieren eines Swan-Ganz-Katheters bei jedem elektivchirurgischen Patienten zur Identifikation eines physiologischen Transfusionstriggers erscheint nicht vertretbar. Zudem handelt es sich bei der Berechnung der $\mathrm{VO}_{2}$ nach dem Fick-Prinzip um eine diskontinuierliche Methode, d. h. der Zeitpunkt des $\mathrm{VO}_{2}$-Abfalls kann ,,verpasst" werden. Vergleiche von gemessener und berechneter $\mathrm{VO}_{2}$ bei extremer Hämodilution lassen darüber hinaus eine systematische Unterschätzung der tatsächlichen $\ddot{\mathrm{VO}}_{2}$ durch die Berechnung nach dem Fick-Prinzip vermuten.

- Tachykardie ist ein Kompensationsmechanismus der Verdünnungsanämie bei extremer Hämodilution und ist anfänglich noch kein Zeichen einer beginnenden Gewebehypoxie. Die Abgrenzung zu einer transfusionsbedürftigen Tachykardie ist somit nur bei gleichzeitiger Berücksichtigung anderer physiologischer Parameter möglich, die wiederum den Einsatz eines Swan-Ganz-Katheters erfordert.

- Die Sensitivität von ST-Segmentanalyse im EKG sowie der transösophagealen Echokardiographie (TEE) bei der Identifikation subendokardialer Myokardischämien beträgt $60 \%$ bzw. 80-90\%, d. h. fehlende Veränderungen in EKG und TEE schließen eine Myokardischämie nicht sicher aus.

Da gerade während eines stärkeren, anhaltenden intraoperativen Blutverlusts immer ein Sicherheitsbereich für die Gewebeoxygenierung eingehalten werden sollte, wird ein Patient in dieser Situation nicht routinemäßig bis zum Auftreten von Gewebehypoxie hämodiluiert.

Nach Empfehlungen verschiedener Fachgesellschaften ist bei jungen, gesunden Patienten perioperativ eine $\mathrm{Hb}$-Konzentration von $6 \mathrm{~g} / \mathrm{dl}$, bei alten bzw. kardial vorerkrankten Patienten eine $\mathrm{Hb}-$ Konzentration von 8-10 $\mathrm{g} / \mathrm{dl}$ ohne Transfusion tolerabel [8].

Dies sind Hb-Konzentrationen, die intraoperativ ohne die Gefahr einer Gewebehypoxie tolerierbar sind (Normovolä- mie vorausgesetzt). Die angegebenen Konzentrationen stellen jedoch lediglich Richtwerte dar. Transfusionsbedarf kann daher bereits bei höheren Hb-Konzentrationen bestehen. Andererseits sind bei gesunden Patienten wesentlich niedrigere Konzentrationen ( $<3 \mathrm{~g} / \mathrm{dl})$ ohne Anzeichen von Gewebehypoxie beobachtet worden siehe (Abschn. 2.3).

\section{Durchführung der Transfusion}

Jeder geplanten Transfusion muss die Testung der Kompatibilität von Spender- und Empfängerblut durch die Blutbank bzw. durch einen dazu autorisierten Facharzt vorangehen.

\section{Kompatibilitätstestung}

- Bestimmung der Blutgruppe des Empfängers (AB0-, Rhesus-System).

- Durchführung einer sog. Kreuzblutprobe, d. h. einer „Testtransfusion“ im Reagenzglas (Spender-Erythrozyten + Empfänger-Serum) zum Ausschluss einer Inkompatibilität innerhalb des AB0-, Rhesus-Systems sowie der Kell-, Kidd- und Duffy-Blutgruppensysteme.

- Spezieller Antikörpersuchtest (Empfänger-Serum + kommerziell angebotene Erythrozyten mit spezifischen Oberflächenantigenen).

Durch alleinige Blutgruppenbestimmung kann bei 99,8 \% aller Transfusionen eine Blutgruppeninkompatibilität ausgeschlossen werden, bei zusätzlicher Durchführung von Kreuzprobe und Antikörpersuchtest in 99,95 \%. Das Blut für die Kreuzprobe sollte an einem anderen Tag entnommen werden als das Blut für die Blutgruppenbestimmung. Durch den Blutgruppenvergleich in beiden Blutproben kann dann das Risiko einer Patienten- oder Probenverwechslung noch weiter reduziert werden.

Die Kreuzprobe hat ab dem Zeitpunkt der Blutabnahme nur für 72 h Gültigkeit. Bei vortransfundierten Patienten mit Immunisierung gegen Blutgruppenantigene kann eine erneute Transfusion und damit Antigenexposition - trotz fehlendem Antikörpernachweis - zu einer explosionsartigen Immunantwort („Boosterung“) führen.

EK werden $\mathrm{ABO}$-gleich transfundiert. In Notfallsituationen sollte initial Blut der Blutgruppe 0, Rhesus-negativ verabreicht werden. Gleichzeitig wird Blut des Empfängers an die Blutbank gesandt und nach Abschluss der weiteren Austestung (Kreuzblutprobe, Antikörperscreening, blutgruppenkompatibles Blut transfundiert; Tab. 8).

Die Transfusion von Rhesus positivem Blut auf Rhesus negative Empfänger sollte nur in Notfallsituationen erwogen werden. In jedem Fall muss eine serologische Untersuchung 
Tab. 8 Mögliche Blutgruppenkombinationen bei der Transfusion von Erythrozyten- und Thrombozytenkonzentraten

\begin{tabular}{|l|l|}
$\begin{array}{l}\text { Blutgruppe des } \\
\text { Patienten }\end{array}$ & $\begin{array}{l}\text { Transfusion mit Konserven der } \\
\text { Blutgruppe }\end{array}$ \\
\hline A & A und 0 \\
\hline B & B und 0 \\
\hline AB & AB, A, B und 0 \\
\hline 0 & nur 0 \\
\hline
\end{tabular}

2-4 Monate nach Transfusion zur Feststellung evtl. gebildeter Antikörper (Immunisierung) erfolgen. Bei Patientinnen im gebährfähigen Alter kann eine Immunisierung durch Verabreichung von Anti-D-Immunglobulin $(300 \mu \mathrm{g}$ i.v. $)$ verhindert werden.

Nicht sofort benötigtes Blut muss im OP-Bereich kühl und erschütterungsfrei gelagert werden.

Die Kühlkette gilt als unterbrochen, wenn die Temperatur der Konserve auf über $8^{\circ} \mathrm{C}$ angestiegen ist. Dies ist bereits nach einer Zwischenlagerung von 15 min bei Raumtemperatur der Fall.

Einmal erwärmtes Blut darf für eine spätere Transfusion nicht mehr gekühlt werden, sondern ist nach Unterbrechung der Kühlkette innerhalb von $6 \mathrm{~h}$ zu transfundieren.

Im Operationssaal erfolgt die Transfusion erst nach erneuter AB0-Blutgruppentestung des Empfängers (Bedside-Test). Der Bedside-Test ist unabdingbar von einem Arzt selbst oder unter seiner direkten Aufsicht durchzuführen. Eine Testung der Konserve ist nicht erforderlich.

- Cave Die Unterlassung des Bedside-Tests oder die Unterlassung der Dokumentation des Ergebnisses sind per se ärztliche Kunstfehler.

Jedes EK muss unmittelbar vor der Transfusion vom transfundierenden Arzt einer optischen Qualitätsprüfung unterzogen werden (Unversehrtheit des Blutbeutels, Koagelbildung, Verfärbung, Herstellungs- bzw. Verfallsdatum). Die Transfusion des EK erfolgt über spezielle Transfusionsbestecke (170-200 $\mu \mathrm{m}$ Filter, DIN 58360 TG). Sie muss unter Beachtung von akut auftretenden Nebenwirkungen durch den transfundierenden Arzt eingeleitet werden. Empfohlen wird eine zügige Transfusion von $10 \mathrm{ml}$ des EK gefolgt von einer 5- bis 10-minütigen Beobachtung des Patienten. Alle Blutprodukte müssen - auch bei Abbruch einer Transfusion - mit Konserven-, bzw. Chargennummer sowie der Uhrzeit der Transfusion auf dem Anästhesieprotokoll verzeichnet werden.

Der leere Blutbeutel muss nach erfolgter Transfusion für $24 \mathrm{~h}$ bei $+4 \pm 2{ }^{\circ} \mathrm{C}$ aufbewahrt werden. Nicht benötigtes
Blut muss der Blutbank ohne Unterbrechung der Kühlkette zurückgegeben werden.

Seit dem 01.10.2001 dürfen nur noch leukozytendepletierte Blutprodukte transfundiert werden. Die Transfusion von Erythrozytenkonzentraten über spezielle Leukozytenadhäsionsfilter ist seither unnötig.

Effektivität der Transfusion von Erythrozytenkonzentraten Trotz Zusatz von Additivlösungen (CPDA-1, SAG-Mannitol, PAGGS-Mannitol etc.) führen der Abfall des pH-Werts und der ATP-Konzentration in gelagerten Blutkonserven bereits nach kurzer Zeit (3-5 Tagen) zu morphologischen und funktionellen Veränderungen der Erythrozyten (Bildung von Sphärozyten, reduzierte Verformbarkeit der Erythrozytenmembran, reduziertes 2,3-Diphosphoglycerat, gesteigerte $\mathrm{O}_{2}$-Affinität).

Die Wiederherstellung normaler 2,3-DPG-Konzentrationen und damit physiologischer $\mathrm{O}_{2}$-Transporteigenschaften benötigt nach Transfusion ,alter“ EK ( $>7$ Tage) zwischen 24 und $36 \mathrm{~h}$. Es ist davon auszugehen, dass die transfundierten Erythrozyten in dieser Zeit nur unzureichend an der Gewebeoxygenierung teilnehmen. Die mangelnde Effektivität gelagerter Erythrozytenkonzentrate ( $>15$ Tage) bei der Gewebeoxygenierung konnte bereits im Tierexperiment [52] und am Patienten [53] nachgewiesen werden. Neue Daten bringen bei herzchirurgischen Patienten die Transfusion gelagerter EK ( $>14$ Tage) mit erhöhten Komplikationsraten (u. a. Nierenversagen, Sepsis) und erhöhter Letalität in Verbindung [54].

Bei akuter Anämie mit Gewebehypoxie sollte darauf geachtet werden, frische Erythrozytenkonzentrate (Alter $<10-15$ Tage) zu transfundieren.

\subsubsection{Gefrorenes Frischplasma Herstellung und Lagerung}

Gefrorenes Frischplasma (GFP oder ,fresh frozen plasma“, FFP) wird aus dem Blut einer Einzelspende durch Zentrifugation gewonnen, separiert, innerhalb der ersten $6-8 \mathrm{~h}$ nach Abnahme tiefgefroren $\left(-80{ }^{\circ} \mathrm{C}\right)$ und kann anschließend bei -30 bis $-40{ }^{\circ} \mathrm{C}$ für $12-24$ Monate gelagert werden. Eine Einheit GFP enthält etwa 200-350 ml Plasma einschließlich sämtlicher Gerinnungsfaktoren, Plasmaproteine (Fibrinolyseenzyme, AT, Protein C und S, $\alpha_{2}$-Makroglobulin, $\alpha_{2}$-Antiplasmin, Plasminogenaktivatorinhibitor), Blutfette, Mineralien und Spurenelemente. Gerade die im Fall einer größeren Blutung erforderlichen prokoagulatorischen Faktoren (z. B. Fibrinogen, Gerinnungsfaktoren) 
sind in GFP allerdings nur in subphysiologischer Konzentration enthalten.

- Definitionsgemäß ist in $1 \mathrm{ml}$ GFP je eine internationale Einheit aller Gerinnungsfaktoren und -inhibitoren enthalten. Die tatsächliche Aktivität der in GFP enthaltenen prokoagulatorischen Komponenten ist jedoch subphysiologisch.

Der mittlere Proteingehalt beträgt $60 \mathrm{~g} / \mathrm{l}$, die Resterythrozytenzahl $<1000 / \mu 1$, die Restleukozytenzahl $<500 / \mu 1$ und die Restthrombozytenzahl $<20.000 / \mu 1$.

Neben GFP sind in Deutschland zugelassen:

- Solvent-Detergent behandeltes Plasma (SDP): wird aus 500-1600 Einzelspenderplasmen hergestellt und ist nach Ultrafiltration völlig zellfrei.

- Methylenblau-Licht behandeltes Plasma (MLP): ist Einzelspenderplasma welches mit Methylenblau versetzt und mit Rotlicht (Wellenlänge $590 \mathrm{~nm}$ ) bestrahlt wird.

- Lyophilisiertes Humanplasma (LHP): ist Einzelspenderplasma, welches nach Quarantänelagerung und Zellfiltration lyophilisiert wird und erst kurz vor Anwendung aufgelöst wird.

\section{Infektionsrisiko}

Die Freigabe von Einzelspenderplasmen seitens der Blutspendedienste erfolgt nach einer derzeit 6-monatigen Quarantänelagerung, wenn bei einer nachfolgenden Blutspende oder Blutprobe die transfusionsrelevanten Infektionsmarker (Hepatitis-B, -C und HIV) weiterhin beim Spender nicht nachweisbar sind (sog. Quarantäneplasma). Durch dieses Vorgehen wird zum einen der potenziellen Gefahr einer manifesten Infektion trotz fehlender Infektionsmarker (sog. Virusreplikationsfenster) Rechnung getragen, zum anderen wird durch die „Doppeltestung“ die Wahrscheinlichkeit eines Testversagens reduziert.

SDP (Poolplasma) wird nach einer kurzen Sperrlagerung vor der Abfüllung in Therapieeinheiten einer Virusinaktivierung mit dem Solvent-Detergent-Verfahren unterzogen. Diese Methode verhindert mit hoher Sicherheit die Übertragung von lipidumhüllten Viren (Hepatitis-B, -C und HIV). Da ein großer Plasmapool durch wenige mit nichtlipidumhüllten Viren (Parvovirus-B-19, Hepatitis-A-Virus) infizierte Blutspender kontaminiert werden kann, setzen die Hersteller zu deren Ausschluss zunehmend molekulargenetische Verfahren zum Nachweis bzw. Ausschluss von Virusgenomen ein. Das Methylenblau-Licht-Verfahren inaktiviert die meisten klinisch relevanten Viren effektiv (Ausnahme ParvovirusB-19).

- Vom infektiologischen Standpunkt kann die Infusion von GFP als "weitgehend sicher" betrachtet werden. Genaue Zahlen liegen diesbezüglich aber nicht vor.

\section{Indikation zur perioperativen Verabreichung von GFP}

Nach den Leitlinien des Vorstands und des wissenschaftlichen Beirats der Bundesärztekammer aus dem Jahr 2008 [8] sowie den Praxisleitlinien der ASA-Task-Force [30] bestehen die in der Übersicht dargestellten Indikationen für die perioperative Verabreichung von GFP.

\section{Verabreichung von GFP}

- Indikationen

- Notfallbehandlung bei klinisch manifester (mikrovaskulärer) Blutungsneigung oder bei akuten Blutungen aufgrund einer komplexen Störung des Hämostasesystems, insbesondere bei schwerem Leberparenchymschaden mit Synthesestörung

- Verbrauchskoagulopathie (DIC) mit Blutung

- Verlust oder Verdünnungskoagulopathie bei Patienten mit exzessivem Blutverlust und Massivtransfusion (d. h. Blutaustausch $>1$ Blutvolumen) + erhöhte klinische Blutungsneigung

- Substitution bei hereditärem Faktor-V- oder Faktor-XI-Mangel

- Thrombotisch-thrombozytopenische Purpura, adultes hämolytisch-urämisches Syndrom

- Keine Indikationen

- Volumenersatztherapie

- Albuminsubstitution

- Ersatz von Gerinnungsfaktoren ohne klinisch manifeste Blutungsneigung oder akute Blutung

Evidenz für die Anwendung von GFP besteht allerdings lediglich im Rahmen einer Massivtransfusion und bei der Behandlung von Patienten mit Marcumar induzierter intrakranieller Blutung [55].

\section{Verabreichung von GFP}

Vor der Infusion von GFP ist weder eine Kreuzprobe noch ein Bedside-Test vorgeschrieben. Auch der Rhesusfaktor bleibt bei der Infusion von GFP unberücksichtigt. GFP enthält die Isoagglutinine des ABO-Blutgruppensystems und muss daher blutgruppenkompatibel (AB0-identisch bzw. $A B 0$-verträglich) verabreicht werden. Im Notfall kann ohne vorherige Testung GFP eines Spenders mit der Blutgruppe $A B$ infundiert werden (Tab. 9).

Die Infusion von GFP sollte innerhalb von 30 min nach Auftauen der Konserve in $37{ }^{\circ} \mathrm{C}$ warmem Wasser (GFP-Schüttler) über ein spezielles Transfusionsbesteck (170-200 $\mu \mathrm{m}$ Filter) erfolgen. Die Infusion bei immunsupprimierten Patienten und onkologisch-chirurgischen Eingrif- 
Tab. 9 Mögliche Blutgruppenkombinationen bei der Infusion von gefrorenem Frischplasma (GFP)

\begin{tabular}{|l|l|}
\hline \multicolumn{1}{|c}{ Blutgruppe des Patienten } & Infusion von Plasma der Blutgruppe \\
\hline $\mathrm{A}$ & $\mathrm{A}$ und $\mathrm{AB}$ \\
\hline $\mathrm{B}$ & $\mathrm{B}$ und $\mathrm{AB}$ \\
\hline $\mathrm{AB}$ & nur $\mathrm{AB}$ \\
\hline 0 & $0, \mathrm{~A}, \mathrm{~B}$, und $\mathrm{AB}$ \\
\hline
\end{tabular}

fen erfordert keine Anwendung spezieller Leukozytenfilter. Bezüglich der Dokumentation der Anwendung gelten dieselben Richtlinien wie für Erythrozytenkonzentrate.

\section{Dosierung}

Die Infusion von einer Einheit GFP (ca. 200-300 ml) erhöht den Quick-Wert des Patienten bestenfalls um ca. 5-6 \%. Diese Quick-Wert-Erhöhung pro Einzel-GFP-Transfusion nimmt mit jedem weiteren transfundierten GFP ab (Verdünnungseffekt). Zur Erhöhung des Quick-Werts z. B. von $20 \%$ auf $40 \%$ sind demnach mindestens 8 Einheiten GFP notwendig.

Die Applikation von 1 oder 2 Einheiten GFP - wie so oft vom Operateur zur Verbesserung der Blutgerinnung gefordert - ist als wenig wirksam anzusehen. Insgesamt wird der Einsatz von GFP zur Stabilisierung der Gerinnung im Rahmen schwerer Blutungskomplikationen zunehmend verlassen und durch die zielorientierte Verabreichung von Gerinnungsfaktorenkonzentraten (Fibrinogenkonzentrat, PPSB) ersetzt.

\subsubsection{Thrombozytenkonzentrate}

\section{Herstellung}

Thrombozytenkonzentrate (TK) werden entweder durch Zentrifugation aus frisch entnommenem Vollblut oder durch maschinelle Thrombozytenapherese gewonnen und mit Plasma des Spenders oder additiver Lösung aufgeschwemmt.

\section{Zur Verfügung stehende TK-Präparationen}

- Gepooltes TK: Zusammenführung von 4-6 blutgruppenkompatiblen Einzelspenden. Standard-TK zur perioperativen Transfusion. 240-360 × 109 Thrombozyten in 200-350 ml Plasma oder einer Plasmaersatzlösung.

- Thrombozytenapherese-TK: $200-400 \times 10^{9}$ Thrombozyten eines Einzelspenders in 200-300 ml stabilisiertem Frischplasma. Enthält meist auch Leukozyten $\left(<1 \times 10^{6}\right)$ und Erythrozyten $\left(<3 \times 10^{9}\right)$.

\section{Lagerung}

Einzelspende-TK können in speziell dafür vorgesehenen Einrichtungen bei $+22 \pm 2{ }^{\circ} \mathrm{C}$ und unter ständiger Bewegung (,Thrombozytenschaukel“) für bis 5 Tage gelagert werden. Um ein optimales Transfusionsergebnis zu erzielen, ist eine möglichst kurze Lagerungsdauer (12 h nach Herstellung) anzustreben. Frische, nichtaktivierte transfundierte Thrombozyten lassen sich 7-10 Tage im Blut eines gesunden Empfängers nachweisen.

- Cave TK dürfen nicht gekühlt transportiert oder zwischengelagert werden, da dies innerhalb kurzer Zeit zum Funktionsverlust der Thrombozyten führt.

\section{Infektionsrisiko}

Für HIV, Hepatitis B und C besteht ein identisches Infektionsrisiko wie bei Erythrozytenkonzentraten. Zusätzlich besteht ein erhöhtes Risiko für HTLV- und bakterielle Infektionen (Lagerung bei Raumtemperatur!). Grundsätzlich ist das Infektionsrisiko bei gepoolten TK höher als bei aus Einzelspenden gewonnenen TK.

\section{Indikationen zur perioperativen Transfusion von TK}

Nach den Leitlinien der Bundesärztekammer aus dem Jahr 2008 [8] sowie den Praxisleitlinien der ASA-Task-Force [30] sollten TK prinzipiell nur bei Thrombozytopenie (Trombozytenzahl $<50.000 / \mu 1$ ) und gleichzeitig klinisch manifester Blutungsneigung transfundiert werden. Bei neurochirurgischen (intrakraniellen) Operationen sollte eine Thrombozytenzahl $>70.000-100.000 / \mu 1$ angestrebt werden.

Die prophylaktische Verabreichung von TK bei notfallmäßig durchzuführenden chirurgischen Eingriffen bleibt speziellen Patientengruppen vorbehalten (primäre oder sekundäre Knochenmarkinsuffizienz, manifeste disseminierte intravasale Gerinnung, iatrogene Inhibition der Thrombozytenfunktion mit Glykoprotein-IIb/IIIa-Antagonisten, z. B. Abciximab oder Acetylsalicylsäurepräparaten sowie heparininduzierte Thrombopenie). Bei Planung einer Periduralanästhesie wird eine Thrombozytenzahl von $>80.000-100.000 / \mu 1$ empfohlen. Für die Spinalanästhesie gilt ein Grenzwert von 50.000/ $\mu$ l. Zentrale Venenkatheter (ZVK) können bei Patienten ohne Blutungsneigung bei einer Thrombozytenzahl bis zu $10.000 / \mu 1$ angelegt werden.

Indikation zur prophylaktischen

Thrombozytentransfusion vor chirurgischen Eingriffen

- Vor kleineren operativen Eingriffen bei vorbestehender thrombozytärer Blutungssymptomatik oder bei Thrombozytenzahlen $\leq 20.000 / \mu 1$

- Vor größeren operativen Eingriffen und Eingriffen mit hohem Blutungsrisiko bei Thrombozytenzahlen $\leq 50.000 / \mu 1$

- Vor operativen Eingriffen mit sehr hohem Blutungsrisiko bei Thrombozytenzahlen $\leq 70.000-100.000 / \mu 1$ 


\section{Auswahl und Dosierung}

Thrombozyten tragen AB0-Blutgruppen-Merkmale auf ihrer Zelloberfläche.

TK müssen demnach unter Berücksichtigung ihrer Kompatibilität im AB0-System ausgewählt werden (Tab. 8). Aufgrund der Kontamination aller TK-Präparate mit Erythrozyten ist auch auf die Rhesus-Kompatibilität der Konserve zu achten.

Bei Rhesus-negativen Frauen im gebärfähigen Alter sollte, wenn die Transfusion von Rhesus-positiven TK unvermeidlich ist, eine Prophylaxe mit Anti-D-Immunglobulin (300 $\mu$ g i.v.) durchgeführt werden. Bei immunsupprimierten Patienten und onkologisch-chirurgischen Eingriffen sollten leukozytendepletierte TK transfundiert werden.

Die Dosierung einer TK-Transfusion kann nach folgender Formel abgeschätzt werden:

Dosis $($ Thrombozytenzahl $)=$ gewünschter Anstieg $\left(\times \frac{10^{9}}{1}\right)$ $\times$ Blutvolumen $[1] \times 1,5$

Beispiel Gewicht des Patienten: $80 \mathrm{~kg}$ (Blutvolumen: $80 \mathrm{~kg}$ $\times 66 \mathrm{ml} / \mathrm{kgKG})$. Aktuelle Thrombozytenzahl $20 \times 10^{9} / 1$.

Gewünschter Anstieg: $30 \times 10^{9} / 1$.

Dosis $=30 \times 10^{9} \times 5,3 \times 1,5=239 \times 10^{9}=24 \times 10^{10}$. Entsprechend 4-5 50-ml-Einzelspender-TK-Einheiten.

Die Transfusion sollte rasch (innerhalb von $30 \mathrm{~min}$ ) über ein Standardtransfusionsbesteck (Porengröße 170-200 $\mu \mathrm{m}$ ) erfolgen. Bezüglich der Dokumentation der Anwendung gelten dieselben Richtlinien wie für Erythrozytenkonzentrate und GFP.

\subsubsection{Prothrombinkomplex (PPSB)}

\section{Herstellung}

PPSB-Konzentrate enthalten die Proenzyme der Faktoren des Prothrombinkomplexes (Faktor II, VII, IX und X), Protein C, $\mathrm{S}$ und $\mathrm{Z}$ sowie geringe Mengen an Heparin. In manchen Präparaten ist auch Antithrombin III enthalten.

\footnotetext{
- Cave Infusion bei Patienten mit heparininduzierter Thrombopenie (HIT)!
}

Die Faktoren werden aus großen Plasmapools durch Ionenaustauschchromatographie in Kombination mit verschiedenen Fällungsverfahren isoliert. PPSB-Konzentrate sind nur hinsichtlich des Faktor-IX-Gehalts standardisiert, d. h. die Angaben auf den verschiedenen Packungsgrößen 200, 250, 300, 500 und 600 Einheiten beziehen sich lediglich auf Faktor IX. Alle anderen in PPSB enthaltenen Komponenten unterliegen zum Teil erheblichen Schwankungen. Aktivierte Gerinnungsfaktoren und aktiviertes Protein C bzw. Plasmin sind in den heute verfügbaren PPSB-Präparaten nicht mehr enthalten (Ausnahme: FEIBA der Fa. Baxter enthält die Faktoren VII und VIII in aktivierter Form).

\section{Infektionsrisiko}

Durch Anwendung spezieller Verfahren zur Virusinaktivierung können PPSB-Präparate heute als weitestgehend sicher bezüglich der Infektion mit umhüllten Viren (z. B. HIV, Hepatitis B und C) sowie mit dem nichtumhüllten HepatitisA-Virus betrachtet werden. Für andere nichtumhüllte Viren wie z. B. Parvovirus $B_{19}$ können die Verfahren zur Virusinaktivierung von nur eingeschränktem Wert sein (Cave: Risiko der fetalen Infektion bei Anwendung während Schwangerschaft).

\section{Lagerung}

PPSB ist bei $+2{ }^{\circ} \mathrm{C}$ bis $+8{ }^{\circ} \mathrm{C}$ aufzubewahren. Nach Auflösung der Trockensubstanz ist die Lösung sofort zu infundieren.

\section{Indikation zur perioperativen Transfusion von PPSB}

Hauptindikation für die präoperative Verabreichung von PPSB ist die rasche und mit geringer Volumenbelastung verbundene Anhebung der Faktoren des Prothrombinkomplexes vor notfallmäßigen chirurgischen Eingriffen bei markumarisierten Patienten. Zunehmend Einzug findet die Verabreichung von PPSB bei der Gerinnungstherapie im Rahmen massiver perioperativer Blutverluste als Ersatz bzw. Ergänzung der Infusion von GFP. Ziel hierbei ist die Anhebung bzw. Konsolidierung des Quick-Werts auf 30-40\% (kleinere Verletzungen oder operative Eingriffe) bzw. auf 60-80\% (schwere Verletzungen oder größere operative Eingriffe).

\section{Dosierung}

Als Faustregel für die zu applizierende Initialdosis gilt:

$$
\begin{aligned}
\text { Initialdosis (Einheiten) }= & \text { Korpergewicht }(\mathrm{kg}) \\
& \times \text { gewünschter } \\
& \text { Faktorenanstieg }(\%)
\end{aligned}
$$

Die Infusion muss langsam erfolgen. Nach Applikation der Initialdosis sollte jeder weiteren Applikation eine entsprechende Kontrolle der Gerinnungsparameter Quick und PTT vorangehen. Gemäß Transfusionsgesetz besteht für die Applikation von PPSB Dokumentationspflicht.

\section{Akute, unerwünschte Wirkungen}

Insgesamt gilt die Verabreichung von PPSB heute als sicher. Insbesondere die Gefahr von Thromboembolien, DIC und hyperfibrinolytische Blutungen - ehemals ausgelöst durch die Infusion aktivierter Gerinnungsfaktoren - ist bei Anwendung moderner Präparate weitestgehend gebannt. Selten werden allergische/anaphylaktoide Reaktionen beim Empfänger beobachtet. 


\subsubsection{Antithrombin (AT)}

\section{Herstellung}

Aus großen Plasmapools durch Affinitäts- oder Ionenaustauschchromatographie hergestelltes Konzentrat von humanem Serinproteaseinhibitor. AT ist der wichtigste Inhibitor von Thrombin und Faktor Xa. In geringerem Maße werden auch die aktivierten Gerinnungsfaktoren VII, IX, XI und XII sowie Kallikrein, Plasmin und die $\mathrm{C}_{1}$-Esterase des Komplementsystems gehemmt. Die Inaktivierung der Gerinnungsfaktoren durch AT ist ein langsamer Prozess, der durch Heparin beschleunigt wird.

\section{Infektionsrisiko}

Durch spezielle Verfahren zur Virusinaktivierung kann AT heute als sicher bezüglich der Infektion mit HIV, Hepatitis B und $\mathrm{C}$ betrachtet werden.

\section{Lagerung}

AT kann als Trockensubstanz bei $+2{ }^{\circ} \mathrm{C}$ bis $+8{ }^{\circ} \mathrm{C}$ über Monate gelagert werden. Die Substanz muss nach Aufschwemmen mit Lösungsmittel sofort appliziert werden. Geläufige Packungsgrößen sind 500 und 1000 IE.

\section{Indikation zur perioperativen Applikation von AT}

Die wichtigste Indikation für die perioperative Verabreichung von AT ist die Verbesserung der Heparinantikoagulation:

- bei erhöhter Thromboembolieneigung (z. B. chronischer Leberparenchymschaden, nephrotisches Syndrom),

- dissiminierte intravasale Gerinnung (DIC) in Ergänzung zu GFP. Der Nachweis einer Reduktion der Letalität durch fehlt allerdings bislang,

- hereditärer AT-Mangel.

Gemäß Transfusionsgesetz besteht für die Applikation von AT Dokumentationspflicht.

\section{Dosierung}

Als Faustregel gilt:

1 Einheit $\frac{\mathrm{AT}}{\mathrm{kgKG}}$ hebt die AT - Aktivität um $1-2 \%$ an

Bei entsprechender Indikation ist eine Anhebung der ATAktivität auf mindestens $80 \%$ sinnvoll.

\section{Akute Nebenwirkungen}

Selten wurden anaphylaktoide Reaktionen nach ATApplikation beobachtet.

\subsubsection{Fibrinogenkonzentrat Herstellung}

Aus großen Plasmapools hergestelltes Konzentrat. Fibrinogen ist Substrat der plasmatischen Blutgerinnung und wesentlicher
Ligand bei der Aktivierung und Aggregation von Thrombozyten. Daneben gehört Fibrinogen zu den Akut-Phase-Proteinen und steigt bei Infektionen in kurzer Zeit auf ein Vielfaches seines Normalwertes $(1,5-4 \mathrm{~g} / \mathrm{l})$ an.

\section{Infektionsrisiko}

In Analogie zu PPSB kann Fibrinogenkonzentrat als weitestgehend sicher bezüglich der Infektion mit HIV, Hepatitis A, $\mathrm{B}$ und $\mathrm{C}$ betrachtet werden. Ein Restrisiko für eine Übertragung nichtumhüllte Viren wie z. B. Parvovirus $B_{19}$ besteht. Fibrinogenkonzentrat sollte daher bei Schwangeren nicht eingesetzt werden.

\section{Lagerung}

Fibrinogenkonzentrat kann als Trockensubstanz bei $+2{ }^{\circ} \mathrm{C}$ bis $+8{ }^{\circ} \mathrm{C}$ über Jahre gelagert werden. Die Substanz muss nach Aufschwemmen mit Lösungsmittel sofort appliziert werden. Geläufige Packungsgrößen sind $1 \mathrm{~g}$ bzw. 2 g Fibrinogenkonzentrat.

\section{Indikation zur perioperativen Applikation von Fibrino- genkonzentrat}

Im Gegensatz zur Aktivität der Faktoren des Prothrombinkomplexes und der Thrombozytenzahl fällt die Serumfibrinogenkonzentration im Rahmen der Infusionstherapie eines massiven Blutverlusts bereits sehr früh verdünnungsbedingt ab. Ein ausreichendes Angebot an Fibrinogen ist allerdings für die Bildung stabiler Gerinnsel unerlässlich (Fibrin $=$ „Kit im Clot"). Da ein adäquates Angebot durch die Infusion von GFP allein nicht realisierbar ist, kann bei massiven Blutverlusten und der Ausbildung einer diffusen Blutungsneigung (Verlust-, bzw. Verdünnungskoagulopathie) die Applikation eines Fibrinogenkonzentrates sinnvoll sein. Die Serumfibrinogenkonzentration sollte dann $>1,5-2 \mathrm{~g} / \mathrm{l}$ gehalten werden, was in der Regel die Verabreichung von 2-4 g Fibrinogenkonzentrat erfordert. Gemäß Transfusionsgesetz besteht für die Applikation von Fibrinogenkonzentrat Dokumentationspflicht.

\section{Kontraindikationen}

Bei disseminierter intravasaler Gerinnung (DIC) kann die Infusion von Fibrinogenkonzentrat zu einer Zunahme der Mikrozirkulationsstörung und des Organversagens führen.

\section{Dosierung}

Faustregel:

$$
\text { Fibrinogendosis }(\mathrm{g})=\text { erwünschter Anstieg }(\mathrm{g} / \mathrm{l})
$$$$
\times \text { Plasmavolumen }(1)
$$ 
- Cave In mit Kolloiden versetztem Plasma werden mit den üblichen Analysegeräten falsch hohe Fibrinogenkonzentrationen bestimmt. Im Rahmen von massiven Blutungen sollte die Fibrinogenkonzentration direkt mit der Methode nach Clauss bestimmt werden.

\subsubsection{Rekombinanter Faktor VIla (rFVIla) Herstellung}

Rekombinanter Faktor VII wird unter Verwendung einer Nierenzellreihe von Baby-Hamstern hergestellt. Durch hydrolytische Spaltung des Proteins entsteht aktivierter Faktor VII . Das rFVIIa-Konzentrat enthält keine anderen aktivierten Gerinnungsfaktoren.

\section{Infektionsrisiko}

Durch spezielle Verfahren zur Virusinaktivierung kann rFVIIa-Konzentrat als sicher bezüglich der Infektion mit HIV, Hepatitis B und C betrachtet werden.

\section{Lagerung}

rFVIIa-Konzentrat kann als Trockensubstanz bei $+2{ }^{\circ} \mathrm{C}$ bis $+8{ }^{\circ} \mathrm{C}$ für 3 Jahre gelagert werden. Die Substanz muss nach Aufschwemmen mit Lösungsmittel sofort appliziert werden. Nicht sofort benötigter, aufgeschwemmter rFVIIa kann bei $2-8{ }^{\circ} \mathrm{C} 24 \mathrm{~h}$ gelagert werden. Geläufige Packungsgrößen sind $1,2 \mathrm{mg}, 2,4 \mathrm{mg}$ und 4,8 mg rFVIIa-Konzentrat.

\section{Indikation zur perioperativen Applikation von rFVIIa- Konzentrat \\ Die Applikation von rFVIIa-Konzentrat ist in der BRD zuge- lassen für die Behandlung bzw. Prävention von Blutungen bei Patienten mit angeborener und erworbener Hemmkörper- hämophilie, Thrombasthenie Glanzmann und angeborenem Faktor-VII-Mangel. Gemäß Transfusionsgesetz besteht für die Applikation von rFVIIa Dokumentationspflicht.}

- Die Anwendung im Rahmen massiver Blutverluste mit therapierefraktärer mikrovaskulärer Blutungsneigung entspricht einer Anwendung außerhalb zugelassener Indikationen (sog. „off-label-use").

Zwar wurden in einzelnen Fallberichten spektakuläre Erfolge einer Therapie mit rFVIIa-Konzentrat bei der Blutungskontrolle berichtet. Kontrollierte Daten bezüglich einer Verbesserung des Überlebens fehlen bislang. Ebenso ist der optimale Zeitpunkt für die Applikation von rFVIIa bei massiven Blutverlusten unklar. Die Applikation erfolgt aber - nicht zuletzt aufgrund der hohen Kosten des Präparats - häufig spät, d. h. als „Ultima-ratio“-Therapie nach erfolgloser Ausschöpfung aller sonst vorhandenen Möglichkeiten.

- Die erfolgversprechende Verabreichung von rFVIlaKonzentrat erfordert folgende minimale Rahmenbedin- gungen: Kontrolle chirurgischer Blutungsquellen, Körpertemperatur $>35{ }^{\circ} \mathrm{C}$, Fibrinogenkonzentration $>1,5 \mathrm{~g} / \mathrm{l}$, Thrombozytenzahl $\geq 50.000 / \mu \mathrm{l}, \mathrm{pH}$-Wert $\geq 7,2$, ionisiertes Kalzium $\geq 0,9 \mathrm{mmol} / \mathrm{l}$.

\section{Kontraindikationen}

Faktor VIIa führt über Komplexbildung mit dem in tiefen Gefäßwandschichten lokalisierten Gewebefaktor zu einer Aktivierung von Faktor $\mathrm{X}$ und wirkt hauptsächlich am Ort eines Gefäß- bzw. Gewebeschadens. Bei blutenden Patienten mit bekannten Thrombosen, koronarer Herzerkrankung oder peripherer arterieller Verschlusskrankheit ist die Applikation von rFVIIa-Konzentrat kritisch abzuwägen.

\section{Dosierung}

Die optimale Dosierung von rFVIIa-Konzentrat ist bis dato unklar. Empfohlen wird eine Initialdosis von $90-120 \mu \mathrm{g} /$ kgKG.

\subsubsection{Faktor-VIII-, Faktor-VIII-/v.-Willebrand- Faktor und Faktor-IX-Konzentrat}

\section{Herstellung}

Konzentrate der Faktoren VIII, VIII/v.-Willebrand-Faktor und IX werden aus Kryopräzipitaten - z. T. auch gentechnisch - hergestellt. Der Reinheitsgrad eines Faktorenkonzentrats wird als „spezifische Aktivität“ angegeben (Einheiten des wirksamen Faktors pro mg Gesamtprotein).

\section{Infektionsrisiko}

Durch Anwendung spezieller virusinaktivierender Verfahren gelten Faktorenkonzentrate heute als sicher bezüglich der Infektion mit HIV, Hepatitis B und C.

\section{Lagerung}

Faktorenkonzentrate können bei $+4{ }^{\circ} \mathrm{C}$ bis $+8{ }^{\circ} \mathrm{C}$ über Monate gelagert werden. Die gebrauchsfertige Lösung sollte sofort infundiert werden.

\section{Indikationen zur perioperativen Anwendung}

- Faktor-VIII-Konzentrat: schwere (Faktor-VIII-Restaktivität $<2 \%$ ) oder mittelschwere (Faktor-VIII-Restaktivität 2-5 \%) Hämophilie A.

- Faktor-VIII-/v.-Willebrand-Faktor: v.-Willebrand-Syndrom Typ II und III (funktionsgestörter oder fehlender vWF).

- Faktor-IX-Konzentrat: schwere und mittelschwere Hämophilie B.

Bei milder Hämophilie A (Faktor-VIII-Restaktivität 15-50 \%) sowie bei v.-Willebrand-Syndrom Typ I (Restaktivität 10-40 \%) können die entsprechenden Faktoren durch das Vasopressinanalogon Desmopressin (DDAVP; 
oben) aus körpereigenen Speichern freigesetzt und dadurch deren Plasmakonzentrationen bis auf das 3-fache gesteigert werden.

Gemäß Transfusionsgesetz besteht für die Applikation der genannten Faktorenkonzentrate Dokumentationspflicht.

\section{Dosierung}

Als Faustregel für die Applikation von Faktor VIII, VIII/ vWF und IX gilt:

- die Verabreichung von 1 Einheit pro $\mathrm{kgKG}$ führt zum Anstieg des jeweiligen Faktors im Plasma um 1 \%.

- Vor Operationen mit großen Wundflächen und hoher Blutungsgefahr (einschließlich Tonsillektomie) sollten bei Risikopatienten 50-80 E/kgKG verabreicht werden;

- vor Operationen mit kleinen Wundflächen 25-40 E/kgKG.

\section{Akute, unerwünschte Wirkungen}

Selten wurden nach Verabreichung der verschiedenen Faktorenkonzentrate anaphylaktoide Reaktionen oder eine Ausbildung von Antikörpern gegen die zugeführten Gerinnungsfaktoren (sog. Hemmkörperhämophilie) beobachtet.

\subsubsection{Massivtransfusion Definition}

Werden innerhalb von $24 \mathrm{~h}$ Blut und Blutkomponenten in der Größenordnung eines Blutvolumens des Patienten transfundiert, spricht man von einer Massivtransfusion.

Ursache sind häufig große chirurgische Eingriffe bei bereits präoperativ pathologisch verändertem Gerinnungsstatus (z. B. Leberchirurgie, Polytrauma, Gestose bzw. HELLP-Syndrom). Folgende Probleme sind beim Umsatz von derart umfangreichen Transfusionsvolumina zu berücksichtigen.

\section{Unerwünschte Wirkungen}

Abfall der Körpertemperatur Die Transfusion ungewärmter Blutkonserven mit einer Temperatur von $4{ }^{\circ} \mathrm{C}$ führt unweigerlich zu einem raschen Abfall der Körperkerntemperatur. Dadurch verschlechtert sich zum einen die Gerinnungssituation weiter, zum anderen steigt das Risiko maligner Herzrhythmusstörungen $\left(<30^{\circ} \mathrm{C}\right)$.

Bei Massivtransfusionen ist daher das Anwärmen der Blutkomponenten zwingend notwendig.

Verschlechterung der Blutgerinnung Eine Verschlechterung der Blutgerinnung (,diffuse“ Blutungsneigung) während
Massivtransfusionen ist häufig Ausdruck der Verdünnung von Fibrinogen, Faktor V und VIII sowie Thrombozyten.

Aus ungeklärten Gründen tritt eine hämorrhagische Diathese bei akuter Entwicklung einer Thrombopenie bei höheren Thrombozytenzahlen auf als bei langsamer Entwicklung.

Initial kann die Verabreichung von Fibrinogenkonzentrat (2-4 g, Zielserumkonzentration von Fibrinogen $>150 \mathrm{mg} / \mathrm{dl}$ ) sinnvoll sein. Die Transfusion von Thrombozytenkonzentraten und GFP/PPBS wird bei einer Thrombozytenzahl von $50.000 / \mu \mathrm{l}$ bzw. einem Quick-Wert von $30-40 \%$ empfohlen. Bei extremen Blutverlusten sollten EK und GFP im Verhältnis 1:1 bis 1:2 transfundiert werden.

Weitere Ursachen einer Verschlechterung der Blutgerinnung während Massivtransfusion sind:

- Verbrauchskoagulopathie im Rahmen einer disseminierten intravasalen Gerinnung (DIC), ausgelöst durch die Freisetzung von Gewebsthromboplastin aus minderperfundierten, hypoxischen Gewebearealen.

- Hämolytische Transfusionsreaktion bei Transfusion blutgruppeninkompatiblen Bluts.

Zitratintoxikation Während einer Massivtransfusion mit CPDA-1-stabilisierten EK und GFP werden dem Patienten erhebliche Mengen Natriumzitrat als Bestandteil der Additivlösung infundiert. Natriumzitrat bindet ionisiertes Kalzium. Bei Infusion von mehr als $150 \mathrm{ml}$ Blut/min kann bei einem $70 \mathrm{~kg}$ schweren Mann eine Hypokalzämie mit Hypotonie, gesteigertem zentralen Venendruck und EKGVeränderungen (Verlängerung der QT-Zeit) resultieren. Aufgrund des raschen, hepatischen Abbaus des infundierten Zitrats zu Bikarbonat und sofortiger Freisetzung von Kalzium aus endogenen Speichern ist eine Kalziumgabe (z. B. $10 \mathrm{ml} \mathrm{Ca-Glukonat} 10 \%$ pro $1000 \mathrm{ml}$ EK bzw. GFP langsam i.v.) nur selten bei gleichzeitig bestehenden Leberfunktionsstörungen notwendig.

Bei Transfusion von SAG-Mannitol bzw. PAGGS-Mannitol stabilisierten EK besteht keine Gefahr einer Hypokalzämie.

Hyperkaliämie Drei Wochen und länger gelagerte Blutkonserven enthalten Kalium in Konzentrationen zwischen 19 und $30 \mathrm{mmol} / \mathrm{l}$. Bei Infusion von mehr als $120 \mathrm{ml} \mathrm{Blut} / \mathrm{min} \mathrm{kann}$ bei einem $70 \mathrm{~kg}$ schweren Mann eine Hyperkaliämie mit typischen EKG-Veränderungen (hohe, spitze T-Welle) resultieren. Die EKG-Veränderungen sind in der Regel nach Gabe von Kalziumchlorid (z. B. $10 \mathrm{ml} \mathrm{CaCl} 20,5 \mathrm{mmol} / \mathrm{ml}$ langsam i.v.) reversibel. 
pH-Verschiebungen Die Lagerung von Erythrozytenkonzentraten führt zu einer Ansäuerung des Inhalts aufgrund der kontinuierlichen Produktion von Laktat (Glykolyse in Erythrozyten) und $\mathrm{CO}_{2}$. Der $\mathrm{pH}$-Wert eines 3 Wochen alten EK liegt bei 6,9 , der $\mathrm{pCO}_{2}$ bei $150-220 \mathrm{mmHg}$. Aufgrund der hepatischen Metabolisierung des gleichzeitig infundierten Natriumzitrates zu Bikarbonat führt eine Massivtransfusion jedoch eher zu einer metabolischen Alkalose als zu einer metabolischen Azidose.

Gewebehypoxie Wie bereits weiter oben erwähnt, sinken mit zunehmender Lagerungsdauer von Erythrozytenkonzentraten die Verformbarkeit der Erythrozytenmembran sowie der intraerythrozytäre Gehalt an 2,3-DPG. Folge ist ein ungünstig verändertes Fließverhalten der transfundierten Erythrozyten in der mikrovaskulären Strombahn (Erythrozytenstase, Gewebehypoperfusion) und eine schlechtere Abgabe des an Hämoglobin angelagerten Sauerstoffs an die Gewebe (Abnahme des $\mathrm{p}_{50}$-Werts).

Bei Massivtransfusionen sollte daher bevorzugt Blut transfundiert werden, das nicht älter als 15 Tage ist.

\section{Künstliche $\mathrm{O}_{2}$-Träger}

Die zu erwartende Kostenexplosion im Transfusionswesen zum einen bedingt durch Spendermangel, zum anderen durch die Behandlungspflicht transfusionsassoziierter Folgeerkrankungen (chronische Hepatitis, Leberzirrhose, Wundinfektion, Tumorrezidiv) - lässt erkennen, welch enormer sozioökonomischer Stellenwert der Entwicklung von synthetisch hergestellten „Blutersatzstoffen“ zukommt (Tab. 10). Bei entsprechender industrieller Massenproduktion könnte die Bereitstellung und Verabreichung derartiger Substanzen unabhängig vom Spendeverhalten der Bevölkerung werden; die besonders kostenbelastenden infektiologischen und immunologischen (AB0-Kompatibilität!) Kontrolluntersuchungen würden entfallen.

\section{Vermutlich wird eine künstlich hergestellte Infusionslösung niemals sämtliche physiologische Funktionen von Vollblut übernehmen können; daher wird vordringlich versucht, die $\mathrm{O}_{2}$-Transportfunktion der Erythrozyten zu ersetzen.}

In den letzten 20 Jahren wurden zwei Substanzgruppen im Tierexperiment und in klinischen Studien auf ihre Sicherheit und Wirksamkeit bei schwerer, transfusionsbedürftiger Anämie untersucht:

- Lösungen auf der Basis von isoliertem Hämoglobin (sog. „hemoglobin based oxygen carriers“, HBOC) und
- Perfluorokarbone (PFC; ausführliche Übersicht in [56]).

Infusionslösungen auf der Basis von isoliertem menschlichem und tierischem (bovinem) Hämoglobin wurden für den 1:1-Ersatz eines Blutverlusts konzipiert und zeigten in einzelnen Fallberichten auch ihre Effektivität bei der Therapie einer anämischen Hypoxie. Allerdings weisen HBOC neben ihrer Fähigkeit zum $\mathrm{O}_{2}$-Transport eine derzeit noch schwer kontrollierbare vasokonstriktorische Potenz auf, deren Bedeutung für Organperfusion und -funktion bislang nicht vollständig geklärt ist. Dennoch erhielt die Rinderhämoglobinlösung Hemopure (Biopure Inc., Cambridge, USA) als bisher einziger Vertreter dieser Lösungen im April 2001 die Zulassung in Südafrika.

Perfluorokarbon (PFC)-Emulsionen werden rein synthetisch hergestellt und erhöhen die Löslichkeit von Sauerstoff in Plasma. Immunsuppressive Effekte bei Hochdosisapplikation sowie die fehlende onkotische Eigenschaft verbieten den 1:1-Ersatz von Blutverlusten durch PFC. Als Supplement bei normovolämischer Hämodilution und Hyperoxie, konnte die niedrig dosierte Bolusanwendung der PFC-Emulsion Oxygent (Alliance Pharmaceutical Corp., San Diego, USA) die intraoperative Anämietoleranz steigern. 1996 wurde in Russland Perftoran 10 \% (Perftoran Corp., Pushchino, Rußland) für den perioperativen Einsatz bei Patienten zugelassen.

\section{$5 \quad$ Perioperatives Management bei Zeugen Jehovas}

Selbst vor großen Operationen mit statistisch belegtem Transfusionsbedarf wird ein gläubiger Zeuge Jehovas seine behandelnden Ärzte auf seine Ablehnung von Frembluttransfusionen (allogene Erythrozyten, Plasma, Thrombozyten) hinweisen - auch für den Fall der Entwicklung einer letalen Anämie. Bei Abschluss eines Behandlungsvertrages muss der Wunsch des volljährigen Patienten respektiert und ein Weg gesucht werden, ihm eine therapeutische Option bei kalkulierbarem Risiko zu eröffnen. Hauptziel ist hierbei, den ,point of no return“ einer sich entwickelnden Anämie bzw. Koagulopathie niemals zu erreichen (Übersicht in: [57]).

Präoperativ stehen die Optimierung des kardiopulmonalen Zustands des Patienten sowie die Diagnose und Korrektur einer Anämie oder Gerinnungsstörung im Vordergrund. Gerinnungswirksame Pharmaka sollten mit ausreichendem zeitlichem Abstand zur Operation abgesetzt werden. Entscheidend ist das Einholen einer detaillierten schriftlichen Einwilligung des Zeugen Jehovas in blutverlustreduzierende und fremdblutvermeidende Verfahren (Tab. 11). Während die klassische präoperative Eigenblutspende abgelehnt wird, 
Tab. 10 Künstliche $\mathrm{O}_{2}$-Träger: Stand der klinischen Forschung

\begin{tabular}{|c|c|c|c|c|c|}
\hline $\mathrm{O}_{2}$-Träger & Hersteller & $\begin{array}{l}\text { Ursprung, } \\
\text { Konzentration }\end{array}$ & Indikation & $\begin{array}{l}\text { Klinische } \\
\text { Prüfphase }\end{array}$ & Präparatname \\
\hline $\begin{array}{l}\text { Pyridoxiliertes, } \\
\text { Polyoxyethylenglykol-konjugiertes } \\
\mathrm{Hb}\end{array}$ & $\begin{array}{l}\text { Curacyte Health } \\
\text { Sciences, BRD } \\
\text { (ehemals Apex } \\
\text { Bioscience Inc.) }\end{array}$ & Humanes $\mathrm{Hb} 8 \mathrm{~g} / \mathrm{dl}$ & $\begin{array}{l}\text { Kreislaufstabilisierung } \\
\text { im septischen Schock }\end{array}$ & III & PHP \\
\hline Diaspirin-gekoppeltes $\mathrm{Hb}$ & $\begin{array}{l}\text { Baxter } \\
\text { Healthcare Corp., } \\
\text { USA }\end{array}$ & Humanes $\mathrm{Hb} 10 \mathrm{~g} / \mathrm{dl}$ & $\begin{array}{l}\text { Perioperative Reduktion } \\
\text { von } \\
\text { Fremdbluttransfusion }\end{array}$ & $\begin{array}{l}\text { bis III, dann } \\
\text { abgebrochen }\end{array}$ & HemAssist \\
\hline Glutaraldehyd-polymerisiertes $\mathrm{Hb}$ & $\begin{array}{l}\text { Biopure Corp., } \\
\text { USA }\end{array}$ & Rinder-Hb $13 \mathrm{~g} / \mathrm{dl}$ & $\begin{array}{l}\text { Reduktion von } \\
\text { Fremdbluttransfusion } \\
\text { PTCA }\end{array}$ & III & Hemopure \\
\hline $\begin{array}{l}\text { Polyoxyethylenglykol-konjugiertes } \\
\mathrm{Hb}\end{array}$ & $\begin{array}{l}\text { Enzon Corp., } \\
\text { USA }\end{array}$ & Rinder-Hb 6 g/dl & $\begin{array}{l}\text { Steigerung der } \\
\text { Radiosensitivität von } \\
\text { Tumoren }\end{array}$ & $\begin{array}{l}\text { I/II, dann } \\
\text { abgebrochen }\end{array}$ & - \\
\hline O-Raffinose-polymerisiertes $\mathrm{Hb}$ & $\begin{array}{l}\text { Hemosol Inc., } \\
\text { Kanada }\end{array}$ & Humanes $\mathrm{Hb} 10 \mathrm{~g} / \mathrm{dl}$ & $\begin{array}{l}\text { Reduktion von } \\
\text { Fremdbluttransfusion }\end{array}$ & $\begin{array}{l}\text { bis III, dann } \\
\text { abgebrochen }\end{array}$ & Hemolink \\
\hline $\begin{array}{l}\text { Pyridoxiliertes, Glutaraldehyd- } \\
\text { polymerisiertes } \mathrm{Hb}\end{array}$ & $\begin{array}{l}\text { Northfield Lab. } \\
\text { Inc., USA }\end{array}$ & Humanes $\mathrm{Hb} 10 \mathrm{~g} / \mathrm{dl}$ & $\begin{array}{l}\text { Reduktion von } \\
\text { Fremdbluttransfusion }\end{array}$ & $\begin{array}{l}\text { bis III, dann } \\
\text { abgebrochen }\end{array}$ & Polyhem \\
\hline $\begin{array}{l}\text { Polyoxyethylenglykol-konjugiertes } \\
\mathrm{Hb}\end{array}$ & $\begin{array}{l}\text { Sangart Corp., } \\
\text { USA }\end{array}$ & Humanes $\mathrm{Hb} 4 \mathrm{~g} / \mathrm{dl}$ & $\begin{array}{l}\text { Reduktion von } \\
\text { Fremdbluttransfusion }\end{array}$ & III & Hemospan \\
\hline Rekombinantes $\mathrm{Hb}$ & $\begin{array}{l}\text { Baxter } \\
\text { Healthcare Corp., } \\
\text { USA }\end{array}$ & E. coli $5-10 \mathrm{~g} / \mathrm{dl}$ & $\begin{array}{l}\text { Reduktion von } \\
\text { Fremdbluttransfusion }\end{array}$ & $\begin{array}{l}\text { I/II, dann } \\
\text { abgebrochen }\end{array}$ & $\begin{array}{l}\mathrm{rHb}-1.1 \\
\mathrm{rHb}-2.0\end{array}$ \\
\hline Perfluorooctylbromid & $\begin{array}{l}\text { Alliance } \\
\text { Pharmaceutical } \\
\text { Corp., USA }\end{array}$ & $\begin{array}{l}\text { Synthetisch } 60 \% \\
\text { (Gew./Vol.) }\end{array}$ & $\begin{array}{l}\text { Reduktion von } \\
\text { Fremdbluttransfusion }\end{array}$ & $\begin{array}{l}\text { III, derzeit } \\
\text { unterbrochen }\end{array}$ & Oxygent \\
\hline Perfluorodichlorooctan & $\begin{array}{l}\text { HemaGen Inc., } \\
\text { USA }\end{array}$ & $\begin{array}{l}\text { Synthetisch } 40 \% \\
\text { (Gew./Vol.) }\end{array}$ & $\begin{array}{l}\text { Reduktion von } \\
\text { Gas-embolie während } \\
\text { HLM }\end{array}$ & $\begin{array}{l}\text { I, derzeit } \\
\text { unterbrochen }\end{array}$ & OxyFluor \\
\hline $\begin{array}{l}\text { Perfluorodecaline/- } \\
\text { paramethylcyclohexilpiperidine }\end{array}$ & $\begin{array}{l}\text { Perftoran Corp., } \\
\text { Russland }\end{array}$ & $\begin{array}{l}\text { Synthetisch } 10 \% \\
\text { (Gew./Vol.) }\end{array}$ & $\begin{array}{l}\text { Reduktion von } \\
\text { Fremdbluttransfusion }\end{array}$ & $\begin{array}{l}\text { Seit } 1996 \text { in } \\
\text { Russland } \\
\text { zugelassen }\end{array}$ & Perftoran \\
\hline
\end{tabular}

Tab. 11 Akzeptanz und Ablehnung fremdblutvermeidender Maßnahmen durch Zeugen Jehovas

\begin{tabular}{|l|l|}
$\begin{array}{l}\text { Verfahren } \\
\text { Präoperative Eigenblutspende }\end{array}$ & $\begin{array}{l}\text { Akzeptanz durch Zeugen } \\
\text { Jehovas }\end{array}$ \\
$\begin{array}{l}\text { Akute } \\
\text { normovolämischeHämodilution } \\
\text { (ANH) }\end{array}$ & $\begin{array}{l}\text { (ja) Voraussetzung: } \\
\text { geschlossenes System }\end{array}$ \\
\hline Maschinelle Autotransfusion (MAT) & $\begin{array}{l}\text { (ja) Voraussetzung: } \\
\text { geschlossenes System }\end{array}$ \\
\hline Bestrahlung von MAT-Blut & $\begin{array}{l}\text { (ja) Individuelle } \\
\text { Entscheidung }\end{array}$ \\
\hline $\begin{array}{l}\text { Rekombinantes } \\
\text { humanesErythropoeitin (rHuEPO) }\end{array}$ & ja \\
\hline $\begin{array}{l}\text { Fibrinogenkonzentrat, PPSB, Faktor- } \\
\text { XIII-Konzentrat }\end{array}$ & $\begin{array}{l}\text { (ja) Individuelle } \\
\text { Entscheidung }\end{array}$ \\
\hline $\begin{array}{l}\text { Rekombinanter humaner Faktor VIIa } \\
\text { Antifibrinolytika, Desmopressin }\end{array}$ & ja \\
\hline Hämoglobinlösungen (human/bovin) & $\begin{array}{l}\text { (ja) Individuelle } \\
\text { Entscheidung } \\
\text { (ja) Individuelle }\end{array}$ \\
\hline Perfluorokarbonemulsionen & Entscheidung \\
\hline
\end{tabular}

werden eine akute normovolämische Hämodilution (ANH) und die maschinelle Autotransfusion (MAT) bei Einhaltung bestimmter Voraussetzungen (geschlossener Kreislauf zwischen Patient, Schlauchsystem und Sammelbeutel) akzeptiert. Gentechnisch hergestellte Präparate wie Erythropoetin und rekombinanter Faktor VIIa werden grundsätzlich akzeptiert, bei Humanalbuminpräparaten, Gerinnungsfaktorenkonzentrate (PPSB, Fibrinogen, Faktor XIII) und AT III kann sich der Zeuge Jehovas individuell nach seinem Gewissen entscheiden. Bei Unsicherheit des Patienten ist die Einschaltung des regionalen Krankenhausverbindungskomitees äuBerst hilfreich.

Intraoperativ sollten Maßnahmen zur Minimierung des Blutverlusts konsequent zum Einsatz kommen (blutungsarmes Operieren, Lagerung des Operationsgebiets über Herzhöhe, Bevorzugung von Regionalanästhesie und TIVA, Aufrechterhaltung von Normothermie und physiologischem pH-Wert, ZVD-Management, kontrollierte Hypotension, Auswahl möglichst gerinnungsinerter Infusionslösungen, bei beginnender diffuser Blutungsneigung frühzeitige Applikation 
von Fibrinogenkonzentrat, PPSB, Antifibrinolytika, Desmopressin, Faktor-XIII- und evtl. Faktor-VIIa-Konzentrat). Im Falle unvorhergesehener Blutverluste und der Entwicklung einer potenziell lebensbedrohlichen Anämie kann die Anämietoleranz des Patienten durch verschiedene Maßnahmen akut gesteigert werden (Aufrechterhaltung von Normovolämie, hyperoxische Beatmung, kontinuierliche Applikation von Noradrenalin, adäquate Narkosetiefe, komplette Muskelrelaxierung). Hierdurch kann Zeit bis zur chirurgische Kontrolle der Blutung gewonnen werden.

Bei schwerer postoperativer Anämie sollten die genannten Maßnahmen auf der Intensivstation fortgesetzt werden. In speziellen Fällen kann die Anämietoleranz zusätzlich durch die Induktion von Hypothermie gesteigert werden. Künstliche $\mathrm{O}_{2}$-Träger als Alternative zur Erythrozytentransfusion stehen in der BRD nicht zur Verfügung, können aber theoretisch aus Südafrika (Hemopure) und Russland (Perftoran) bezogen werden.

\section{Literatur}

1. Marik PE, Baram M, Vahid B (2008) Does the central venous pressure predict fluid responsiveness? A systematic review of the literature and the tale of the seven mares. Chest 134:172-178

2. S3-Leitlinien „Intravasale Volumentherapie beim Erwachsenen“ der Deutschen Gesellschaft für Anästhesiologie und Intensivmedizin, AWMF-Register-Nr.001/020, 2014

3. Dunham CM, Siegel JH, Weireter L et al (1991) Oxygen debt and metabolic acedemia as quantitative predictors of mortality and the severity of the ischemic insult in hemorrhagic shock. Crit Care Med 19:231-243

4. Staab DB, Sorensen VJ, Fath JJ et al (1999) Coagulation defects resulting from ambient temperature-induced hypothermia. J Trauma 36:634-638

5. Kurz A, Sessler DI, Lenhard R (1996) Perioperative normothermia to reduce the incidence of surgical wound infection and shorten hospitalization. N Engl J Med 334:1209-1215

6. De Lorenzo C, Calatzis A, Welsch U, Heindl B (2006) Fibrinogen concentrate reverses dilutional coagulopathy induced in vitro by saline but not by hydroxyethyl starch $6 \%$. Anesth Analg 102:1194-1200

7. Scheingraber S, Rehm M, Sehmisch C, Finsterer U (1999) Rapid saline infusion produces hyperchloremic acidosis in patients undergoing gynecologic surgery. Anesthesiology 90:1265-1270

8. Bundesärztekammer auf Empfehlung ihres wissenschaftlichen Beirates (2014) Querschnittsleitlinien zur Therapie mit Blutkomponenten und Plasmaderivaten. 4., überarb. Aufl. Deutscher Ärzteverlag, Köln

9. Hourfar MK, Jork C, Schottstedt V et al (2008) Experience of German Red Cross blood donor services with nucleic acid testing: results of screening more than 30 million blood donations for human immunodeficiency virus- 1 , hepatitis $\mathrm{C}$ virus and hepatitis $\mathrm{B}$ virus. Transfusion 48:1558-1566

10. Karger R, Kretschmer V, Wulf H (2004) Risiken der Transfusion von Blutkomponenten: Aktuelle Anhaltszahlen für eine „quantitative" Risikoaufklärung. Anästh Intensivmed 45:430-434

11. Vamvakas EC, Blajchman MA (2010) Blood still kills: six strategies to further reduce allogeneic blood transfusion-related mortality. Transfus Med Rev 24:77-124

12. Vorstand der Bundesärztekammer (2010) Richtlinien zur Gewinnung von Blut und Blutbestandteilen und zur Anwendung von
Blutprodukten (Hämotherapie). Deutscher Ärzteverlag. ISBN-Nr. 978-3-7691-1294-8

13. Moore SB (2006) Transfusion-related acute lung injury (TRALI): clinical presentation, treatment, and prognosis. Crit Care Med 34: S114-S117

14. Gajic O, Gropper MA, Hubmayr RD (2006) Pulmonary edema after transfusion: how to differentiate transfusion-associated circulatory overload from transfusion-related acute lung injury. Crit Care Med 34:S109-S113

15. Taylor RW, O'Brian J, Trottier SJ et al (2006) Red blood cell transfusions and nosocomial infections in critically ill patients. Crit Care Med 34:2302-2308

16. Atzil S, Arad M, Glasner A et al (2008) Blood transfusion promotes cancer progression: a critical role for aged erythrocytes. Anesthesiology 109:989-997

17. Heiss MM, Mempel W, Delanoff C et al (1994) Blood transfusionmodulated tumor recurrence: first results of a randomized study of autologous versus allogeneic blood transfusion in colorectal cancer surgery. J Clin Oncol 12:1859-1867

18. Shander A, Hofmann A, Ozawa S et al (2010) Activity-based costs of blood transfusions in surgical patients at four hospitals. Transfusion 50:753-765

19. Carson JL, Duff A, Poses RM et al (1996) Effect of anaemia and cardiovascular disease on surgical mortality and morbidity. Lancet 348:1055-1060

20. Goodnough LT, Maniatis A, Earnshaw P et al (2011) Detection, evaluation and management of preoperative anaemia in the elective orthopaedic surgical patient: NATA guidelines. $\mathrm{Br} \mathrm{J}$ Anaesth 106:13-22

21. Kozek-Langenecker SA, Afshari A, Albaladejo P et al (2013) Management of severe perioperative bleeding. Guidelines from the European Society of Anesthesiology. Eur J Anaesthesiol 30:270-382

22. Gogarten W, Vandermeulen E et al (2010) Regional anaesthesia and antithrombotic agents: recommendations of the European Society of Anaesthesiology. Eur J Anaesthesiol 27:999-1015

23. Thomas MJG, Gillon J, Desmond MJ (1996) Preoperative autologous donation. Transfusion 36:633-639

24. Penner M, Sibrowski W (1994) Nutzen und Risiken der Eigenblutspende. Infusionsther Transfusionsmed 21(suppl 1):64-68

25. Friedman BA, Oberman HA, Chadwick AR, Kingdon KI (1976) The maximum surgical blood order schedule and surgical blood use in the United States. Transfusion 16:380-387

26. European Commission, Sirchia G, Giovanetti AM, McClelland B, Fraccia GN (1994) Safe and good use of blood in surgery (SANGUIS). Use of blood products and artificial colloids in 43 European hospitals. European Commission, Luxembourg

27. Habler O, Schwenzer K, Zimmer K et al (2004) Effects of standardized acute normovolemic hemodilution on intraoperative allogeneic blood transfusion in patients undergoing major maxillofacial surgery. Int J Oral Maxillofac Surg 33:467-475

28. Kick O, Daniel E (1997) Mathematical considerations in the practice of acute normovolemic hemodilution. Transfusion 37:141-143

29. Egli GA, Zollinger A, Seifert B et al (1997) Effect of progressive haemodilution with hydroxyethyl starch, gelatin and albumin on blood coagulation. Br J Anaesth 78:684-689

30. American Society of Anesthesiologists (2006) Practice guidelines for blood transfusion and adjuvant therapies. Anesthesiology 105:198-208

31. College of American Pathologists (1998) Practice parameter for the use of red blood cell transfusions. Arch Pathol Lab Med 122:130-138

32. Bryson GL, Laupacis A, Wells GA, The International Study of Perioperative Transfusion (1998) Does acute normovolemic hemodilution reduce perioperative allogeneic transfusion? A Metaanalysis. Anesth Analg 86:9-15

33. Segal JB, Blasco-Colmenares E, Norris EJ, Guallar E (2004) Preoperative acute normovolemic hemodilution: a meta-analysis. Transfusion 44:632-644 
34. Monk TG, Goodnough LT, Brecher ME et al (1999) A prospective randomized comparison of three blood conservation strategies for radical prostatectomy. Anesthesiology 91:24-33

35. Van Daele MERM, Trouwborst A, Van Woerkens LCSM et al (1994) Transoesophageal echocardiographic monitoring of preoperative acute hypervolemic hemodilution. Anesthesiology 81:602-609

36. Mielke LL, Entholzner EK, Kling M et al (1997) Preoperative acute hypervolemic hemodilution with hydroxyethylstarch: an alternative to acute normovolemic hemodilution? Anesth Analg 84:26-30

37. Habler O, Meier J, Pape A et al (2006) Perioperative Anämietoleranz Mechanismen, Einflussfaktoren, Grenzen. Anaesthesist 55:1142-1156

38. Gombotz H (2003) Physiologische Grenzen der Verdünnungsanämie bei Intensivpatienten. J Anästh Intensivmed 1:84-87

39. Mauermann WJ, Shilling AM, Zuo Z (2006) A comparison of neuroaxial block versus general anesthesia for elective total hip replacement: a meta-analysis. Anesth Analg 103:1018-1025

40. Choi WS, Samman N (2008) Risks and benefits of deliberate hypotension in anaesthesia: a systematic review. Int J Oral Maxillofac Surg 37:687-703

41. Endrich B, Franke N, Peter K, Messmer K (1987) Induced hypotension: action of sodium nitroprusside and nitroglycerin on the microcirculation. Anesthesiology 66:605-613

42. Hansen E, Knuechel R, Altmeppen J, Taeger K (1999) Blood irradiation for intraoperative autotransfusion in cancer surgery: demonstration of efficient elimination of contaminating tumor cells. Transfusion 39:608-615

43. Geoghegan J, Daniels JP, Moore P et al (2009) Cell salvage at caesarean section: the need for an evidence-based approach. BJOG 116:743-747

44. Carless PA, Hentry DA, Moxey AJ et al (2010) Cell salvage for minimising perioperative allogeneic blood transfusion. Cochrane Database Syst Rev 4:CD001888

45. Dirkmann D, Hanke A, Görlinger K, Peters J (2008) Hypothermia and acidosis synergistically impair coagulation in human whole blood. Anesth Analg 106:1627-1632
46. Jones R, Moulton CE, Hardy KJ (1998) Central venous pressure and its effects on blood loss during liver resection. $\mathrm{Br} \mathrm{J}$ Surg 85:1058-1060

47. Fergusson DA, Hebert PC, Mazer CD et al (2008) A comparison of aprotinin and lysine analogues in high-risk cardiac surgery. N Engl J Med 358:2319-2331

48. Hiippala ST, Myllylä GJ, Vahtera EM (1995) Hemostatic factors and replacement of major blood loss with plasma-poor red cell concentrates. Anesth Analg 81:360-365

49. Grashey R, Mathonia P, Mutschler W, Heindl B (2007) Durch Thrombelastographie gesteuertes perioperatives Gerinnungsmanagement. Unfallchirurg 110:259-263

50. Habler O (2015) Management akuter Blutverluste ohne Point-ofCare (POC)-Monitoring. In: Eckart J, Forst H, Briegel J (Hrsg) Intensivmedizin. Ecomed-Storck Verlag, Hamburg; 70. Erg.-Lfg.; IX-6.5:1-16

51. Bunn HF, May MH, Kochalaty WF, Shields CE (1969) Hemoglobin function in stored blood. J Clin Invest 48:311-321

52. Fitzgerald RD, Martin CM, Dietz GE et al (1997) Transfusing red blood cells stored in citrate phosphate dextrose adenine- 1 for 28 days fails to improve tissue oxygenation in rats. Crit Care Med 25:726-732

53. Marik PE, Sibbald WJ (1993) Effects of stored-blood transfusion on oxygen delivery in patients with sepsis. JAMA 269:3024-3029

54. Koch CG, Li L, Sessler DI et al (2008) Duration of red-cell storage and complications after cardiac surgery. $N$ Engl $J$ Med 358:1229-1239

55. Roback JD, Caldwell S, Carson J et al (2010) Evidence-based practice guidelines for plasma transfusion. Transfusion 50:1227-1239

56. Habler O, Pape A, Meier J, Zwißler B (2005) Künstliche Sauerstoffträger als Alternative zur Bluttransfusion. Anaesthesist 54:741-754

57. Habler O, Voß B (2010) Perioperatives Management bei Zeugen Jehovas. Anaesthesist 59:297-311 